\author{
UNIVERSIDADE DE SÃO PAULO \\ FFCLRP - DEPARTAMENTO DE FÍSICA \\ PROGRAMA DE PÓS-GRADUAÇÃO EM FÍSICA APLICADA À \\ MEDICINA E BIOLOGIA
}

\title{
Estudo de dosimetria gel polimérica em Radioterapia com feixes de elétrons utilizando ressonância magnética e simulação Monte Carlo
}

Thatiane Alves Pianoschi

Versão corrigida

Ribeirão Preto - SP

2013 
THATIANE ALVES PIANOSCHI

\title{
Estudo de dosimetria gel polimérica em Radioterapia com feixes de elétrons utilizando ressonância magnética e simulação Monte Carlo
}

\begin{abstract}
Tese apresentada ao Departamento de Física da Faculdade de Filosofia, Ciência e Letras de Ribeirão Preto da Universidade de São Paulo, como parte das exigências para obtenção do título de Doutor em Ciências.
\end{abstract}

Área de concentração: Física Aplicada à Medicina e Biologia.

Orientadora: Prof ${ }^{\mathrm{a}}$. Dr ${ }^{\mathrm{a}}$. Patrícia Nicolucci.

Versão corrigida

Ribeirão Preto - SP

2013 
Autorizo a reprodução e divulgação total ou parcial deste trabalho, por qualquer meio convencional ou eletrônico, para fins de estudo e pesquisa, desde que citada à fonte.

\section{Catalogação da Publicação}

Departamento de Física

Faculdade de Filosofia, Ciências e Letras de Ribeirão Preto da

Universidade de São Paulo

Pianoschi, Thatiane Alves

Estudo de dosimetria gel polimérica em Radioterapia com feixes de elétrons utilizando ressonância magnética e simulação Monte Carlo.

Ribeirão Preto, 2013.

120p.:il.; $30 \mathrm{~cm}$

Tese de doutorado, apresentada ao Departamento de Física da Faculdade de Filosofia, Ciências e Letras de Ribeirão Preto da Universidade de São Paulo Área de concentração: Física Aplicada à Medicina e Biologia.

Orientadora: Prof $^{\mathrm{a}}$.Dr ${ }^{\mathrm{a}}$. Patrícia Nicolucci

1. Radioterapia. 2. MAGIC- $f$ gel. 3. Feixe de elétrons. 4.Controle da qualidade. 5. Código PENELOPE. 
Dedico esse trabalho aos meus pais e a minha irmã pelo amor de uma vida toda e ao meu marido por realizar meu maior sonho, amar alguém verdadeiramente. 


\section{Agradecimentos}

À Deus por ter me dado o dom da vida e por estar ao meu lado todos os dias.

À minha orientadora, Prof. Dr. Patrícia Nicolucci, por ser uma das pessoas mais justas que já conheci. Obrigada pelos ensinamentos, pelas orientações, pela paciência e pelas inspirações. Ser sua orientanda foi uma honra. Muito Obrigado!!!

À Dr. Cassiana Viccari Saciloto, que faz parte da minha vida desde a graduação. Não tenho palavras para descrever minha admiração por você. Sua bondade cativa a todos a sua volta. Que Deus traga ao mundo mais pessoas como você... Assim, muito obrigado!!! Não poderia deixar de lembra aqui sua linda família: João, Julia e Alice.

Ao Hospital do Câncer de Barretos pelo possibilidade de realizar as medidas experimentais, em especial aos físicos Marcelo Santanna e Daiane Cesar. A disposição de vocês em realizar as irradiações foi incomparável. Muito obrigado!!!

Ao Hospital das Clínicas de Ribeirão Preto pelo apoio nesses anos de pesquisa.

Aos professores do departamento de Física pelo ensino, oportunidade e convívio nesses anos. Em especial ao Prof. Dr. Carlos Alberto Pelá pelos tantos momentos de ensinamento.

Aos funcionários do departamento de Física, em especial aos técnicos Luiz Aziani e

Carlos Renato, por que além da dedicação, paciência e disposição. A qualidade do trabalho realizado por vocês é incomparável. Gostaria de um agradecer especialmente especial a secretária Nilza Leone por sua dedicação.

Aos meus amigos Mairon, Renata e Edu, Daniela e Jonatas, Carol e Luiz, Sandra e Deividson, Fabio e Milene, Karla e Cristiano, Jeane e Antônio Cesar, meu muito obrigado. Mesmo que a vida nos afaste vocês sempre estarão guardados em meu coração.

Aos amigos de grupo, Laurinha, Eduardo e, especialmente, Aninha, por ser essa pessoa tão iluminada, que esteve tão presente na etapa final de meu trabalho. Muito obrigado!!!

A toda grande Família Alves e Família Pianoschi pelo amor, companheirismo, conversas e muitas risadas sempre. Muito obrigado a todos. 
Aos meus sogros, Agustín e Zoila, por me acolherem de forma tão especial, sempre me incentivando, torcendo e orando por nossas vidas. Sou muito feliz em fazer parte da família de vocês agora. Muchas Gracias!!!

Aos meus cunhados, Cecilia, Nivia, Frank, Hugo, Fabiola, Henri, Cati e Wilber. E aos meus sobrinhos, Daniel, Ariana, Nataly Ximena e Mirko Sebatian, pelo carinho nesses anos, sempre torcendo por nossa felicidade. Muchas Gracias!!!

A minha amada prima-irmã, Jolie, que sempre esteve ao meu lado, agradeço pelas conversas, pelos conselhos, pelo carinho e pela paciência em aceitar minha ausência em momentos tão importantes. Acima de tudo, agradeço por ter confiado sempre em mim. Muito Obrigado!!! Não posso esquecer de sua família que está sempre em minhas orações: Evandro, Leticia e Gustavo.

A minha amada irmã, Thaisa, você é um anjo em minha vida. Sempre disposta a ajudar, ouvir, aconselhar e torcer por mim. Que Deus lhe abençoe sempre. Ao meu querido cunhado, Marcelo, que a gente continue sempre junto em todos momentos. Muito Obrigado!!!

Aos meus avôs, Adelina e Antenor, vocês são o maior exemplo de amor que tive a vida toda. Obrigada por todos os momentos de afeto e ternura. Sem vocês eu não seria a pessoa que sou hoje. Muito obrigado!!!

Em memória, aos meus avós maternos, Adelina e João, pois mesmo distante tenho certeza estiveram comigo nessa caminhada.

Aos meus pais, Luiz Cláudio e Rosa Maria, por me ensinarem o significado da palavra família. Vocês estiveram ao meu lado em todos os momentos, me apoiando, me guiando me dando forças para continuar e nunca desistir de meus objetivos. Assim, vocês são os grandes responsáveis pelo que sou hoje. Muito, Muito obrigado!!!

Em especial, quero agradecer ao meu amado marido, Mirko, por ser esse companheiro inigualável. Você esteve ao meu lado em todos os minutos dessa caminhada. Agradecer à você por essa conquista. Esse agradecimento é tão pequeno perto do que sua ajuda significou para mim, mas é a única forma de expressar minha gratidão. Sem seu amor esse trabalho seria impossível. Muito obrigado!!! Mas acima de tudo, amo muito você!!! 


\section{Resumo}

Pianoschi, T.A. Estudo de dosimetria gel polimérica em Radioterapia com feixes de elétrons utilizando ressonância magnética e simulação Monte Carlo. 2013. 120f. Tese (doutorado) - Departamento de Física, Faculdade de Filosofia, Ciências e Letras de Ribeirão Preto, Universidade de São Paulo, Ribeirão Preto, 2013.

Radioterapia com feixe de elétrons tem sido empregada, frequentemente, para tratamentos de neoplasias superficiais devido às características de alcance bem definido e alto gradiente de dose em pouca profundidade. Para que as novas técnicas radioterápicas com esse tipo de feixe possam ser implementadas com segurança é necessária a realização de um controle da qualidade rigoroso. Protocolos recomendam que o controle da qualidade, para esse tipo de feixe, seja realizado com câmara de ionização, porém dosímetros termoluminescentes, diodos e filmes também são empregados com essa finalidade. Entretanto, esses dosímetros não possuem simultaneamente um conjunto de características essenciais para realização do controle da qualidade, como alta resolução espacial, baixa dependência energética, possibilidade de uso em altos gradientes de dose e distribuição tridimensional de dose. Nesse trabalho avaliou-se a utilização do dosímetro polimérico MAGIC- $f$ gel em aplicações para o controle da qualidade em Radioterapia com feixes de elétrons. As leituras das amostras de gel foram realizas por ressonância magnética cujos resultados foram comparados com os obtidos por simulação Monte Carlo. Como parte de um controle da qualidade para feixe de elétrons foram determinados parâmetros dosimétricos, como perfil de dose e porcentagem de dose em profundidade, e fatores de qualidade do feixe, como $\mathrm{R}_{50}$, em condições de referência e para campos pequenos. Comparando os dados clínicos com os obtidos com o dosímetro MAGIC- $f$ foram encontradas diferenças máximas de $4 \%$. Além disso, foram avaliadas pelo método de comparação do índice gama as distribuições de dose de aplicações clínicas com feixes de elétrons. Considerando os critérios de $3 \%$ e $3 \mathrm{~mm}$, os resultados obtidos para o índice gama mostraram concordâncias acima de $94 \%$ para os métodos dosimétricos utilizados. Dessa forma, de acordo com as medidas dosimétricas realizadas com o dosímetro MAGIC- $f$ gel conclui- se que a dosimetria polimérica gel pode ser empregada como uma ferramenta auxiliar em procedimentos de controle da qualidade em Radioterapia com feixes de elétrons, assim como uma ferramenta na determinação das distribuições tridimensionais de dose para feixe de elétrons.

Palavras-chave: Radioterapia, MAGIC- $f$ gel; Feixe de elétrons, Controle da qualidade, código PENELOPE. 


\begin{abstract}
Pianoschi, T.A. Study of polymer gel dosimetry in Radiotherapy with electron beams using magnetic resonance imaging and Monte Carlo simulation. 2013. 120f. Thesis ( Ph.D. ) - Departamento de Física, Faculdade de Filosofia, Ciências e Letras de Ribeirão Preto, Universidade de São Paulo, Ribeirão Preto, 2013.
\end{abstract}

Electron beam radiotherapy has been used frequently for treatments of superficial tumors, due its characteristics of well-defined range and high dose gradient at low depth. For new radiotherapy techniques with this type of beam, a strict quality control is necessary for a safe implementation. Protocols recommend that the quality control for electron beams must be performed with an ionization chamber. However, thermoluminescent dosimeters, films and diodes are also used for this purpose. Although, these dosimeters do not have a set of essential characteristics for performing quality control, like high spatial resolution, low energy dependence, possibility of use in high dose gradients and three dimensional dose distribution acquisition. The present work evaluated the use of MAGIC- $f$ gel dosimeter for the quality control in radiotherapy with electron beams. The readings of the gel samples were made by magnetic resonance imaging and Monte Carlo simulation was used to compare the obtained results. As part of a quality control for the electron beam parameters as percentage depth dose and beam profile were determined. Also beam quality factors, such as $\mathrm{R}_{50}$, were calculated in reference conditions and for small fields. The obtained results were compared with clinical data and MAGIC- $f$ the maximum obtained difference was $4 \%$. In addition, dose distributions from clinical applications with electron beams were evaluated by the gamma index. Considering the criteria of $3 \%$ DD and $3 \mathrm{~mm}$ DTA, the results showed concordance greater than $94 \%$ for all dosimetric methods. Thus, according to the dosimetric measurements through MAGIC- $f$ gel dosimeter it can be inferred that the gel dosimeter can be used as auxiliary tool in the quality control procedures in radiotherapy to electron beam. Also, MAGIC- $f$ is a useful a tool to determine tridimensional dose distributions of electron beam.

Keywords: Radiotherapy, MAGIC- $f$ gel ,Electron beam, Quality control, PENELOPE code. 


\section{LISTA DE FIGURAS}

Figura 1: Porcentagem de dose em profundidade, com indicação dos parâmetros dosimétricos relacionados a um feixe de elétrons (IAEA, 2003).

Figura 2: Perfil de campo para feixe de elétrons de $6 \mathrm{MeV}$ e campo de 10 x $10 \mathrm{~cm}^{2} \ldots . . .7$

Figura 3: Curvas de isodose típicas para um feixe de elétrons $9 \mathrm{MeV}$ e com campo de irradiação de 10 x $10 \mathrm{~cm}^{2}$ (IAEA, 2003) ....................................................................... 8

Figura 4: Tela do sistema de planejamento Eclipse ${ }^{\circledR}$ para um caso tratado com feixes clínicos de elétrons..................................................................................................... 10

Figura 5: MAGIC- $f$ gel irradiado com feixes clínicos de elétrons de diferentes energias.

Figura 6: Vetor magnetização $M$ : (a) o vetor $M_{z}$ antes da aplicação do pulso de radiofrequência tem intensidade $\mathbf{M}_{0}$ (b) depois da aplicação do pulso de radiofrequência $\left(90^{\circ}\right), \mathrm{M}_{\mathrm{Z}}$ é rotacionado para o plano xy e tem intensidade zero em $\mathrm{Z}$, (c) o vetor $\mathrm{M}_{\mathrm{Z}}$ tende a voltar ao seu estado de equilíbrio no eixo $\mathrm{z}(\mathrm{d})$ vetor $\mathrm{M}_{\mathrm{z}}$ restabelecido seu estado inicial.

Figura 7: Vetor magnetização $M$ : (a) posição de equilíbrio do vetor $\mathrm{M}_{\mathrm{z}}$, na direção do campo magnético e com intensidade $\mathrm{M}_{0}$, (b) depois de aplicado o pulso de radiofrequência $\left(90^{\circ}\right), \mathrm{M}_{\mathrm{z}}$ é rotacionado para o plano xy e tem intensidade zero em $\mathrm{Z}$ e $M_{x y}$ tem intensidade $M_{0}$, (c) núcleos com magnetização xy distintas, diminuindo a intensidade do vetor $\mathbf{M}_{\mathrm{xy}}(\mathrm{d})$ Defasagem completa do vetor $\mathbf{M}_{\mathrm{xy}}$ ao mesmo tempo que se estabelece o retorno a posição inicial.

Figura 8: Objetos simuladores utilizados nos procedimentos de irradiação com MAGIC$f$ gel: (a) caracterização do dosímetro; (b) e (c) validação do dosímetro; (c) e (d) irradiaçõoes em condições clínicas............................................................................ 24

Figura 9: Espectros de energia para feixes de elétrons de 6, 9, 12 e $15 \mathrm{MeV}$ baseados no

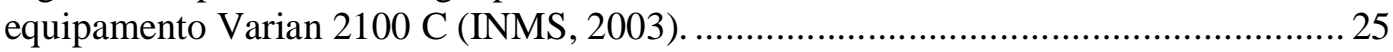

Figura 10: Primeiro passo da manufatura do dosímetro polimérico MAGIC-f: dissolução

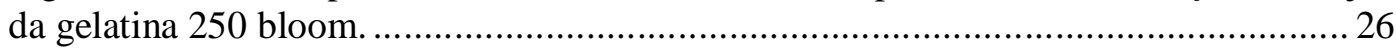

Figura 11: Tomógrafo de ressonância magnética do HC-RP com uma bobina de cabeça e objeto simulador de cabeça com gel para leitura. 27

Figura 12: Imagem de ressonância magnética de objetos simuladores preenchidos com MAGIC- $f$ gel e irradiados com um feixe clínico de elétrons de $6 \mathrm{MeV}$ : (a) mapa dos tempos de relaxação transversal (T2) e (b) mapa de R2 ..................................... 28

Figura 13: Esquema do posicionamento do objeto simulador usado para o estudo da homogeneidade da bobina de cabeça do tomógrafo de RM......................................... 30 
Figura 14: Geometria de irradiação para MAGIC- $f$ gel utilizada para o estudo da reprodutibilidade do dosímetro em feixes de elétrons. (a) Posicionamento do material de gel para irradiação, (b) vista superior da amostra de gel durante a irradiação. 31

Figura 15: Geometria de irradiação utilizada para a determinação das curvas PDP para feixes de elétrons de 6, 9, 12 e $15 \mathrm{MeV}$ em um campo de 10 x $10 \mathrm{~cm}^{2}$ e DFS $100 \mathrm{~cm} .34$

Figura 16: Acessório utilizado para irradiação de campos pequenos para feixes de elétrons: (a) colimador adicional, (b) colimador adicional acoplado ao colimador padrão para elétrons

Figura 17: Esquema da configuração dos campos de irradiação para o estudo dos campos adjacentes somados: (a) 5 campos de $5 \times 1 \mathrm{~cm}^{2}$, (b) campo de $5 \times 5 \mathrm{~cm}^{2} \ldots \ldots \ldots \ldots \ldots \ldots . \ldots . \ldots . . . .38$

Figura 18: Colimador adicional utilizado para colimação de um campo de 5 x $1 \mathrm{~cm}^{2}$ para feixe de elétrons de $6 \mathrm{MeV}$. 38

Figura 19: Irradiação do dosímetro MAGIC- $f$ para verificação da distribuição de dose de uma geometria de tratamento de linfoma conjunctival: (a) aplicador adicional de cerrobend utilizado no tratamento, (b) geometria de irradiação para o tratamento. ...... 40

Figura 20: Tela do sistema de planejamento Eclipse ${ }^{\circledR}$ para o caso de doença subclínica de linfonodos localizados tratado com feixe de elétrons de $6 \mathrm{MeV}$. 41

Figura 21: Posicionamento do objeto simulador para obtenção das imagens de CT que foram utilizadas para o planejamento: (a) objeto simulador de cabeça com a máscara termoplástica e suporte de cabeça e pescoço, (b) objeto simulador posicionado no CT.42

Figura 22: Geometria de irradiação do dosímetro MAGIC- $f$ gel para determinação das distribuições de dose de um caso clínico utilizando feixe de elétrons. 42

Figura 23: Tela do sistema de planejamento Eclipse ${ }^{\circledR}$ para um caso de cabeça e pescoço irradiado com feixe clínico de elétrons de $9 \mathrm{MeV}$ e de fótons de $6 \mathrm{MV}$.

Figura 24: Mapas das intensidades do sinal de tempo de relaxação (T2) nos cortes axiais para o estudo da homogeneidade da bobina de cabeça de um tomógrafo de ressonância magnética de 3,0 T em diferentes posições do objeto simulador: (a) corte axial superior, (b) corte axial central e (c) corte axial inferior. 46

Figura 25: Histogramas das intensidades do sinal no corte axial superior em regiões distintas: (a) corte todo, (b) região central com 9,5 cm de diâmetro.

Figura 26: Histogramas das intensidades do sinal no corte axial central em regiões distintas: (a) corte todo, (b) região central com 9,5 cm de diâmetro.

Figura 27: Histogramas das intensidades do sinal no corte axial inferior em regiões distintas: (a) corte todo, (b) região central com 9,5 cm de diâmetro.

Figura 28: Comparação entre valores stopping power para os materiais gerados pelo código de simulação PENELOPE e dados da literatura (NIST, 2013)........................ 48 
Figura 29: PDPs obtidas com simulação utilizando o código PENELOPE para os materiais "agua.mat" e "magicf.mat" para os feixes clínicos de elétrons de: (a) $6 \mathrm{MeV}$; (b) $9 \mathrm{MeV}$; (c) $12 \mathrm{MeV}$ e (d) $15 \mathrm{MeV}$. 50

Figura 30: Resposta do dosímetro MAGIC- $f$ em função da dose absorvida para o teste de reprodutibilidade para um feixe de elétrons de $6 \mathrm{MeV}$.

Figura 31: Resposta do dosímetro MAGIC- $f$ em função da dose absorvida e do tempo de leitura após a irradiação 53

Figura 32: Resposta do dosímetro MAGIC- $f$ em função da dose absorvida para os feixes de elétrons de 6, 9, 12 e $15 \mathrm{MeV}$ (a)valores de R2 absolutos; (b) valores de R2 normalizados para a energia de $6 \mathrm{MeV}$. 54

Figura 33: Resposta do dosímetro MAGIC- $f$ em função da dose absorvida para os feixes de 6, 9, 12 e $15 \mathrm{MeV}$ para um intervalo de dose absorvida restrito, 1 a $10 \mathrm{~Gy}$. 55

Figura 34: Resposta do dosímetro MAGIC- $f$ em função da taxa de dose para os feixes de 6, 9, 12 e $15 \mathrm{MeV}$. 57

Figura 35: MAGIC- $f$ gel depois de irradiado para determinação das curvas de PDP nas energias de 6, 9, 12 e $15 \mathrm{MeV}$, como mostrado na figura da esquerda para direita.......58

Figura 36: Curvas de PDP obtidas com PENELOPE, MAGIC- $f$ e dados clínicos para feixes clínicos de elétrons de: (a) $6 \mathrm{MeV}$; (b) $9 \mathrm{MeV}$; (c) $12 \mathrm{MeV}$ e (d) $15 \mathrm{MeV}$......... 59

Figura 37: MAGIC- $f$ gel depois de irradiado para determinação da curva de perfil de campo para a energia de $6 \mathrm{MeV}$.

Figura 38: Curvas de perfil de campo obtidas com PENELOPE, MAGIC- $f$ e dados clínicos para feixes clínicos de elétrons de: (a) $6 \mathrm{MeV}$; (b) $9 \mathrm{MeV}$; (c) $12 \mathrm{MeV}$ e (d) 15 $\mathrm{MeV}$. 64

Figura 39: Distribuição de dose de um campo de $1 \times 1 \mathrm{~cm}^{2}$ para a energias de $6 \mathrm{MeV}$ com colimação de: (a) cerrobend, (b) acrílico e (c) subtração das distribuições de dose de (a) e (b).

Figura 40: Comparação dos resultados com colimadores de cerrobend e acrílico para o feixe clínico de $6 \mathrm{MeV}$ para um campo de 1 x $1 \mathrm{~cm}^{2}$ : (a) PDP, (b) perfil de campo.....6 68

Figura 41: Comparação dos resultados com colimadores de cerrobend e acrílico para o feixe clínico de $12 \mathrm{MeV}$ para um campo de $1 \times 1 \mathrm{~cm}^{2}$ : (a) PDP, (b) perfil de campo... 68

Figura 42: MAGIC- $f$ irradiado com um feixe de elétrons de $6 \mathrm{MeV}$ para determinação das curvas de PDP em função do tamanho de campo: (a) $1 \times 1 \mathrm{~cm}^{2}$, (b) $5 \times 5 \mathrm{~cm}^{2} \ldots \ldots . .70$

Figura 43: Distribuição de dose para um campo de $1 \times 1 \mathrm{~cm}^{2}$ para o feixe clínico de elétrons de $6 \mathrm{MeV}$ obtidas com: (a) PENELOPE, (b) MAGIC- $f$ e (c) TPS Eclipse ${ }^{\circledR}$.... 70 
Figura 44: Distribuição de dose para um campo de 5 x $5 \mathrm{~cm}^{2}$ para o feixe clínico de elétrons de $6 \mathrm{MeV}$ obtidas com: (a) PENELOPE, (b) MAGIC- $f$ e (c) TPS Eclipse ${ }^{\circledR} \ldots 71$

Figura 45: Curvas de PDP para o feixe clínico de elétrons de $6 \mathrm{MeV}$ obtidas com MAGIC$f$, PENELOPE e TPS Eclipse ${ }^{\circledR}$ para os campos: (a) 1 x $1 \mathrm{~cm}^{2}$ e (b) $5 \times 5 \mathrm{~cm}^{2} \ldots \ldots \ldots \ldots . . . .72$

Figura 46: Curvas de PDP para o feixe clínico de elétrons de 9 MeV obtidas com MAGIC$f$, PENELOPE e TPS Eclipse ${ }^{\circledR}$ para os campos: (a) 1 x $1 \mathrm{~cm}^{2}$ e (b) $5 \times 5 \mathrm{~cm}^{2} \ldots \ldots \ldots \ldots . . . . .72$

Figura 47: Curvas de PDP para o feixe clínico de elétrons de $12 \mathrm{MeV}$ obtidas com MAGIC-f, PENELOPE e TPS Eclipse ${ }^{\circledR}$ para os campos: (a) $1 \times 1 \mathrm{~cm}^{2}$ e (b) $5 \times 5 \mathrm{~cm}^{2} .73$

Figura 48: Distribuições de dose para um feixe clínico de elétrons de $6 \mathrm{MeV}$ obtida utilizando PENELEOPE para um campo $5 \times 5 \mathrm{~cm}^{2}$ irradiados: (a) campo único, (b) soma de campos 5 x $1 \mathrm{~cm}^{2}$ e (c) subtração das distribuições de dose de (a) e (b).................. 77

Figura 49: Perfis de campo obtidos de dados simulados com PENELOPE para um feixe clínico de elétrons de $6 \mathrm{MeV}$ em um campo $5 \times 5 \mathrm{~cm}^{2}$ irradiados com campo único e soma de campos 5 x $1 \mathrm{~cm}^{2}$ em diferentes profundidades: (a) entrada do objeto simulador, (b) profundidade de máxima dose e (c) profundidade terapêutica................................. 78

Figura 50: Perfis de campo obtidos de dados simulados com PENELOPE para um feixe clínico de elétrons de $9 \mathrm{MeV}$ em um campo $5 \times 5 \mathrm{~cm}^{2}$ irradiados com campo único e soma de campos $5 \times 1 \mathrm{~cm}^{2}$ em diferentes profundidades: (a) entrada do objeto simulador, (b) profundidade de máxima dose e (c) profundidade terapêutica.

Figura 51: Perfis de campo obtidos de dados simulados com PENELOPE para um feixe clínico de elétrons de $12 \mathrm{MeV}$ em um campo 5 x $5 \mathrm{~cm}^{2}$ irradiados com campo único e soma de campos $5 \times 1 \mathrm{~cm}^{2}$ em diferentes profundidades: (a) entrada do objeto simulador, (b) profundidade de máxima dose e (c) profundidade terapêutica. 79

Figura 52: Perfis de campo obtidos de dados simulados com MAGIC- $f$ para um feixe clínico de elétrons de $6 \mathrm{MeV}$ em um campo $5 \times 5 \mathrm{~cm}^{2}$ irradiados com campo único e soma de campos $5 \times 1 \mathrm{~cm}^{2}$ em diferentes profundidades: (a) superfície, (b) profundidade de máxima dose e (c) profundidade terapêutica. 81

Figura 53: Perfis de campo obtidos de dados simulados com Eclipse ${ }^{\circledR}$ para um feixe clínico de elétrons de $6 \mathrm{MeV}$ em um campo $5 \times 5 \mathrm{~cm}^{2}$ irradiados com campo único e soma de campos $5 \times 1 \mathrm{~cm}^{2}$ em diferentes profundidades: (a) superfície, (b) profundidade de máxima dose e (c) profundidade terapêutica. 82

Figura 54: MAGIC- $f$ irradiado com um feixe clínico de elétrons de $6 \mathrm{MeV}$ para avaliação das distribuições de dose para tratamentos que necessitem de espaço entre campos de irradiação. 83

Figura 55: Distribuições de dose para dois campos adjacentes irradiados em um feixe clínico de elétrons de $6 \mathrm{MeV}$ obtidas com: (a) PENELOPE, (b)MAGIC- $f$ e (c) TPS Eclipse $^{\circledR}$ 84 
Figura 56:Perfil de campo da irradiação adjacentes de dois campos obtidas utilizando PENELOPE, MAGIC- $f$ e TPS Eclipse ${ }^{\circledR}$, para o feixe clínico de elétrons de $6 \mathrm{MeV}$ na profundidades de máxima dose. 85

Figura 57: MAGIC- $f$ irradiado simulando um tratamento de linfoma conjuntival, com visualização: (a) lateral (b) superior. 86

Figura 58: Perfis de campo de um tratamento de linfoma conjuntival irradiado com colimador central de cerrobend. 87

Figura 59: Distribuição de dose do plano central para campo único para o feixe clínico de elétrons de $6 \mathrm{MeV}$ obtidas com: (a) PENELOPE, (b) MAGIC- $f$ e (c) TPS Eclipse ${ }^{\circledR}$.... 88

Figura 60: Mapas de índice $\gamma$ comparando as distribuições de dose obtidas com (a) PENELOPE e MAGIC- $f$, (b) TPS Eclipse ${ }^{\circledR}$ e MAGIC- $f$, (c) TPS Eclipse ${ }^{\circledR}$ e PENELOPE, para os critérios 3\% de DD e $3 \mathrm{~mm}$ de DTA, para um feixe clínico de elétrons de $6 \mathrm{MeV}$.

Figura 61: Distribuição de dose do plano central para um tratamento de cabeça e pescoço irradiado com uma combinação de feixes clínicos, dois feixes de elétrons de $9 \mathrm{MeV}$ e dois feixes de fótons de $6 \mathrm{MV}$ ambos paralelos e opostos, obtidas com: (a) PENELOPE, (b) MAGIC- $f$ e (c) TPS Eclipse ${ }^{\circledR}$.

Figura 62: Mapas de índice $\gamma$ comparando as distribuições de dose obtidas com (a) PENELOPE e MAGIC- $f$, (b)TPS Eclipse ${ }^{\circledR}$ e MAGIC- $f$ (c) TPS Eclipse ${ }^{\circledR}$ e PENELOPE, critérios 3\% de DD e $3 \mathrm{~mm}$ de DTA e, para um tratamento de cabeça e pescoço irradiado com feixes clínicos de elétrons de $9 \mathrm{MeV}$ e de fótons de $6 \mathrm{MV}$....... 92 


\section{LISTA DE TABELAS}

Tabela 1: Composição do dosímetro MAGIC- $f$ gel para um litro de solução................. 26

Tabela 2: Espessuras dos colimadores adicionais. 36

Tabela 3: Diferenças percentuais máximas entre as respostas do dosímetro MAGIC- $f$ para teste de reprodutibilidade.

Tabela 4: Diferenças percentuais máximas da resposta do dosímetro MAGIC- $f$ em função da taxa de dose.

Tabela 5: Diferenças percentuais máximas entre as curvas de PDP determinadas com PENELOPE, MAGIC-f e dados clínicos do HCB.

Tabela 6: Valores de $\mathrm{R}_{50}$ nas energias de $6 \mathrm{MeV}$ a $15 \mathrm{MeV}$. 60

Tabela 7: Valores de $\mathrm{d}_{\max }$, para as energias de $6 \mathrm{MeV}$ a $15 \mathrm{MeV}$ 61

Tabela 8: Valores $\mathrm{R}_{\mathrm{p}}$, para as energias de $6 \mathrm{MeV}$ a $15 \mathrm{MeV}$.

Tabela 9: Valores de porcentagem de dose na superfície para as nas energias de $6 \mathrm{MeV}$ a $15 \mathrm{MeV}$. 62

Tabela 10: Diferença entre os valores dose na superfície para as nas energias de $6 \mathrm{MeV}$ a $15 \mathrm{MeV}$ 62

Tabela 11: Diferenças percentuais máximas entre as curvas de perfil de campo determinadas com PENELOPE, MAGIC- $f$ e dados clínicos do HCB. 64

Tabela 12: Variação percentual máxima na comparação dos parâmetros dosimétricos para as irradiações com colimadores adicionais de cerrobend e acrílico, nas energias de $6 \mathrm{MeV}$ e $12 \mathrm{MeV}$ para um campo de $1 \mathrm{x} 1 \mathrm{~cm}^{2}$.

Tabela 13: Valores de $\mathrm{R}_{50}$ para o campo de $1 \times 1 \mathrm{~cm}^{2}$. 73

Tabela 14: Valores de $\mathrm{d}_{\max }$ para o campo de $1 \times 1 \mathrm{~cm}^{2}$. 74

Tabela 15: Valores de RP para o campo de $1 \times 1 \mathrm{~cm}^{2}$ 74

Tabela 16: Valores de dose na superfície para o campo de $1 \times 1 \mathrm{~cm}^{2}$. 74

Tabela 17: Valores de $\mathrm{R}_{50}$ das curvas de porcentagem de dose profunda para o campo de $5 \times 5 \mathrm{~cm}^{2}$.

Tabela 18: Valores de $d_{\max }$ das curvas de porcentagem de dose profunda para o campo de $5 \times 5 \mathrm{~cm}^{2}$. 
Tabela 19: Valores de $R_{P}$ das curvas de porcentagem de dose profunda para o campo de

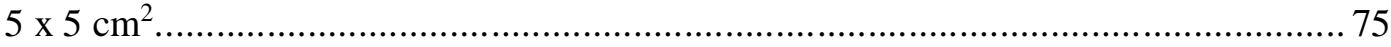

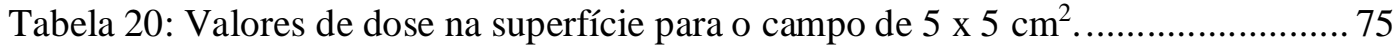




\section{ÍNDICE}

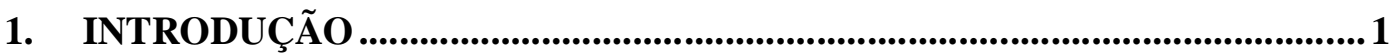

2. FUNDAMENTAÇÃO TEÓRICA ….......................................................

2.1. Radioterapia com feixe de elétrons ............................................................

2.1.1. Porcentagem de dose em profundidade ……………………………..... 5

2.1.2. Perfil de campo ............................................................................. 6

2.1.3. Curvas de isodose ........................................................................ 8

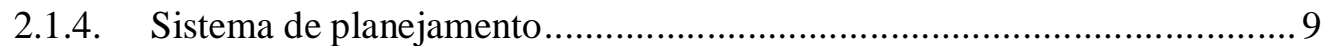

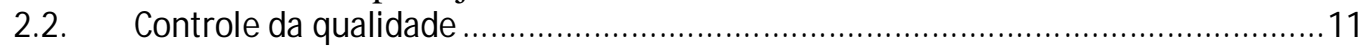

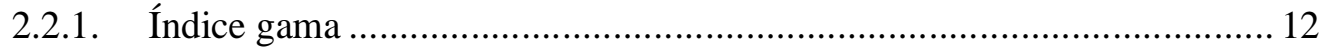

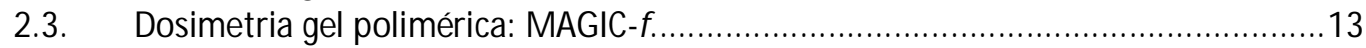

2.3.1. Polimerização do dosímetro MAGIC-f f............................................... 15

2.3.2. Método de leitura dos dosímetros poliméricos utilizando ressonância

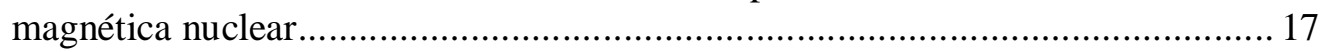

2.4. Simulação Monte Carlo com o código PENELOPE..............................................20

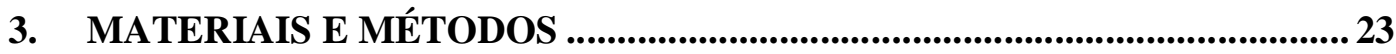

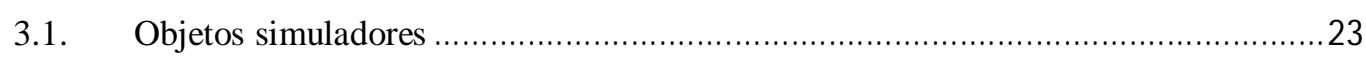

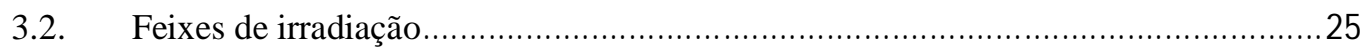

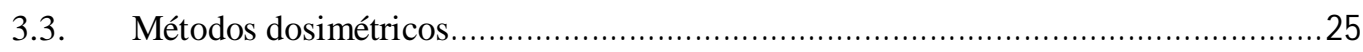

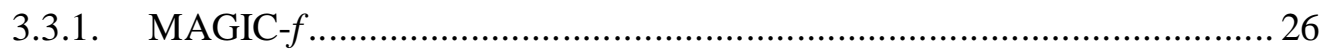

3.3.2. Código de simulação Monte Carlo PENELOPE ……………………….... 29

3.3.3. Sistema de planejamento................................................................... 29

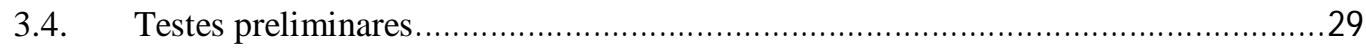

3.4.1. Homogeneidade da bobina de ressonância magnética.................................30

3.4.2. Simulação do material do dosímetro MAGIC-f gel...................................30

3.5. Caracterização do dosímetro MAGIC-f ............................................................

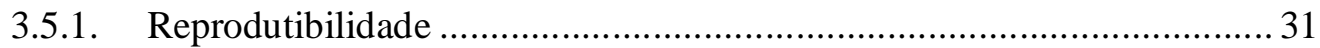

3.5.2. Estabilidade temporal da resposta do MAGIC- $f$ gel .............................. 32

3.5.3. Dependência da resposta do MAGIC- $f$ gel com a dose absorvida e energia

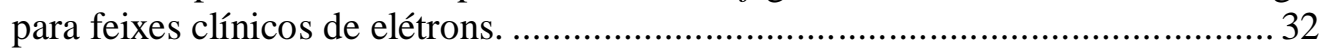

3.5.4. Dependência da resposta do MAGIC- $f$ gel com taxa de dose para feixes

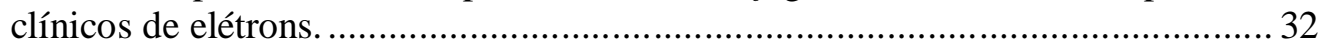

3.6. Avalição de parâmetros dosimétricos com MAGIC-f gel .........................................33

3.6.1. Porcentagem de dose em profundidade ................................................... 33

3.6.2. Perfil de campo.................................................................................. 34

3.7. Avaliação de condições de irradiação com MAGIC-f gel .........................................35

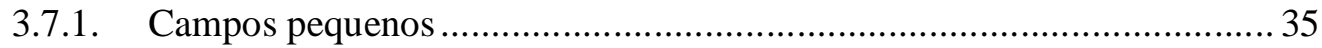

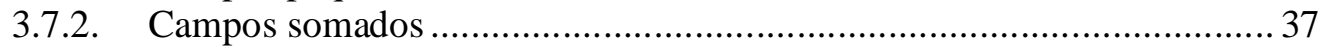

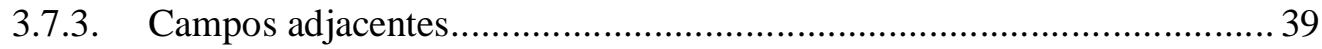

3.8. Verificação de tratamentos ...........................................................................

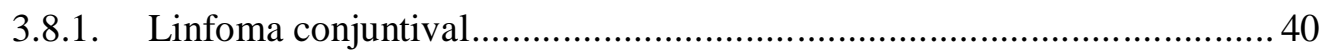

3.8.2. Doença subclínica de linfonodo ........................................................... 41 


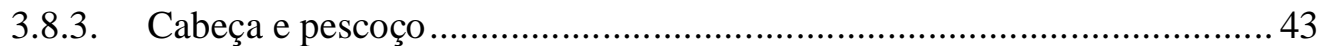

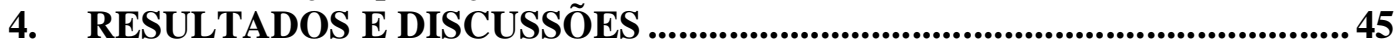

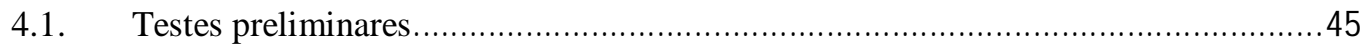

4.1.1. Homogeneidade da bobina de ressonância magnética........................... 45

4.1.2. Simulação do material MAGIC- $f$ gel .................................................... 48

4.2. Caracterização do dosímetro MAGIC-f …....................................................... 50

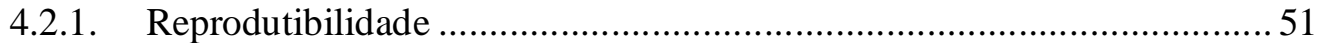

4.2.2. Estabilidade temporal da resposta do MAGIC- $f$ gel ............................. 52

4.2.3. Dependência de resposta do MAGIC- $f$ gel com a dose absorvida e energia para feixes clínicos de elétrons ....................................................................... 53

4.2.4. Dependência de resposta do MAGIC- $f$ gel com a taxa de dose para feixes

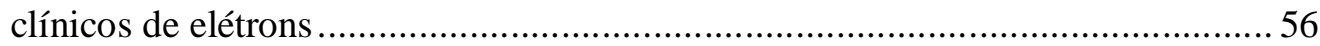

4.3. Avaliação dos parâmetros dosimétricos com MAGIC-f gel ......................................58

4.3.1. Porcentagem de dose em profundidade .............................................5 58

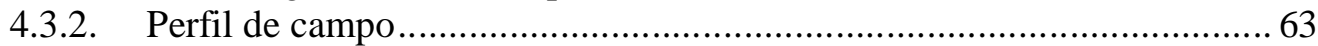

4.4. Avaliação de condições de irradiação com MAGIC-f gel ...................................6 65

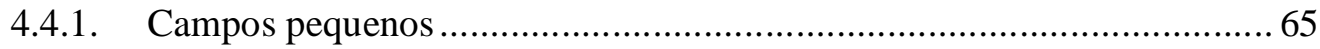

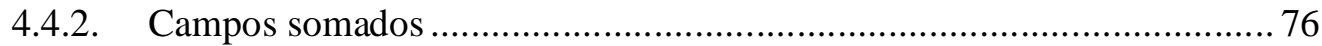

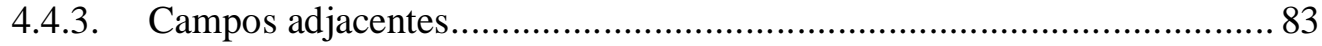

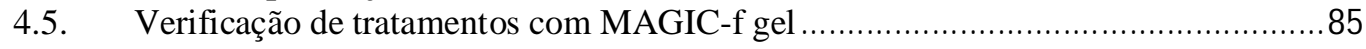

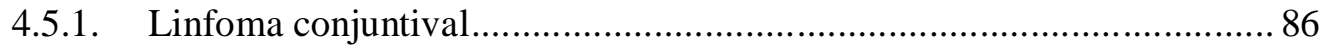

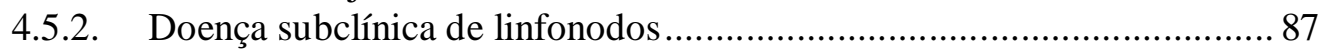

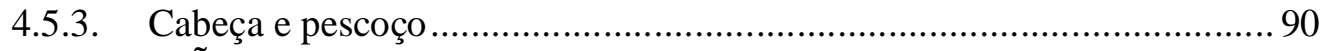

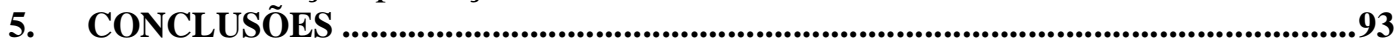

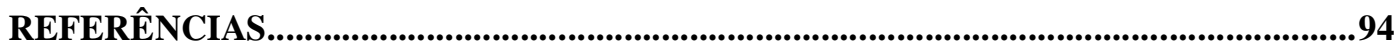




\section{INTRODUÇÃO}

Feixes de elétrons são utilizados em radioterapia devido a sua capacidade de entregar altas doses no volume alvo e baixas doses em regiões adjacentes devido ao alto gradiente de dose característico desse tipo de radiação. Dessa forma, feixes de elétrons são utilizados para tratamentos superficiais, como por exemplo, micoses fungóide e câncer de mama (DOGAN et al, 2013; HARRISON et al, 2011; HINDS et al, 2013). Além disso, este tipo de feixe também é utilizado em radioterapia intra-operatória, por exemplo em tratamentos de câncer do intestino e mama e para fornecer reforço de dose após mastectomia (DEBENHAM et al, 2013; SWEETING et al, 2013; OSTI et al, 2013).

Com o avanço tecnológico nos equipamentos de terapia e com a melhoria dos algoritmos utilizados nos sistemas de planejamento computadorizado, técnicas conformacionais, muito bem estabelecida para feixes de fótons, têm se tornado uma possibilidade para feixes de elétrons (JIN et al, 2008; e ELDIB et al, 2013). Estudos mostram que modulação de feixe de elétrons na radioterapia (MERT, do inglês Modulation Electron RadioTherapy) pode ser realizada utilizando os colimadores existentes para feixes de fótons ou ainda através do desenvolvimento de colimadores próprios para elétrons (AL-YAHYA et al, 2007; GAUER et al, 2008; VATANEN et al, 2008; KLEIN et al, 2008; PAPACONSTADOPOULOS E SEUNTJENS, 2013). Pesquisas mostram a aplicação de MERT, por exemplo, em tratamentos para câncer de mama (MA et al, 2003; SUCURU et al, 2010; ALEXANDER et al, 2012).

Devido à complexidade dessas técnicas utilizadas em radioterapia são necessários métodos eficazes para realização do controle da qualidade, visto a presença de altos gradientes de dose, limites restritos de posicionamento e incerteza de dose (ICRU, 1999). Assim, a escolha de um dosímetro mais apropriado para a dosimetria desse tipo de feixe é primordial.

Dessa forma, a câmara de ionização de placas paralelas é o dosímetro de referência para feixes de elétrons de megavoltagem em procedimentos com energias menores que $10 \mathrm{MeV}$ e câmaras tipo dedal podem ser utilizadas para energia maiores que $10 \mathrm{MeV}$ (IAEA, 2000b; ICRU, 2004). Os dosímetros termoluminescentes, diodos e filmes também têm sido empregados na dosimetria desse tipo de feixe (YAPARPALVI et al, 2000; SU et al, 2007; ARJOMANDY et al, 2010; NELSON et al, 2010; LAWLESS el al, 2013). Entretanto, esses dosímetros não possuem, ao mesmo tempo, características apropriadas para determinação da dose com alta resolução espacial, baixa dependência 
energética, possibilidade de uso em altos gradientes de dose, além de não proporcionarem distribuições tridimensional de dose, um dos requisitos para realização de controle da qualidade em técnicas modernas e de modulação de feixe (IAEA, 2003; BLAKE et al, 2013; MARSOLAT et al, 2013). Trabalhos recentes mostram que os dosímetros atuais, como EPIDS e cintiladores, estão sendo empregados em dosimetria tridimensional. Entretanto, esses dosímetros fazem reconstruções das distribuições de dose planares para gerar distribuições de dose tridimensionais (BECK et al, 2009; GREER, 2013; KROLL et al, 2013; STATHAKIS et al, 2013).

Dosímetros a base de gel têm sido estudados para uso em dosimetria em feixes de fótons principalmente por suas características de alta resolução espacial, sensibilidade, determinação tridimensional da distribuição de doses no tratamento e equivalência em água (CRESCENTI el al 2007; WONG et al 2007; OLIVEIRA et al, 2009a). A dependência de algumas características desses dosímetros, como sensibilidade e resolução espacial em função da dose, da energia e da taxa de dose, são bem estabelecidos para feixes de fótons, entretanto, a literatura não mostra dados consolidados para outros tipos de feixes, como, por exemplo, feixes de elétrons (OLIVEIRA et al 2009b; SAMPAIO et al, 2011).

Dentre os dosímetros a base de géis encontram-se os dosímetros poliméricos que também vêm sendo empregados em diversas aplicações de radioterapia, como, por exemplo, para verificações de distribuições de dose em diferentes tratamentos (McJURY et al, 2000; SELLAJUMAR et al, 2010; GORIJIARA et al, 2011; SEMNICKA e KLUSON, 2012; VANDECASTEELE e DE DEENE, 2013). Dentre eles, pode-se destacar o dosímetro polimérico MAGIC, por sua manufatura em condições atmosféricas normais (DING et al, 2012; ALJAMAL et al, 2013). Assim, devido ao potencial de aplicação desse tipo de dosímetro em radioterapia MAGIC- $f$ gel pode ser um método dosimétrico auxiliar para determinação de controle de qualidade em feixes de elétrons e estabilidade de dose em temperatura ambiente (PAVONI e BAFFA, 2012; PAVONI et al, 2012).

Outra ferramenta eficaz para o estudo de feixes clínicos são os códigos de simulação Monte Carlo, que representam uma alternativa conveniente em relação aos métodos experimentais apresentando a vantagem de propiciar estudos detalhados, e em diferentes condições, de diversos processos que envolveriam procedimentos experimentais demorados, complexos e de alto custo (KRAMER, 2000). O uso do método Monte Carlo para a simulação de fenômenos de atenuação da radiação e de deposição de dose em 
materiais tem crescido continuamente com o desenvolvimento de códigos específicos para essas aplicações (VERHAEGEN, 2002; ROGERS, 2006). Devido ao algoritmo misto de transporte de partículas carregadas e uma simplificada metodologia de utilização, o código PENELOPE (SEMPAU et al, 2003) tornou-se muito utilizado em aplicações para Física Médica (TILLY et al, 2002; RODRÍGUEZ et al, 2005; SEMPAU et al 2011; LONDONO et al, 2012; KOIVUNORO et al, 2012; HERMIDA-LOPEZ, 2013).

Conforme contexto apresentado, esse trabalho avaliou a utilização do dosímetro polimérico MAGIC- $f$ gel para o controle da qualidade em Radioterapia com feixes de elétrons. A leitura do dosímetro foi realizada por ressonância magnética e para comparação dos resultados obtidos utilizou-se simulação Monte Carlo PENELOPE. Assim, as distribuições de doses obtidas com os métodos dosimétricos estudados foram avaliadas através da determinação de parâmetros dosimétricos e com a técnica de comparação do índice gama.

Esta tese foi dividida em capítulos que são apresentados a seguir. No Capítulo 2 são descritos os fundamentos teóricos envolvidos nesse estudo, como radioterapia com feixes de elétrons, parâmetros dosimétricos, controle de qualidade, índice gama, dosimetria gel polimérica e simulação Monte Carlo.

No Capítulo 3 são descritos os materiais e métodos utilizados nesse trabalho. Descreve-se os feixes de radiação utilizados e a metodologia para caracterização do dosímetro MAGIC- $f$ para feixes de elétrons, além da metodologia aplicada para determinação de parâmetros dosimétricos. Nesse capítulo também são descritos os procedimentos para verificações de condições de irradiação e de tratamentos clínicos utilizando MAGIC- $f$ e o código PENELOPE em feixes de elétrons.

Os resultados encontrados para caracterização e verificações de condições de irradiação e de tratamentos clínicos, utilizando os métodos dosimétricos estudados para feixes de elétrons, são apresentados no Capítulo 4.

As conclusões do trabalho, evidenciando que o dosímetro MAGIC- $f$ pode ser utilizados como uma ferramenta auxiliar em controle da qualidade para feixes de elétrons, são apresentados no Capítulo 5. 


\section{FUNDAMENTAÇÃO TEÓRICA}

Nesse capítulo é apresentada uma breve fundamentação teórica sobre radioterapia com feixes de elétrons, controle da qualidade, dosimetria gel polimérica e simulação Monte Carlo com o código PENELOPE.

\subsection{Radioterapia com feixe de elétrons}

Feixes de elétrons têm sido utilizados em radioterapia, mais intensamente, a partir de 1970 com o desenvolvimento comercial de aceleradores lineares com várias energias e alvos de raios $\mathrm{X}$ retráteis, tornando-se uma importante opção em radioterapia e sendo empregados para tratamentos de câncer de pele e lábios, câncer na parede torácica e pescoço, vias respiratórias superiores, lesões digestivas, reforço nos tratamentos de nodos linfáticos, cicatrizes provenientes de cirurgias e tumores residuais (KHAN et al, 1991; HOGSTROM et al, 2006; DOGAN et al, 2013; HINDS et al, 2013).

Esses feixes apresentam vantagens sobre os feixes de fótons para tratamentos superficiais devido ao alcance bem definido de partículas carregadas, proporcionando um platô de dose, entre $90 \%$ e $100 \%$ da dose máxima na superfície, seguido de um alto gradiente de dose em profundidade (JIN et al, 2008; ICRU, 2004).

Feixes de elétrons interagem de forma direta com os átomos do meio (especificamente com os elétrons) através de forças coulombianas, provocando excitações coletivas e/ou colisões elásticas e inelásticas. Através das colisões inelásticas é depositada energia no meio, levando à dose absorvida. As partículas carregadas atravessam um meio com uma sequência de interações, perdendo a sua energia, normalmente, em pequenas porções até serem completamente freadas. A ocorrência de colisões inelásticas está dada pela função do poder de freamento (do inglês, stopping power) que representa a perda de energia por unidade de caminho percorrido (YOSHIMURA, 2009).

Quando um elétron possui energia cinética elevada pode interagir fortemente com o campo elétrico de um núcleo do meio, sofrendo, um desvio da sua trajetória e perdendo parte da sua energia em forma de Bremmsstrahlung. Para os feixes e materiais utilizados em Radioterapia, perdas de energia por colisão são mais significativas que as perdas por radiação. 
Para a utilização de feixes de elétrons em tratamentos radioterápicos é necessário a caracterização do feixe, que pode ser realizada a partir de parâmetros dosimétricos específicos. Esses parâmetros dependem da energia do feixe, da distância fonte superfície e do tamanho do campo de irradiação, assim como da geometria e da composição do volume a ser irradiado (KHAN, 2010).

\subsubsection{Porcentagem de dose em profundidade}

Características dosimétricas dos feixes de elétrons podem ser obtidas por meio da curva de porcentagem de dose em profundidade (PDP), que expressa a dose relativa percentual em uma profundidade qualquer em relação à profundidade de máxima dose, de acordo com a equação 1 :

$$
P D P(d)=\frac{D_{d}}{D_{m}} \cdot 100 \%
$$

em que $\mathrm{D}_{\mathrm{d}}$ é a dose depositada na profundidade de interesse e $\mathrm{D}_{\mathrm{m}}$ é a dose depositada na profundidade de máxima dose.

A PDP é função que depende da energia do feixe, das folhas espalhadoras dos elétrons, dos colimadores, da distância fonte-superfície, do tamanho e da forma do campo de irradiação (HOGSTROM, 2006). Recomenda-se que esse parâmetro seja determinado a uma distância fonte superfície de $100 \mathrm{~cm}$ em um objeto simulador de água, para evitar correções das variações dos stopping power da água para outro material. Para energias mais utilizadas nos serviços de radioterapia, a medida da PDP pode ser feita com tamanhos de campo de $10 \times 10 \mathrm{~cm}^{2}$ a $20 \times 20 \mathrm{~cm}^{2}$ (IAEA, 2004).

A partir da PDP é possível determinar parâmetros que caracterizam um feixe de elétrons como: alcances máximo $\left(R_{\max }\right)$, prático $\left(R_{p}\right)$ e terapêutico $\left(R_{90}\right)$ do feixe, além do índice de qualidade do feixe $\left(R_{50}\right)$ (IAEA, 2003), como mostrado na Figura 1. 


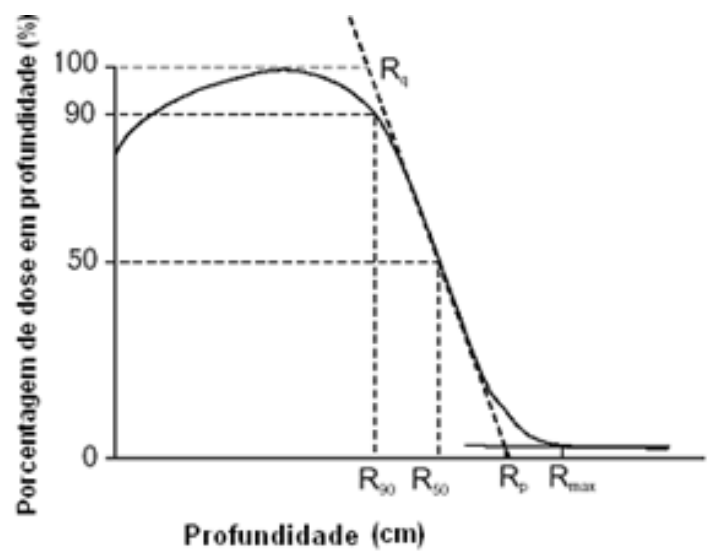

Figura 1: Porcentagem de dose em profundidade, com indicação dos parâmetros dosimétricos relacionados a um feixe de elétrons (IAEA, 2003).

Os alcances $\mathrm{R}_{90}$ e $\mathrm{R}_{50}$ são definidos como as profundidades nas quais a porcentagem de dose absorvida apresenta os valores de $90 \%$ e 50\% da dose máxima, respectivamente. O alcance terapêutico é definido como a profundidade da isodose relevante para o tratamento, que é estabelecido de acordo com a profundidade da região a ser tratada. Geralmente, são utilizadas profundidades de $\mathrm{R}_{95}$ a $\mathrm{R}_{85}$ nos planejamentos dos tratamentos (ICRU, 1984a).

O alcance prático $R_{p}$ é definido como o ponto em que a reta de extrapolação da porção íngreme da curva de PDP intercepta o eixo das profundidades, proporcionando uma aproximação da profundidade máxima em que o feixe de elétrons deposita dose (ICRU, 2004; HOGSTROM et al, 2006). Entretanto, devido às colisões do feixe de elétrons com o meio, profundidades maiores que $\mathrm{R}_{\mathrm{p}}$ ainda recebem dose devido aos elétrons espalhados. A profundidade $\mathrm{R}_{\text {máx }}$ é a máxima profundidade em que o feixe de elétrons deposita dose. Após essa profundidade a dose depositada é devida à contaminação do feixe por Bremsstrahlung.

\subsubsection{Perfil de campo}

O perfil de campo fornece a informação da dose ao longo de um dos eixos perpendiculares ao eixo central do campo de radiação na profundidade de máxima dose, determinado pela razão da dose em um ponto ao longo da direção x ou y do campo e a dose no eixo central do campo de radiação. 
As condições de referência para a realização do perfil de campo, para feixes mais utilizados nos serviços de radioterapia, são: distância fonte superfície de $100 \mathrm{~cm}$ e campo de irradiação de $10 \times 10 \mathrm{~cm}^{2}$ a 20 × $20 \mathrm{~cm}^{2}$.

A figura 2 mostra o perfil de campo de um feixe de elétrons de $6 \mathrm{MeV}$, de um acelerador linear da Varian 2100, irradiado com campo de 10 x $10 \mathrm{~cm}^{2}$ a uma distância fonte superfície de $100 \mathrm{~cm}$.

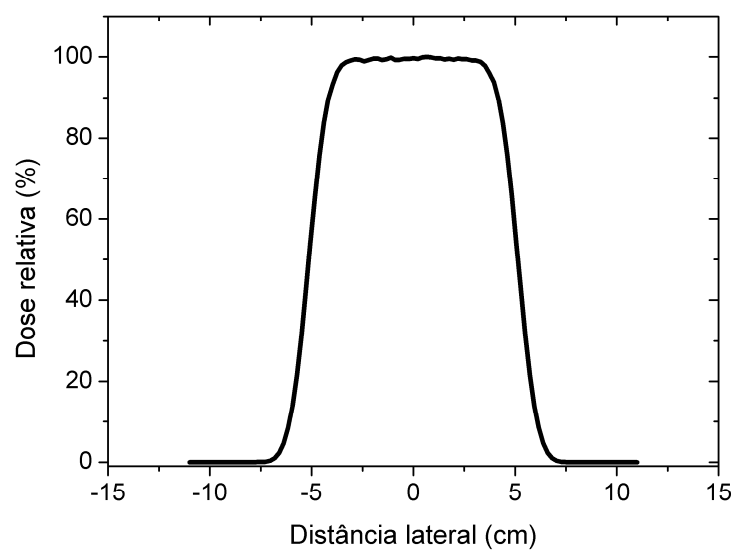

Figura 2: Perfil de campo para feixe de elétrons de $6 \mathrm{MeV}$ e campo de 10 x $10 \mathrm{~cm}^{2}$.

A partir da determinação do perfil de campo podem ser obtidas informações da penumbra e a simetria do campo de irradiação que dependem do tipo e energia do feixe, que são estabelecidos para cada aparelho de tratamento. A penumbra do campo de irradiação é definida como as distâncias laterais do eixo das abcissas referentes aos valores da porcentagem da dose entre $20 \%$ e $80 \%$. A simetria é definida como o desvio percentual máximo na dose entre ambos os lados do campo de radiação em relação ao eixo central, em $80 \%$ do tamanho de campo de irradiação e é determinada pela equação 2 :

$$
S=\frac{\left[D_{d i r}-D_{e s q}\right]_{80 \%}}{D_{\text {eixo }}} .100 \%
$$

em que $\mathrm{D}_{\text {esq }}$, representa a dose absorvida do lado esquerdo, $\mathrm{D}_{\text {dir }}$, representa a dose absorvida do lado direto e $\mathrm{D}_{\text {eixo }}$, dose absorvida no eixo central do campo de irradiação (IAEA, 2003). 
O perfil de campo é sempre determinado na profundidade de máxima dose, enquanto o perfil de dose pode ser obtido em uma profundidade arbitrária. A partir do perfil de dose pode ser obtida a planura, expressa pela equação 3:

$$
P=100 \% \cdot \frac{[D \max -D \min ]_{80 \%}}{[D \max +D \min ]_{80 \%}}
$$

em que é determinada a partir dos valores de dose máxima, $\mathrm{D}_{\text {máx }}$ e dose mínima, $\mathrm{D}_{\text {mín, }}$ dentro dos $80 \%$ centrais da área da campo de irradiação utilizado.

\subsubsection{Curvas de isodose}

As curvas de isodose são linhas que passam por pontos com mesma dose em um plano do volume irradiado e dependem da energia do feixe, do tamanho de campo, da distância fonte superfície e de colimadores do feixe.

A principal característica das curvas de isodose para um feixe de elétrons é o abaulamento nas regiões laterais de baixa dose devido à característica de espalhamento do feixe. A figura 3, mostra as curvas de isodoses para um feixe de $9 \mathrm{MeV}$ obtidos com campo de irradiação de 10 x $10 \mathrm{~cm}^{2}$ e de distância fonte superfície de $100 \mathrm{~cm}$.

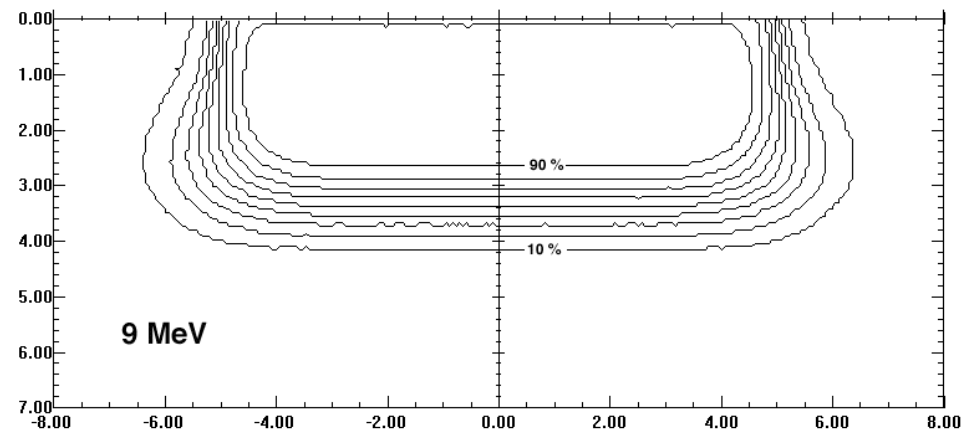

Figura 3: Curvas de isodose típicas para um feixe de elétrons $9 \mathrm{MeV}$ e com campo de irradiação de 10 x $10 \mathrm{~cm}^{2}$ (IAEA, 2003).

Para feixes de elétrons é recomendado por protocolos clínicos (IAEA, 2003) que os parâmetros dosimétricos sejam determinados com uma pequena câmara de ionização cilíndrica ou de placas plano paralelas, dependendo da energia do feixe. Para energias abaixo de $10 \mathrm{MeV}$, câmaras de placas paralelas são recomendadas e para energias 
superiores a essa são recomendadas câmaras cilíndricas. Para a determinação da curva de PDP com outros dosímetros, como filmes, termoluminescentes (TLD) ou diodos, as medidas devem ser comparadas com dados obtidos com o dosímetro padrão.

\subsubsection{Sistema de planejamento}

Os planejamentos em radioterapia determinam distribuições de dose absorvida no volume alvo e nos tecidos sadios adjacentes considerando condições de irradiação, por exemplo, o tipo de feixe, tamanho e quantidade de campos, distância fonte-superfície, filtros entre outros aspectos. Inicialmente, os planejamentos dos tratamentos eram realizados de forma manual a partir de cartas de isodose padronizadas e pelo contorno da superfície do paciente. Assim, as distribuições de dose eram calculadas sobrepondo as cartas de isodose sobre o contorno da região avaliada, sem considerar heterogeneidades nas estruturas internas do paciente. As definições dos tamanhos dos campos, dos pesos dos mesmos e a blindagem das estruturas adjacentes ao tumor eram definidos por imagens geradas por equipamentos de raios X convencionais (PODGORSAK et al, 2005; SALVAJOLI et al, 1999). Com o desenvolvimento da tomografia computadorizada e a evolução dos computadores, os planejamentos radioterápicos foram aprimorados, permitindo a determinação e a visualização das distribuições de dose em 3D. Dessa forma, os sistemas de planejamento computadorizado (TPS do inglês Treatment Planning System) são utilizados para realização dos cálculos dessa distribuição de dose.

O TPS é um pacote de programas que realizam o planejamento computacional de um tratamento permitindo a entrada de informações como: imagens tomográficas do paciente, especificidade do equipamento de irradiação, energia, modalidade de tratamento, acessórios, entre outros (KAWRALOW e BIELAJEW, 1998; AAPM, 1998; IAEA, 2004).

Comercialmente existem vários TPS, que se diferenciam pelo grau de complexidade e, principalmente, pelo algoritmo responsável pelo cálculo de dose. Os algoritmos de cálculos mais atuais fazem correções de contorno e heterogeneidade do meio, calculando as distribuições de doses em vários planos de tratamento. Esses sistemas, também, possuem sub-rotinas que determinam os histogramas dose-volume, que definem a aprovação do tratamento conforme a prescrição médica (SALVAJOLI et al, 1999). 
Os algoritmos de cálculo de dose para feixe de elétrons são consideravelmente diferentes daqueles algoritmos utilizados para feixes de fótons, devido ao tipo de interação que essas partículas sofrem com o meio. Assim, os algoritmos de cálculo de dose para feixes de elétrons baseiam-se na grandeza de interação para esse tipo de partícula, isto é, na perda de energia por caminho percorrido em um determinado meio, expressa em termos dos poderes de freamento que pode ser dividido em colisional e radiativo (ICRU, 1984b).

Existem vários algoritmos utilizados para o cálculo da dose em feixes de elétrons, como o método de pencil beam, phase space evolution, pencial beam generalizado e elétron Monte Carlo entre outros (WEBER e NILSSON, 2002; PODGORSAK et al, 2005; XU et al, 2009).

A figura 4 mostra da tela do sistema de planejamento Eclipse ${ }^{\circledR}$, que utiliza o algoritmo de cálculo pencil beam para determinação de distribuições de dose para feixes clínicos de elétrons (BOYD et al, 2001; DING et al, 2005; CHI et al, 2006; PRICE et al, 2007).

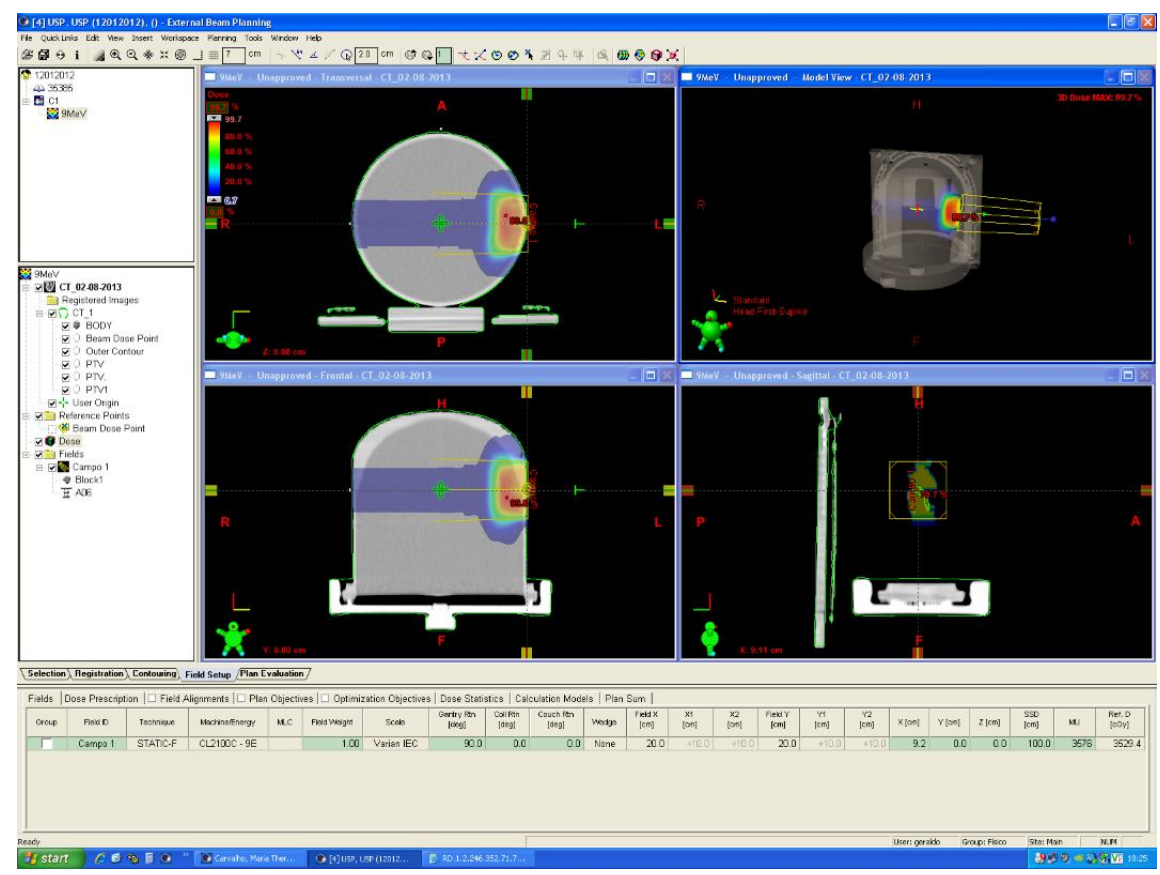

Figura 4: Tela do sistema de planejamento Eclipse ${ }^{\circledR}$ para um caso tratado com feixes clínicos de elétrons. 


\subsection{Controle da qualidade}

A garantia da qualidade dos tratamentos radioterápicos depende de alguns aspectos, dentre eles a qualidade dos sistemas de planejamento e o controle da qualidade dos equipamentos e procedimentos realizados (IPEM, 1999).

Dessa forma, instituições regulamentadoras recomendam a instalação de um programa de garantia da qualidade nos serviços de radioterapia. Várias instituições tem implementado e publicado recomendações para estruturar um programa de garantia da qualidade. Dentre essas instituições podem ser citadas: Organização Mundial de Saúde (WHO, do inglês World Health Organization), Associação Americana de Física Médica (AAPM do inglês American Association of Physicists in Medicine), Sociedade Européia de Radioterapia e Oncologia (ESTRO, do inglês European Society for Radiotherapy \& Oncology), Instituto de Física e Engenharia em Medicina (IPEM, do inglês Institute of Physics and Engineering in Medicine), Agência Internacional de Energia Atômica (IAEA do inglês International Atomic Energy Agency) entre outras instituições (WHO, 2008; KLEIN et al, 2009; GERBI et al 2009; IPEM,1999; IAEA, 2000a; ESTRO, 1995). No Brasil são adotadas as recomendações da Agência Nacional de Vigilância Sanitária (ANVISA), que baseia-se no protocolo da IAEA, na qual recomenda-se que os serviços de radioterapia realizem avaliações externas de qualidade a cada quatro anos (ANVISA 2006).

Dentro do controle da qualidade em Radioterapia, alguns fatores técnicos e físicos podem ser avaliados como, por exemplo, aspectos mecânicos e geométricos dos equipamentos de teleterapia e simuladores, dosimetria, sistemas de planejamento do tratamento, braquiterapia e segurança, estabelecendo uma série de testes que devem ser executados conjuntamente com as tolerâncias aceitáveis e previamente estabelecidas. Assim, um programa de controle da qualidade deve ser usado para verificar e assegurar que os requisitos de qualidade sejam cumpridos, ajustando-se e corrigindo-se adequadamente qualquer não conformidade encontrada (AAPM, 1991; IAEA, 2000a, FURNARI, 2009; PODGORSAK et al, 2005).

O controle da qualidade deve verificar todas as etapas envolvidas no tratamento radioterápico, desde a aquisição de imagens por tomografia computadorizada por raios $\mathrm{X}$ ou por ressonância magnética e durante o planejamento do tratamento até a administração da dose. Assim, para aceleradores lineares antes da utilização do equipamento para tratamento, uma série de testes devem ser realizados e fazendo parte de um procedimento 
conhecido como comissionamento da máquina. Esses dados são utilizados posteriormente como valores de referências para os testes de controle da qualidade da máquina (IPEM, 1999).

Os testes para controle da qualidade de um acelerador linear são realizados em diferentes periodicidades: testes diários, semanais, mensais e anuais. Assim, são realizados testes de procedimentos mecânicos, no qual verifica-se falha no funcionamento dos componentes do aparelho; testes de segurança, que avaliam o funcionamento do travamento da porta, monitores da sala de tratamento entre outros. Procedimentos dosimétricos também devem ser realizados para avaliar a constância dos valores do output do feixe, a constância do perfil de dose, a variação da simetria e planura, a qualidade do feixe de elétrons em $\mathrm{R}_{50}$, entre outros (IAEA, 2000a).

A Comissão Internacional de Unidades e Medidas de Radiação (ICRU, do inglês International Comission on Radiation Units and Measurements) recomenda que a diferença entre a prescrição e a administração de dose no paciente deve estar dentro do intervalo entre - 5\% e + 7\% (ICRU, 1999). Para avaliação das diferenças entre as distribuições de dose planejadas e administradas utilizam-se métodos comparativos, dentre eles o índice gama (ALI et al, 2011).

\subsection{1. Índice gama}

O índice gama, $\gamma$, é uma metodologia desenvolvida por Low e colaboradores (Low et al, 1998) que compara quantitativamente duas distribuições de dose. O método utiliza dois parâmetros para realizar a comparação: um avalia a diferença de dose (DD, do inglês dose difference) e outro considera uma distância aceitável (DTA, do inglês distance-toagreement) para valores de dose entre pontos das distribuições.

O método unifica esses dois parâmetros em uma função que utilizará os critérios de aceitação da DD e DTA estabelecidos em cada tipo de tratamento e avaliará as distribuições de dose, retornando uma resposta de comparação:

$\gamma\left(\mathrm{r}_{\mathrm{m}}\right) \leq 1$, correspondem a pontos avaliados em que as diferenças estão dentro das tolerâncias estabelecidas;

$\gamma\left(\mathrm{r}_{\mathrm{m}}\right)>1$, correspondem a pontos avaliados em que as diferenças estão acimas das tolerâncias estabelecidas. 
A equação 4 apresentação a formulação para o índice gama:

$$
\Gamma=\sqrt{\frac{r^{2}\left(r_{m}, r\right)}{\Delta d_{M}^{2}}+\frac{\delta\left(r_{m}, r\right)}{\Delta D_{M}^{2}}}
$$

em que:

$r\left(r_{m}, r\right)=\left|r-r_{m}\right|$ é a distância radial entre o ponto na distribuição de dose de referência para uma dada dose, $\mathrm{r}_{\mathrm{m}}$, e o ponto na distribuição avaliada para a mesma dose, $\mathrm{r}$;

$\delta\left(r_{m}, r\right)=D(r)-D_{m}\left(r_{m}\right)$ é a diferença de doses nas posições $\mathrm{r}$ e $\mathrm{r}_{\mathrm{m}}$;

$\Delta d_{M}^{2} e \Delta D_{M}^{2}$ são os critérios de DTA e DD, respectivamente.

Deste modo, qualquer valor de $\gamma$ para os pontos pertencentes ao intervalo $r-r_{m}$ é escolhido como o valor mínimo dentro desse intervalo, que é expresso pela equação 5:

$$
\gamma\left(r_{m}\right)=\min \left\{\Gamma\left(r_{m}, r\right)\right\} \forall\{r\} .
$$

Nas avaliações do índice gama, as distribuições de dose experimentais dependem diretamente das incertezas do dosímetro utilizado. Em radioterapia, o dosímetro de referência para feixes de elétrons de megavoltagem é a câmara de ionização. Entretanto, tem-se encontrado na literatura medições de controle da qualidade com outros dosímetro, por exemplo filme radiocrômico (SCHIAPPARELLI et al, 2003; SPEIGHT et al, 2011). Dosímetros poliméricos ainda não são normalmente utilizados, mas poderiam auxiliar em procedimentos de controle da qualidade permitindo assim avaliações tridimensionais.

\subsection{Dosimetria gel polimérica: MAGIC- $f$}

Dosímetros géis poliméricos são compostos que iniciam uma reação de polimerização quando submetidos à radiação, sendo esse processo função da dose absorvida. Esses dosímetros têm a capacidade de guardar informações de distribuições tridimensionais de dose, sendo uma vantagem em comparação a outros dosímetros que fornecem apenas distribuições mono ou bidimensionais de dose, como câmaras de ionização e filmes, respectivamente. Essa vantagem é particularmente importante para 
radioterapia em que a avaliação da distribuição de dose no volume tumoral é essencial para a qualidade do tratamento.

A proposta de géis sensíveis a radiação como dosímetro foi sugerida por Day e Stein em 1950, com géis que alteravam a coloração em função da dose absorvida (DAY et al, 1950). Em 1957, Andrews e colaboradores estudaram por espectroscopia as distribuições de dose em profundidade e o pH de géis sensíveis à radiação (ANDREWS et al, 1957).

A utilização desses géis como dosímetro iniciou-se com Gore e colaboradores em 1984, que investigou os géis Fricke, inicialmente estudados por Fricke e Morse em 1927. Esses géis se baseiam no princípio de oxidação de íons de ferro e nas suas propriedades de relaxação em ressonância magnética sendo que as concentrações dos íons férricos podem ser quantificadas por essa técnica (GORE et al, 1984).

Paralelamente às pesquisas com solução Fricke gel, iniciou-se o estudo com outros dosímetros géis, os dosímetros poliméricos como: BANANA (do inglês bis acrylamide nitrous oxide and agarose) (MARYANSKI et al, 1993), BANG (do inglês bis acrylamide nitrous oxide gel) (MARYANSKI et al, 1994) e PAG (do inglês polymer acrylamide gelatine) (BALDOCK et al, 1998). Nos dosímetros poliméricos nos quais compostos monoméricos dos dosímetros são imersos em uma matriz gelatinosa aquosa sofrendo, assim, uma reação polimérica em função da dose absorvida, resultando em uma matriz de gel polimérico. Esta polimerização rádio-induzida produz mudanças nas propriedades de relaxação de ressonância magnética. Mudanças estas que podem ser relacionadas com a deposição de dose absorvida apresentando um potencial para dosimetria clínica tridimensional. Porém, para esse tipo de dosímetro, a presença de oxigênio inibe a polimerização, de forma que estes necessitam condições hipóxicas durante a confecção, armazenamento e uso. Para solucionar esse problema, Fong e colaboradores, em 2001 (FONG et al, 2001), criaram um novo gel polimérico, MAGIC (do inglês methacrylic and ascorbic acid in gelatin initiated by copper), formado com a combinação de materiais a base de metacrilato, ácido ascórbico e sal de cobre. A captação do oxigênio é dada pelo complexo ascorbato-cobre, que permite a preparação desses géis poliméricos em condições atmosféricas normais (BALDOCK et al, 2001; DE DEENE et al, 2002; GUSTAVSSON et al, 2003).

Outro problema apresentado pelos géis poliméricos era a instabilidade mecânica (derretimento) das amostras quando mantidas à temperatura ambiente, causando uma limitação da utilização desse dosímetro, pois as distribuições de dose eram perdidas. Em 2008, Fernandes e colaboradores (FERNANDES et al, 2008) resolveram esse problema 
acrescentando formaldeído à formulação original do MAGIC, aumentando seu ponto de fusão para $69^{\circ} \mathrm{C}$ e permitindo seu uso em temperaturas ambientes típicas. Esse novo gel é conhecido como MAGIC- $f$.

\subsubsection{Polimerização do dosímetro MAGIC- $f$}

Os monômeros do dosímetro MAGIC- $f$ são dissolvidos em uma matriz de gelatina, sendo que em torno de 90\% de sua constituição é formada por água (DE DEENE, 2004a). Durante a irradiação do dosímetro ocorre um processo conhecido como radiólise da água, isto é, a radiação ionizante interage com a molécula de água criando radicais livres reativos e esse radicais livres irão interagir com os monômeros dos dosímetro. As equações 6 à 10 são exemplos desse radicais.

$$
\begin{gathered}
\mathrm{H}_{2} \mathrm{O} \underset{\text { Radiação }}{\longrightarrow} \mathrm{H}_{2} \mathrm{O}^{+}+e^{-} . \\
\mathrm{H}_{2} \mathrm{O}^{+}+\mathrm{H}_{2} \mathrm{O} \longrightarrow \mathrm{H}_{3} \mathrm{O}^{+}+\mathrm{OH}^{-} . \\
e^{-}+\mathrm{H}_{2} \mathrm{O} \longrightarrow e_{\text {aquoso }}^{-} \\
\mathrm{H}_{3} \mathrm{O}^{+}+e_{\text {aquoso }}^{-} \longrightarrow \mathrm{H}^{+}+\mathrm{H}_{2} \mathrm{O} \\
e_{\text {aquoso }}^{-}+\mathrm{H}_{2} \mathrm{O}^{+} \longrightarrow \mathrm{OH}^{-}+\mathrm{H}^{-}
\end{gathered}
$$

Assim, a radiólise da água pode ser expressa pela equação 11:

$$
\mathrm{H}_{2} \mathrm{O} \stackrel{k_{D}}{\rightarrow} 2 \mathrm{R}^{*}
$$

em que $\mathrm{k}_{\mathrm{D}}$ é a taxa de reação que é diretamente proporcional a dose recebida.

Os radicais livres formados na radiólise da água iniciam o processo de polimerização interagindo com os monômeros do gel. A equação de inicialização do processo de polimerização pode ser representada pela equação 12:

$$
R^{*}+M_{n} \stackrel{k_{1}}{\rightarrow} R M_{n}^{*}
$$


em que $\mathrm{k}_{1}$ é taxa de polimerização inicial, em que é criado um monômero radical. Inicialmente, não existe a formação de polímeros $(n=1)$. Assim, quando $n>1$ existe a formação de polímeros radicais. O crescimento do polímero ocorre por uma reação em cadeia na qual os radicais monoméricos ou poliméricos irão interagir com outros monômeros, como apresentado na equação 13:

$$
R M_{n}^{*}+M_{n} \stackrel{k p(n)}{\longrightarrow} R M_{n+m}^{*}
$$

em que $\mathrm{k}_{\mathrm{p}}$ é a taxa de crescimento do polímero que depende do tamanho da cadeia e do formato do polímero.

A finalização do processo de polimerização pode ocorrer pela interação entre dois radicais que originarão um molécula iniciadora estável, $I$, em vários processos, conhecidos como terminação mútua ou desprorpocionalização (De DENEE, 2006a, 2006b), que são mostradas nas equações 14 a 16:

$$
\begin{gathered}
R^{*}+R^{*} \longrightarrow R R=I \\
R^{*}+R I \longrightarrow I+M_{n} \\
R M_{n}^{*}+R M_{m}^{*} \longrightarrow I+M_{n+m} .
\end{gathered}
$$

Além disso, na presença de oxigênio a finalização pode ocorrer por um outro processo em que os radicais livres se ligam ao oxigênio formando peróxidos, que podem se ligar a outros radicais finalizando assim a reação em cadeia. Devido a esse processo de interação, existe a necessidade de ausência de oxigênio nas amostras para evitar inibição de polimerização dos géis. Dessa forma, os compartimentos utilizados para o armazenamento desses géis devem impedir a difusão do oxigênio até a amostra.

O processo de polimerização pode ser observado visualmente, pois quando os dosímetros são expostos à radiação ionizante ocorre uma alteração em sua propriedade ótica, tornando-o opaco, como pode ser observado na figura 5. 


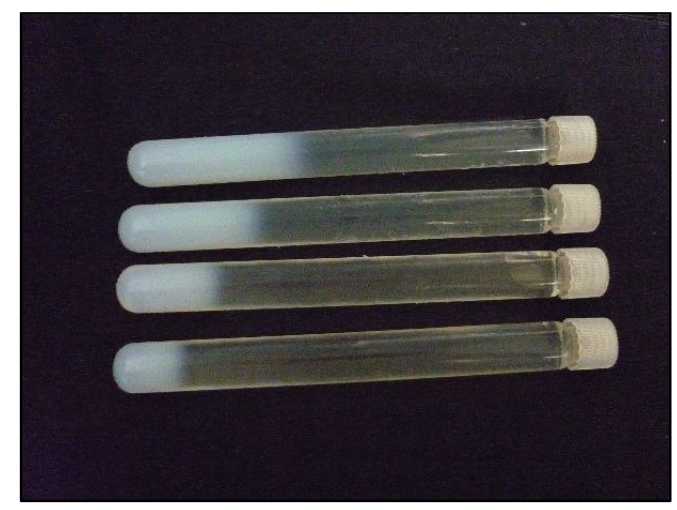

Figura 5: MAGIC- $f$ gel irradiado com feixes clínicos de elétrons de diferentes energias.

Para a quantificação da dose depositada a leitura do dosímetro pode ser realizada através de técnicas como: tomografia óptica (GORE et al, 1996), tomografia computadorizada por raios X (HILTS et al, 2000), ultrassom (MATHER et al, 2002a) e por ressonância magnética (BARAS et al, 2002).

\subsubsection{Método de leitura dos dosímetros poliméricos utilizando ressonância magnética nuclear}

A ressonância magnética pode ser utilizada para a quantificação da dose depositada em géis poliméricos, pois a polimerização induz mudanças nas propriedades de relaxação dos prótons do gel que podem ser determinadas por essas técnicas (HILL et al, 2005; CRESCENTI et al, 2007; LUCI et al, 2007; MARIANI et al, 2007).

As imagens de ressonância magnética são baseadas na excitação magnética dos tecidos do corpo, que ocorre em núcleos atômicos com número ímpar de prótons. O núcleo utilizado em imagens de ressonância magnética é o átomo de hidrogênio, devido a sua abundancia em tecido biológico.

Dessa maneira, na presença de um campo magnético $\left(\mathrm{B}_{0}\right)$, os prótons irão alinharse com o campo, originando momentos magnéticos paralelos e antiparalelos. Assim, uma magnetização macroscópica (M) é detectada no sentido do campo $\mathrm{B}_{0}$. Caso ondas de radiofrequência sejam aplicadas, os estados de energias dos prótons são alterados, mudando a direção do vetor M. Quando os pulsos de radiofrequência são interrompidos, os prótons tendem a retornar ao seu estado de equilíbrio, isto é, estado de menor energia. O tempo para o retorno ao estado de menor energia pode ser dividido em dois componentes, tempo de relaxação longitudinal $\left(\mathrm{T}_{1}\right)$ e transversal $\left(\mathrm{T}_{2}\right)$. 
O tempo necessário para que o vetor magnetização $\mathrm{M}$ retorne a $63 \%$ do valor inicial é conhecido como tempo de relaxação longitudinal ou spin-rede, T1, e segue o comportamento apresentado na equação 17:

$$
M_{z}=M_{0}\left(1-e^{-\frac{t}{T_{1}}}\right)
$$

em que $M_{z}$ é o vetor magnetização no eixo $z, M_{0}$ é a intensidade do vetor no estado de equilíbrio e $t$ é o tempo a partir da retirada do pulso de radiofrequência. A figura 6 mostra esquematicamente o vetor $\mathrm{M}_{\mathrm{z}}$ antes e após a aplicação do pulso de radiofrequência.

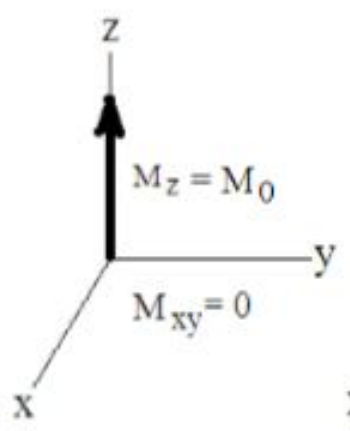

(a)

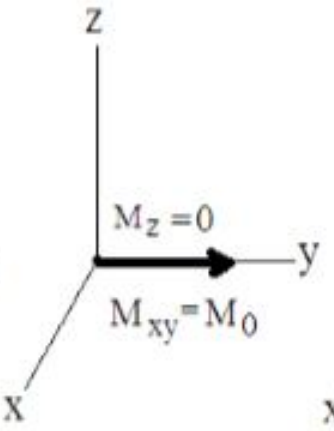

(b)

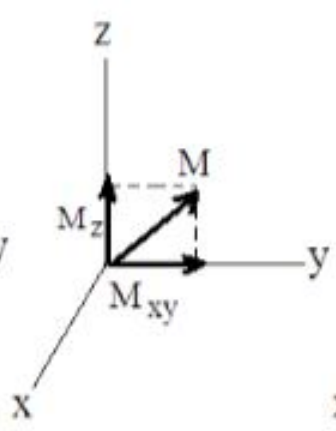

(c)

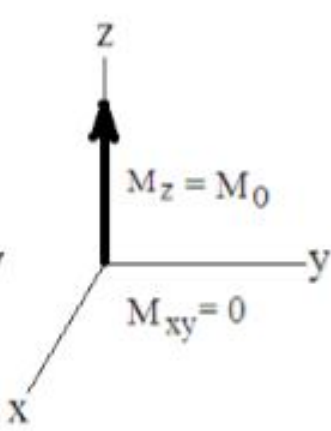

(d)

Figura 6: Vetor magnetização $M$ : (a) o vetor $M_{z}$ antes da aplicação do pulso de radiofrequência tem intensidade $\mathrm{M}_{0}$ (b) depois da aplicação do pulso de radiofrequência $\left(90^{\circ}\right), \mathrm{M}_{\mathrm{z}}$ é rotacionado para o plano xy e tem intensidade zero em $\mathrm{Z}$, (c) o vetor $\mathrm{M}_{z}$ tende a voltar ao seu estado de equilíbrio no eixo $\mathrm{z}(\mathrm{d})$ vetor $\mathrm{M}_{\mathrm{z}}$ restabelecido seu estado inicial.

Quando o vetor magnetização estiver no plano xy, ocorrerá interação dos campos magnéticos de cada núcleo com seu vizinho, fazendo com que os núcleos adquiram magnetizações distintas, diminuindo a intensidade do vetor magnetização $\mathbf{M}_{\mathrm{xy}}$. Assim, o tempo de relaxação transversal, ou spin-spin, é o tempo necessário para que a magnetização no plano xy retorne a $37 \%$ do seu valor inicial e segue o comportamento apresentado na equação 18:

$$
M_{x y}=M_{x y 0}\left(1-e^{-\frac{t}{T_{2}}}\right)
$$

em que $M_{x y}$ é o vetor magnetização no plano xy e $M_{x y 0}$ é a intensidade do vetor quando ele estiver no seu estado de equilíbrio e $t$ é o tempo após a aplicação do pulso de 
radiofrequência. A figura 7 mostra esquematicamente o vetor $M_{x y}$ antes e após a aplicação do pulso de radiofrequência.

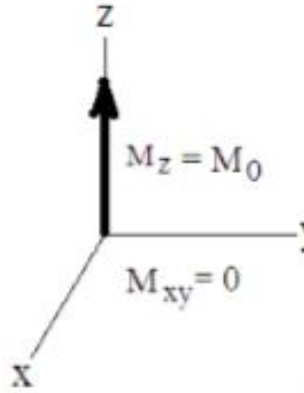

(a)

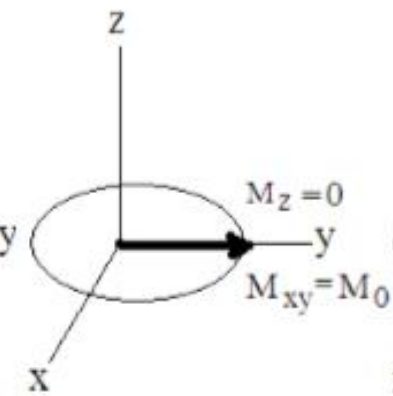

(b)

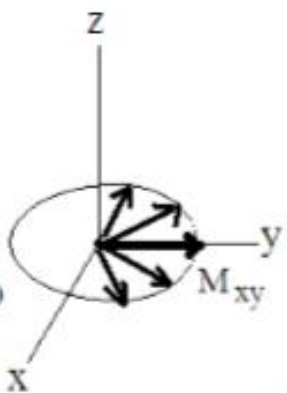

(c)

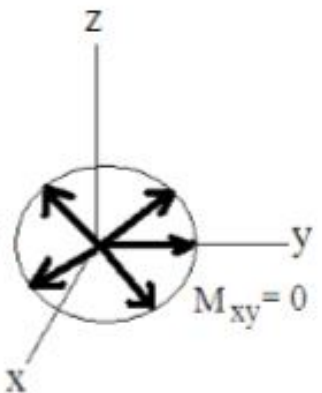

(d)

Figura 7: Vetor magnetização M: (a) posição de equilíbrio do vetor $\mathrm{M}_{\mathrm{z}}$, na direção do campo magnético e com intensidade $\mathrm{M}_{0}$, (b) depois de aplicado o pulso de radiofrequência $\left(90^{\circ}\right), \mathrm{M}_{\mathrm{z}}$ é rotacionado para o plano xy e tem intensidade zero em $\mathrm{Z}$ e $\mathrm{M}_{\mathrm{xy}}$ tem intensidade $\mathrm{M}_{0}$, (c) núcleos com magnetização xy distintas, diminuindo a intensidade do vetor $\mathbf{M}_{\mathrm{xy}}(\mathrm{d})$ Defasagem completa do vetor $\mathbf{M}_{\mathrm{xy}}$ ao mesmo tempo que se estabelece o retorno a posição inicial.

A radiação ionizante induz alterações dos tempos de relaxação do meio, pois as cadeias poliméricas influenciam na mobilidade das moléculas de água ao seu redor reduzindo os movimentos dos prótons da molécula de água. Normalmente a resposta em dose é relacionada com a taxa de relaxação transversal $\left(\mathrm{R}_{2}=1 / \mathrm{T}_{2}\right)$ (MARYANSKI et al, 1994). A equação 19 apresenta a dependência do sinal de ressonância com T2:

$$
S(t) \propto e^{i w t} e^{\frac{-t}{T_{2}}}
$$

em que $S(t)$ é o sinal de ressonância magnética, $t$ é o tempo de repetição dos pulsos e $\mathrm{T}_{2}$ é o tempo de relaxação transversal.

Em uma imagem de ressonância magnética, cada pixel da imagem é resultado desse sinal e estes irão gerar uma distribuição em R2 que será proporcional a dose. 


\subsection{Simulação Monte Carlo com o código PENELOPE}

O método Monte Carlo utiliza a amostragem de números aleatórios e métodos estatísticos para encontrar soluções de problemas matemáticos ou físicos (KRAMER et $a l, 2000)$. Na simulação Monte Carlo (SMC) do transporte da radiação, a história de uma partícula é descrita como uma seqüência probabilística de interações em que, no final, a partícula altera a sua direção de movimento podendo perder parcialmente ou totalmente sua energia e, ocasionalmente, gerar uma partícula secundária (ROGERS, 2006).

Dentre os códigos de SMC mais utilizados para simular a interação da radiação com a matéria, para aplicações em radiologia, estão o EGS (BIELAJEW e ROGERS, 1992), o MCNP (HENDRIKCS et al, 2000) e, mais recentemente, o PENELOPE (SALVAT et $a l, 2008$ ) e o GEANT (ALISSON et al, 2006). Entretanto, a qualidade dos resultados fornecidos pelos diferentes códigos de simulação está diretamente ligada com a exatidão do modelo de transporte implementado e com as bibliotecas que contêm os dados associados à seção de choque das partículas transportadas (ROGERS, 2006). O algoritmo de transporte implementado pelo PENELOPE (SEMPAU et al, 2003) levou à sua intensa utilização em radioterapia (LONDONO et al, 2012; HERMIDA-LOPEZ, 2013; LIU et $a l, 2013)$.

Assim, o código de simulação Monte Carlo PENELOPE, distribuído gratuitamente pela Agência de Energia Nuclear (NEA, do inglês Nuclear Energy Agency), é utilizado para simular o transporte de elétrons, pósitrons e fótons em geometrias e materiais diversos.

O algoritmo de simulação do PENELOPE utiliza um modelo que combina dados numéricos e analíticos de seção de choque para os diferentes tipos de interação e é aplicado para energias iniciais de $1 \mathrm{keV}$ até, aproximadamente, $1 \mathrm{GeV}$. O transporte de fótons é simulado pelo método, detalhado, e a simulação de elétrons e pósitrons é feita por meio de um algoritmo misto, os quais sofrem um grande número de interações antes de serem efetivamente absorvidos pelo meio, tornando inviável a utilização de um método detalhado (ou de classe I) para o transporte dessas partículas.

Assim, para elétrons e pósitrons o código PENELOPE difere dos outros códigos de simulação por utilizar um algoritmo misto (ou classe II), que implementa dois modelos de simulação: a detalhada, para eventos fortes, definidos a partir da deflexão angular (ângulo de espalhamento) ou perda de energia acima de certo valor pré-definido, e condensada, para interações fracas, com deflexão angular (ângulo de espalhamento) ou 
perda de energia menores que os valores pré-estabelecidos. As interações condensadas são descritas por uma aproximação dos múltiplos espalhamentos, que consiste em transformar um grande número de interações fracas em um único evento artificial. A teoria de espalhamento múltiplo implementada em algoritmos de simulação condensada é feita por aproximações, podendo conduzir a erros sistemáticos atribuídos à dependência da simulação com parâmetros que controlam o transporte. Esses parâmetros de controle da simulação influenciam tanto na exatidão quanto no desempenho da simulação e esses parâmetros para o código PENELOPE são descritos abaixo:

1. E $E_{A B S}$, o valor de energia máxima que uma partícula, carregada ou não, pode possuir antes de ser total e localmente absorvida, finalizando o transporte da mesma e iniciando o transporte de uma nova partícula;

2. $\mathrm{C}_{1}$, relacionado com a deflexão angular média produzida por múltiplo espalhamento entre duas colisões fortes consecutivas de uma partícula carregada. Deve ser suficientemente pequeno para permitir simulação detalhada, quando esta for requerida;

3. $\mathrm{C}_{2}$, relacionado com a perda fracional máxima de energia permitida entre eventos de colisão forte de uma partícula carregada.

4. $\mathrm{W}_{\mathrm{CC}}$, a energia máxima perdida por partículas carregadas em colisões fortes;

5. $\mathrm{W}_{\mathrm{CR}}$, a energia máxima perdida por partículas carregadas em perdas radiativas.

Assim, para que a simulação seja mais exata, é necessário que se utilizem pequenos valores de $\mathrm{C}_{1}$ e $\mathrm{C}_{2}$ (em torno de 0,05 ), sendo que o uso de valores maiores que estes fazem com que a simulação perca exatidão, porém torne-se mais rápida. As energias de corte Wcc e $W_{C R}$ podem influenciar na distribuição de energia das partículas sendo simuladas (SALVAT et al, 2008).

As subrotinas FORTRAN desse código são organizadas em quatro arquivos básicos: PENELOPE.f, que contém as subrotinas de transporte das partículas; PENGEOM.f, que contém subrotinas de geometria; PENVARED.f, que contém as subrotinas que executam os métodos de redução variacional e TIMER.f, que gerencia o tempo de simulação. Além desses arquivos, o código apresenta uma base de dados com as características de materiais diversos de interesse em Física Radiológica (ICRU, 1989) e bibliotecas de seção de choque e outras grandezas necessárias para o transporte das partículas. Dentre as principais vantagens do uso desse código de SMC está a utilização das bibliotecas de seção de choque EPDL97 (SALVAT et al, 2008). 
Para iniciar uma simulação com o PENELOPE, o usuário deve editar um arquivo FORTRAN, usuario. $f$, com as chamadas das subrotinas PENELOPE.f, PENGEOM.f, PENVARED.f e TIMER.f, proporcionando o gerenciamento da simulação como um todo, e criando, com esses cinco arquivos FORTRAN, um arquivo usuario.exe.

A simulação é iniciada pela execução do arquivo usuario.exe que busca informações de entrada fornecidas pelo usuário através do arquivo entrada.in, além de informações da geometria através do arquivo geometria.geo, e informações de seção de choque dos materiais envolvidos na simulação através do arquivo material.mat.

$\mathrm{O}$ arquivo entrada.in contém informações sobre o campo de radiação, tipo e energia das partículas primárias, abertura e posição da fonte de radiação, parâmetros de controle da simulação, número de partículas a serem simuladas e tempo total de simulação, além, dos nomes dos arquivos de geometria e material.

Já o arquivo geometria.geo define as regiões de interesse na simulação, cada região devendo ser definida como um corpo específico e sendo escrita por meio de funções quadráticas que definem superfícies que limitam essas regiões, como na equação 20:

$$
F(x, y, z)=A_{x x} x^{2}+A_{y y} y^{2}+A_{z z} z^{2}+A_{x y} x y+A_{x z} x z+A_{y z} y z+A_{x} x+A_{y} y+A_{z} z+A_{0}=0
$$

Para cada corpo no arquivo de geometria deve ser definido um índice de material, correspondendo ao material que preencherá a região interna do corpo. No arquivo de material, são encontrados dados do material e tabelas com parâmetros de transporte e interação de elétrons, fótons e pósitrons em função da energia.

Os dados do arquivo de saída podem ser escolhidos pelo usuário, podendo conter dados de interação e deposição de energia em relação aos corpos definidos no arquivo de geometria. 


\section{MATERIAIS E MÉTODOS}

Neste capítulo são apresentados os materiais e métodos utilizados para caracterização do dosímetro polimérico MAGIC- $f$ para feixes de elétrons e para validação dos métodos dosimétricos utilizados nesse trabalho: MAGIC- $f$, código de simulação PENELOPE e TPS Eclipse ${ }^{\circledR}$ em feixe de elétrons.

Primeiramente, para caracterização do dosímetro MAGIC- $f$ foram realizadas medidas para determinação de sua dependência da resposta em função da dose absorvida, taxa de dose e estabilidade de resposta após a irradiação. Posteriormente, foram validados os métodos dosimétricos utilizados nesse trabalho, em condições de referência para feixes clínicos utilizados. Para essa etapa foram obtidos parâmetros dosimétricos, como curvas de porcentagem de dose em profundidade e perfis de campo. Os resultados obtidos foram comparados com os dados da câmara de ionização, EXradin modelo P11 de placas paralelas, usado no serviço de radioterapia do Hospital do Câncer de Barretos (HCB). Nesta seção também são apresentados as avaliações do dosímetro a base de gel em algumas condições encontradas na clínica, como: campos pequenos, somados e adjacentes.

Como última etapa, foram feitas verificações em condições de irradiação e de simulação de tratamentos clínicos. As distribuições de doses obtidas com MAGIC- $f$ gel e simulação Monte Carlo PENELOPE foram comparadas com os dados obtidos com o TPS Eclipse $^{\circledR}$.

\subsection{Objetos simuladores}

Nesta seção apresentam-se os objetos simuladores de acrílico ou polimetilmetacrilato (PMMA) que foram utilizados nos procedimentos experimentais com o dosímetro MAGIC- $f$ gel.

Para a caracterização do dosímetro utilizaram tubos de vidro de $5 \mathrm{ml}$ de coleta de sangue (vacutainer ${ }^{\circledR}$ ) com $5 \mathrm{~cm}$ de comprimento e $0,8 \mathrm{~cm}$ de diâmetro, figura $8 \mathrm{a}$.

Os objetos simuladores utilizados para a validação do dosímetro gel foram: tubos cilíndricos de vidro de $50 \mathrm{ml}$, com dimensões de $20 \mathrm{~cm}$ de comprimento e de 1,5 cm de diâmetro, assim como também paralelepípedos de PMMA, com dimensões de $12 \times 5 \times 10 \mathrm{~cm}^{3}$, relativos ao comprimento, largura e altura, como mostrado nas figuras $8 \mathrm{~b}$ e $8 \mathrm{c}$. 
Para as determinações das distribuições de dose e para as determinações dos parâmetros dosimétricos com feixes de elétrons, foram usados, também, paralelepípedos de PMMA, nas mesmas dimensões mostradas anteriormente, e um objeto simulador de cabeça com dimensões na parte cilíndrica de $18 \mathrm{~cm}$ de diâmetro e $15 \mathrm{~cm}$ de altura e a parte superior, "ovalada", possui um perímetro de $23 \mathrm{~cm}$, como mostrado nas figuras $8 \mathrm{c} \mathrm{e}$ 8d, usado para as determinações das distribuições de dose da avaliação de um caso clinico.

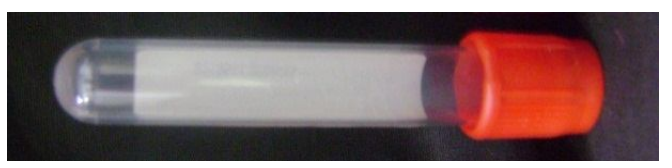

(a)

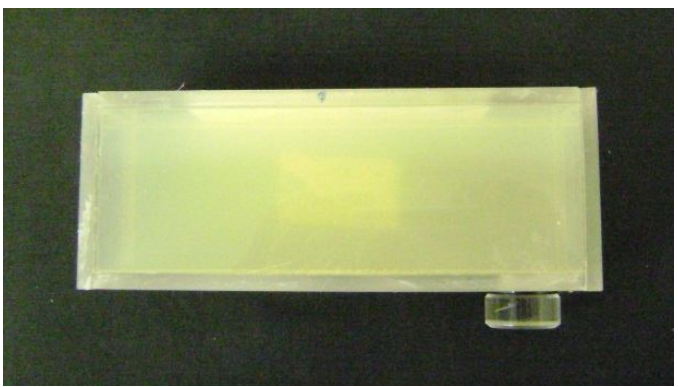

(c)

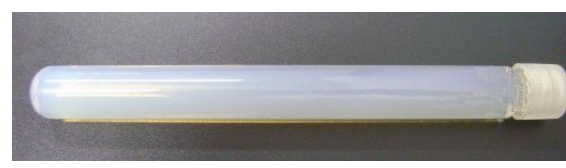

(b)

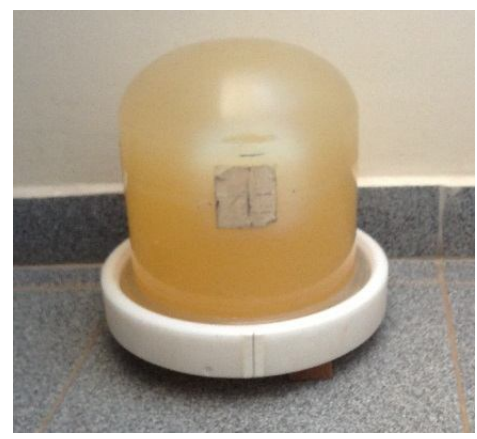

(d)

Figura 8: Objetos simuladores utilizados nos procedimentos de irradiação com MAGIC-f gel: (a) caracterização do dosímetro; (b) e (c) validação do dosímetro; (c) e (d) irradiações em condições clínicas.

Os objetos simuladores foram utilizados para realizar imagens tomográficas em um tomógrafo LightSpeed VCT, multislice de 64 canais, da marca GE do HCB. As imagens obtidas foram utilizadas nos planejamentos das irradiações, por meio do sistema de planejamento Eclipse ${ }^{\circledR}$. Depois de realizados os planejamentos da irradiação, os objetos simuladores foram utilizados para os procedimentos experimentais com MAGIC- $f$ gel. Já para a simulação computacional, com o código PENELOPE, geometrias e condições de irradiação idênticas foram consideradas. 


\subsection{Feixes de irradiação}

As irradiações foram realizadas em um acelerador linear, Varian $2100 \mathrm{C}$, do serviço de radioterapia do $\mathrm{HCB}$, em feixes de elétrons com energias de 6, 9, 12 e $15 \mathrm{MeV}$. Somente para o estudo da variação da resposta do gel em função do tempo de espera para a leitura e da reprodutibilidade foi utilizada a unidade de Cobalto-60, Siemens Gamatron II, do serviço de radioterapia do Hospital das Clínicas de Ribeirão Preto (HCRP).

Para as simulações das diversas irradiações com o código de simulação PENENOPE foram utilizados espectros de energia de equipamentos clínicos de radioterapia publicados na literatura (INMS, 2003) apresentados na figura 9.

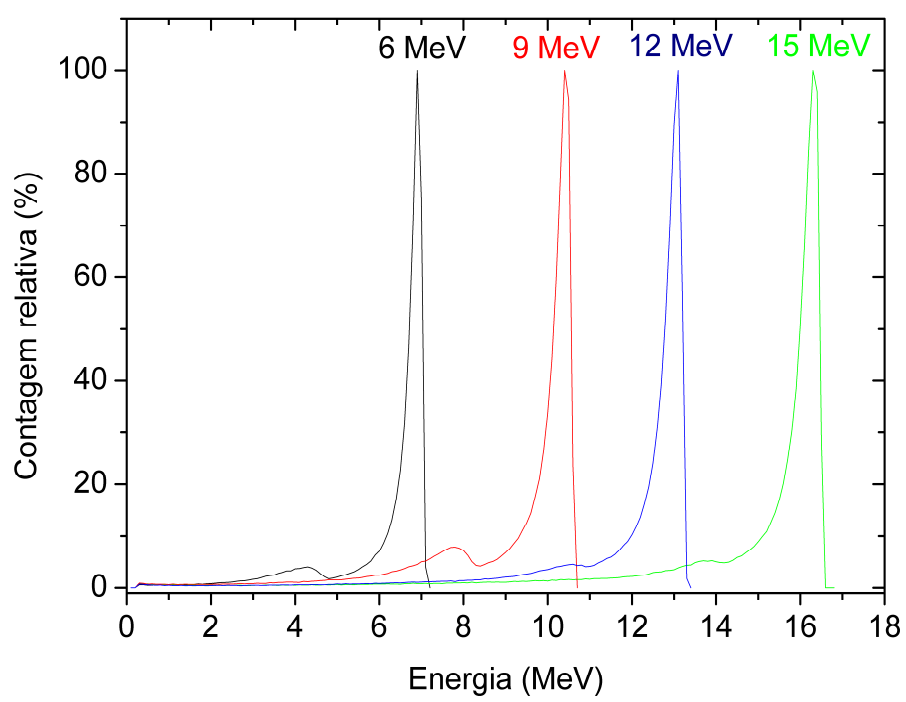

Figura 9: Espectros de energia para feixes de elétrons de 6, 9, 12 e $15 \mathrm{MeV}$ baseados no equipamento Varian 2100 C (INMS, 2003).

Conforme mostrado na figura 9, os espectros dos feixes estão normalizados para o valor máximo de contagem das partículas por energia. O primeiro pico observado para cada energia, mostra a contaminação de fótons devido à interação dos feixes de elétrons, que são espalhados por folhas metálicas e outras partes do acelerador linear produzindo Bremsstrahlung (SEMPAU et al, 2001; INMS 2003).

\subsection{Métodos dosimétricos}

No desenvolvimento desse trabalho foram utilizados os seguintes métodos dosimétricos: dosímetro gel polimérico MAGIC- $f$, simulação Monte Carlo PENELOPE e TPS Eclipse ${ }^{\circledR}$. 


\subsubsection{MAGIC- $f$}

Nesse trabalho foi utilizado o gel polimérico MAGIC- $f$ (do inglês Metacrylic Ascorbic acid and Gelatine Initiated by Cooper solution with formaldehyde), com número atômico efetivo igual a 7,41 e densidade $1,06 \mathrm{~g} / \mathrm{cm}^{3}$ (ALVA et al, 2010). A manufatura do dosímetro foi realizada de acordo com o protocolo desenvolvido por Fernandes (Fernandes et al, 2008). De acordo com o protocolo, água Mili-Q deve ser aquecida até chegar a uma temperatura de, aproximadamente, $30{ }^{\circ} \mathrm{C}$. Nessa temperatura, coloca-se gradativamente, em pequenas quantidades, a gelatina granulada de 250 bloom. Uma vez que a gelatina encontra-se totalmente dissolvida, formando a base gelatinosa, a $36^{\circ} \mathrm{C}$, os outros componentes devem ser adicionados na sequencia mostrada na Tabela 1.

Tabela 1: Composição do dosímetro MAGIC- $f$ gel para um litro de solução.

\begin{tabular}{c|c} 
Componentes & Quantidades \\
\hline Água Mili-Q & $840 \mathrm{ml}$ \\
\hline Gelatina 250 bloom & $82 \mathrm{~g}$ \\
\hline Solução de sulfato de cobre & $20 \mathrm{ml}$ \\
\hline Ácido ascórbico & $352 \mathrm{mg}$ \\
\hline Ácido metacrílico & $59 \mathrm{ml}$ \\
\hline Formaldeído & $30 \mathrm{ml}$
\end{tabular}

A figura 10 mostra parte do processo de manufatura do gel polimérico MAGIC- $f$, quando a gelatina 250 bloom, encontra-se totalmente dissolvida, criando assim, a base gelatinosa do dosímetro MAGIC- $f$.

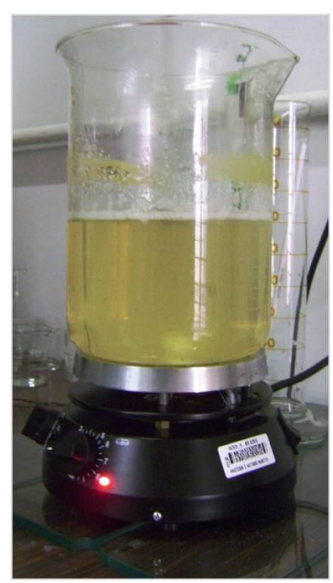

Figura 10: Primeiro passo da manufatura do dosímetro polimérico MAGIC-f: dissolução da gelatina 250 bloom. 
Depois de terminado o processo de manufatura, o dosímetro foi acondicionado em objetos simuladores específicos para cada estudo e com espessura das paredes adequada para evitar a penetração de oxigênio e colocado na geladeira.

\subsubsection{Leitura e aquisição das imagens}

Exceto para os testes de desvanecimento de resposta, as leituras das amostras de gel irradiadas foram realizadas 24 horas após a irradiação, em tomógrafo de ressonância magnética (RM) Philips 3,0 Tesla HCRP, mostrado na figura 11, utilizando uma bobina de cabeça e realizando-se medidas de relaxometria em $\mathrm{T} 2$.

As imagens foram adquiridas em uma sequência multi spin-eco de 16 ecos com tempo ao eco (TE) de $20 \mathrm{~ms}$ e tempo repetição (TR) de $4000 \mathrm{~ms}$ com matrizes de $256 \mathrm{x}$ 256 pixels, fatias de espessura de $1 \mathrm{~mm}$ e o campo de visão (FOV, do inglês "field of view") de acordo com o experimento sendo realizado.

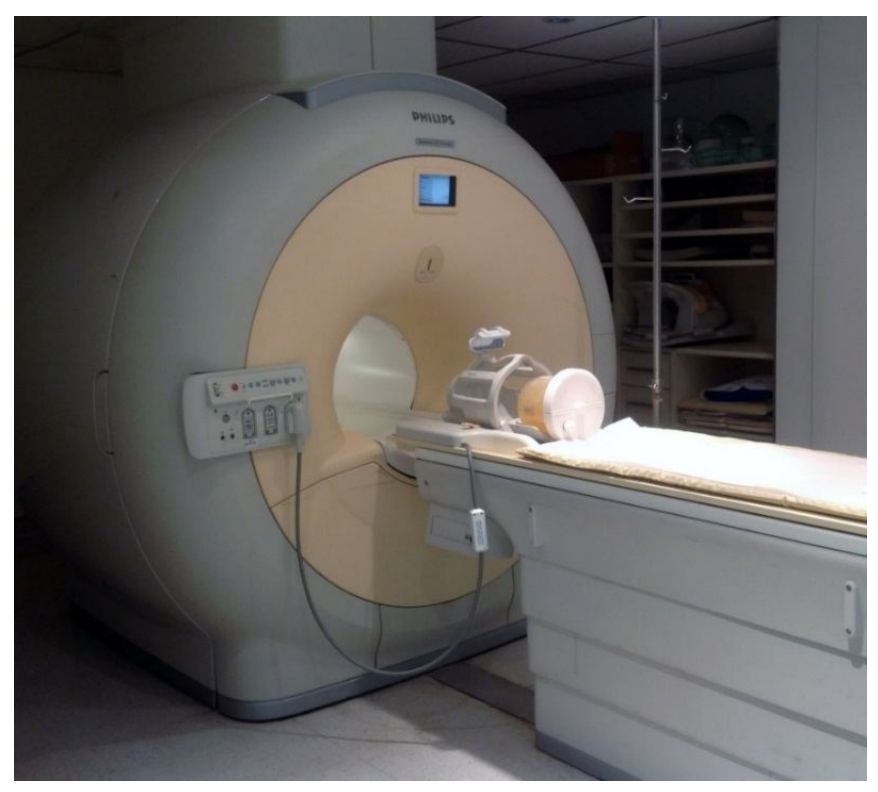

Figura 11: Tomógrafo de ressonância magnética do HC-RP com uma bobina de cabeça e objeto simulador de cabeça com gel para leitura.

Assim, a leitura do dosímetro MAGIC- $f$ foi realizado no tomágrado de RM do HCRP, gerando imagens que foram utilizadas para a caraterização do dosímetro, obtenção dos parâmetros dosimétricos e verificação em condições de irradiação. As leituras dos objetos simuladores foram feitas posicionando-os no centro de um paralelepípedo de PMMA com dimensões de 17 x 14 x $12 \mathrm{~cm}^{3}$, preenchido com uma solução composta por 99,5\% de 
água destilada, $0,2 \%$ de $\mathrm{NaCl}$ e $0,3 \%$, e $\mathrm{MnCl} \cdot 4 \mathrm{H}_{2} \mathrm{O}$. Essa solução foi utilizada nesses estudos para minimizar o efeito da diferença de susceptibilidade magnética do gel e das paredes dos objetos simuladores em relação ao ar, pois nas regiões de interface a leitura é comprometida por artefatos na imagem. Para objetos simuladores maiores, como mostrado na figura 8d, como o utilizado na aplicação de um tratamento de cabeça e pescoço não foi utilizada a solução, pois a variação da susceptibilidade magnética só ocorre nas interfaces e pelas dimensões do objeto simulador, os artefatos da imagem não influenciam nas leituras das regiões de interesse.

Durantes as leituras, os objetos simuladores foram posicionados na região central da bobina de cabeça, pois nessa posição as amostras são submetidas à região mais homogênea do campo magnético, como será mostrado na seção 4.1.1.

As imagens por RM foram analisadas com um programa desenvolvido na plataforma MATLAB $^{\circledR}$, que carrega as imagens DICOM e cria os mapas de R2. Para criar os mapas de R2, o programa carrega todas as imagens DICOM e seus respectivos TE e calcula o logaritmo natural do sinal de cada pixel da imagem, de acordo com a equação 21 , que expressa a proporcionalidade do sinal, $S(t)$, com os valores de R2 para cada $T E$.

$$
\ln (S(t)) \propto R 2 . T E
$$

Com o resultado da aplicação do logaritmo natural são construídas curvas do $\ln (S(t))$ versus TE para cada ponto da imagem, sendo que os coeficientes angulares das curvas são os valores de R2, formando, assim, mapas de R2, que são valores proporcionais a dose absorvida. A figura 12 mostra uma imagem de RM e seu respectivo mapa de R2.

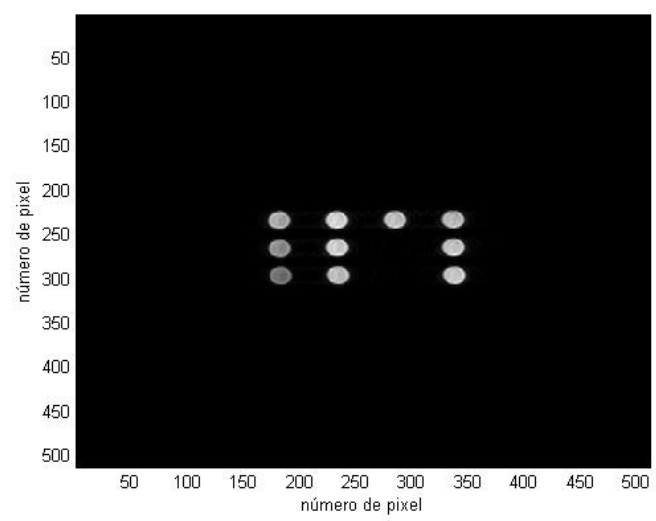

(a)

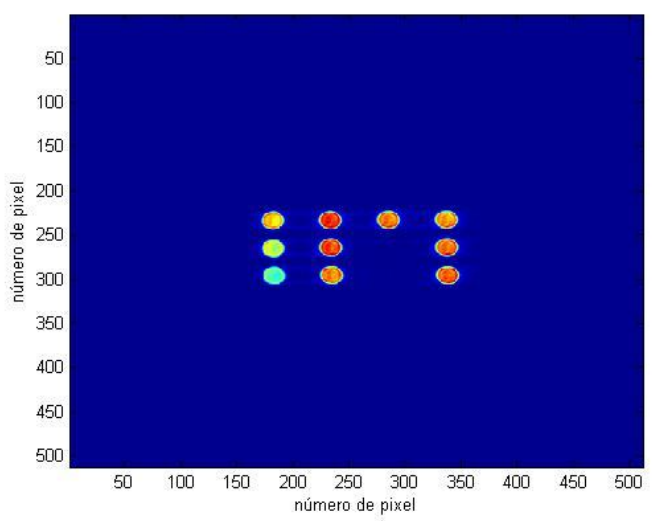

(b)

Figura 12: Imagem de ressonância magnética de objetos simuladores preenchidos com MAGIC- $f$ gel e irradiados com um feixe clínico de elétrons de $6 \mathrm{MeV}$ : (a) mapa dos tempos de relaxação transversal (T2) e (b) mapa de R2. 


\subsubsection{Código de simulação Monte Carlo PENELOPE}

O código de simulação Monte Carlo PENELOPE, versão 2008, (SALVAT et al, 2008) foi utilizado para simular o transporte de feixes de elétrons nas mesmas geometrias, energias e materiais que os utilizados nas condições planejadas e irradiadas. Assim, para as simulações foram utilizados os espectros de energia para os feixes clínicos de elétrons de 6, 9, 12 e $15 \mathrm{MeV}$ baseados no acelerador linear Varian $2100 \mathrm{C}$ (INMS, 2003).

O número de partículas primárias simuladas foi $10^{9}$ partículas, tamanho do pixel de 0,12 $\mathrm{mm}$ para as distribuições de doses nas regiões de interesse. Os resultados da energia depositada em cada voxel foram analisados com um aplicativo desenvolvido em plataforma MatLab ${ }^{\circledR}(\operatorname{ALVA}, 2012)$.

Assim, as distribuições de doses para os feixes de elétrons foram obtidas como resultados da simulação para condições de referência, campos pequenos e para as condições de irradiação e verificação de tratamentos clínicos, possibilitando a obtenção de parâmetros dosimétricos que foram comparados com dados de câmara de ionização e/ou sistema de planejamento e gel.

\subsubsection{Sistema de planejamento}

O TPS utilizado neste estudo foi o Eclipse ${ }^{\circledR}$, versão 8,0 que realizada o cálculo de dose por um algoritmo, PencilBeam. TPS Eclipse ${ }^{\circledR}$ foi utilizado para as determinações dos parâmetros dosimétricos, para a verificação das condições de irradiação como campos pequenos, campos somados e campos adjacentes. Além disso, foi utilizado para realização dos planejamentos de tratamentos clínicos para feixes de elétrons.

\subsection{Testes preliminares}

Anteriormente a utilização do dosímetro MAGIC- $f$ gel em feixes de elétrons, dois estudos foram realizados. Primeiro, foi realizado um estudo da homogeneidade de campo magnético da bobina de cabeça, pois a resposta do dosímetro está diretamente relacionada com esse fator. Além disso, por meio de simulação Monte Carlo determinou-se a equivalência com a água do material MAGIG- $f$ gel em feixes de elétrons. 


\subsubsection{Homogeneidade da bobina de ressonância magnética}

Para avaliação da homogeneidade de campos da bobina de cabeça do tomógrafo por RM foi utilizado um objeto simulador que cobrisse toda região útil da bobina. O objeto simulador utilizado foi um cilindro de PMMA, de $40 \mathrm{~cm}$ de diâmetro e altura de $25 \mathrm{~cm}$ preenchido com uma solução de $0,144 \mathrm{~g}$ de $\mathrm{MnCl}_{2}$ e $6 \mathrm{~g} \mathrm{NaCl}$ diluídos em 8 litros de água. A figura 13 mostra um esquema do cilindro posicionado na bobina de cabeça utilizado para este estudo.

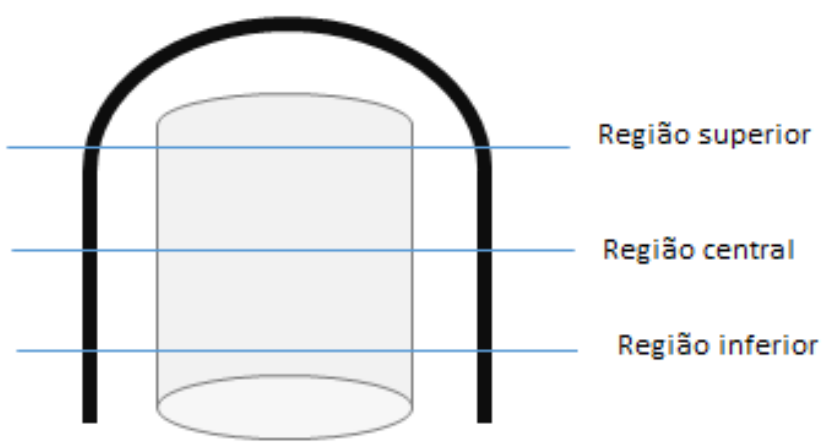

Figura 13: Esquema do posicionamento do objeto simulador usado para o estudo da homogeneidade da bobina de cabeça do tomógrafo de RM.

Foram analisados três regiões do objeto simulador, através de cortes axiais na região central, superior e inferior da bobina. A análise foi realizada através de histogramas do número de pixel pela intensidade do sinal de cada uma das regiões avaliadas.

\subsubsection{Simulação do material do dosímetro MAGIC- $f$ gel}

O código de simulação Monte Carlo PENELOPE foi utilizado para analisar a equivalência do material do dosímetro MAGIC- $f$ com a água para os feixes utilizados nesse estudo.

Para realização desse estudo foram construídos dois arquivos de materiais "agua.mat" e "magicf.mat". Para o arquivo da água o código já possui em seu banco de dados os valores das grandezas de interação para esse material.Para o gel foi necessário introduzir a composição química do mesmo, para dessa forma o código gerar as distribuições de deposição de energia e assim determinar seus parâmetros dosimétricos. Os resultados obtidos com as simulações dos diferentes materiais, "agua.mat" e "magicf.mat", foram avaliados com a determinação de curvas de PDP. 
Assim, as condições de simulação utilizadas foram um objeto simulador cúbico, nas condições de referência, campo $10 \times 10 \mathrm{~cm}^{2}$, distância fonte superfície de $100 \mathrm{~cm}$, espectros de energia de 6, 9, 12 e $15 \mathrm{MeV}$.

\subsection{Caracterização do dosímetro MAGIC- $f$}

Nesta seção são apresentados os materiais e métodos utilizados na caracterização do dosímetro MAGIC- $f$ para feixes clínicos de elétrons. Foram analisadas a reprodutibilidade e estabilidade temporal da resposta do dosímetro, além de estudos sobre a dependência da resposta do dosímetro em função da dose absorvida, taxa de dose e energia dos feixes de elétrons.

As irradiações foram realizadas em um acelerador linear da Varian $2100 \mathrm{C}$, com exceção do estudo de estabilidade temporal da resposta do dosímetro, que foi realizada em um feixe de Co-60.

\subsubsection{Reprodutibilidade}

A reprodutibilidade do dosímetro foi avaliada utilizando amostras do gel acondicionadas em tubos vacutainer ${ }^{\circledR}$. As condições de preparo, irradiação e leitura foram idênticas para as amostras. O feixe de elétrons utilizado para irradiação foi de $6 \mathrm{MeV}$ em um intervalo de 1 a $10 \mathrm{~Gy}$, campo 10 x $10 \mathrm{~cm}^{2}$ e DFS de $100 \mathrm{~cm}$. Para a irradiação, os tubos foram posicionados na profundidade de máxima dose, de $1,5 \mathrm{~cm}$, em um objeto simulador cúbico de PMMA de $50 \times 50 \times 50 \mathrm{~cm}^{3}$, preenchido com água, como mostra a figura 14.

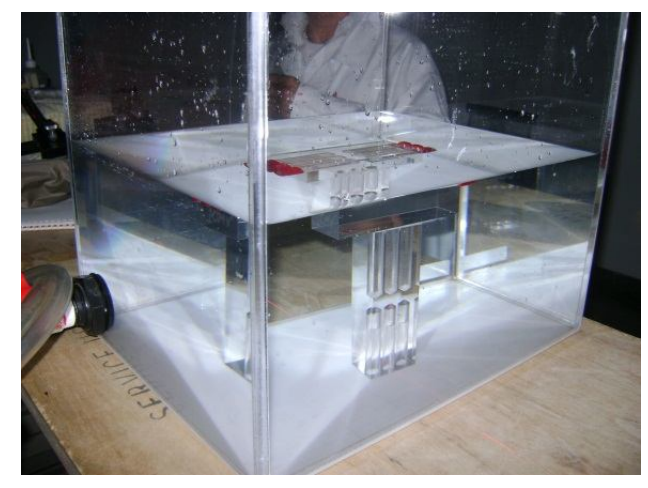

(a)

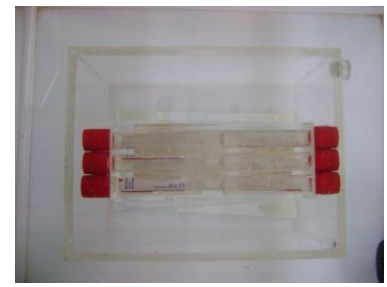

(b)

Figura 14: Geometria de irradiação para MAGIC- $f$ gel utilizada para o estudo da reprodutibilidade do dosímetro em feixes de elétrons. (a) Posicionamento do material de gel para irradiação, (b) vista superior da amostra de gel durante a irradiação. 
A análise foi realizada por meio da curva do sinal R2 em função da dose para cada amostra.

Essa mesma geometria foi utilizada para os outros estudos que utilizaram tubos vacutainer $^{\circledR}$ como objeto simulador, isto é, para o estudo da estabilidade temporal da resposta do dosímetro, dependência com a dose absorvida, taxa de dose e energia do feixe.

\subsubsection{Estabilidade temporal da resposta do MAGIC- $f$ gel}

Para o estudo da variação do sinal de R2 em função do tempo para a leitura após a irradiação, uma amostra de gel foi preparada, acondicionada em tubos vacutainer ${ }^{\circledR} \mathrm{e}$ irradiada variando-se a dose de 1 a 10 Gy para a energia do cobalto-60. A irradiação foi feita seguindo as condições padrão de irradiação, campo de 10 x $10 \mathrm{~cm}^{2}$ e DFS de $80 \mathrm{~cm}$. As leituras das amostras foram feitas de 0 a 96 horas após a irradiação da amostra.

A análise foi realizada através da curva do sinal R2 em função do tempo para a leitura para cada dose de irradiação utilizada.

\subsubsection{Dependência da resposta do MAGIC- $f$ gel com a dose absorvida e energia para feixes clínicos de elétrons.}

A dependência da resposta do MAGIC- $f$ gel com a dose absorvida foi avaliada irradiando-se um mesmo lote de gel com doses variando de 0,5 a 20 Gy, com uma "taxa de dose de $400 \mathrm{UM} / \mathrm{min}$ ". A amostra de gel foi irradiada em feixes de elétrons com as energias de 6, 9, 12 e $15 \mathrm{MeV}$. A irradiação foi feita seguindo as condições padrão de irradiação, campo de $10 \times 10 \mathrm{~cm}^{2}$ e DFS de $100 \mathrm{~cm}$ para todas as energias, com a geometria de irradiação apresentada na figura 14.

A análise foi realizada através da curva do sinal R2 em função da dose para cada energia de feixe utilizado.

\subsubsection{Dependência da resposta do MAGIC- $f$ gel com taxa de dose para feixes clínicos de elétrons.}

A dependência da resposta do MAGIC- $f$ gel com a taxa de dose foi avaliada em um intervalo de "80 a 400 UM/min", depositando-se uma dose de 5 Gy. Uma amostra de gel foi preparada, acondicionada em tubos vacutainer ${ }^{\circledR} \mathrm{e}$ irradiada em feixes de elétrons com as energias de 6,9,12 e $15 \mathrm{MeV}$. A irradiação foi feita seguindo as condições padrão de 
irradiação, campo de $10 \times 10 \mathrm{~cm}^{2}$ e DFS de $100 \mathrm{~cm}$ para todas as energias, com a geometria de irradiação apresentada na figura 14.

A análise foi realizada através da curva do sinal R2 em função da taxa de dose para cada energia de feixe utilizado.

\subsection{Avalição de parâmetros dosimétricos com MAGIC- $f$ gel}

Uma vez caracterizada a resposta do dosímetro para os feixes clínicos de elétrons estudados foram feitas medidas experimentais com MAGIC- $f$ para a determinação dos parâmetros dosimétricos, porcentagem de dose em profundidade e perfil de campo. Os mesmos parâmetros forma simulados com o código PENELOPE e o TPS Eclipse ${ }^{\circledR}$

Os métodos dosimétricos foram validados através da determinação dos parâmetros dosimétricos em condições de referência, campo de 10 x $10 \mathrm{~cm}^{2}$ e DFS de $100 \mathrm{~cm}$.

As irradiações foram realizadas no HCB utilizando um acelerador linear Varian $2100 \mathrm{C}$ em feixes de elétrons com energias de 6, 9, 12 e $15 \mathrm{MeV}$. Com o código PENELOPE e TPS Eclipse ${ }^{\circledR}$ as simulações foram realizadas nas mesmas condições do procedimento de irradiação.

Os parâmetros dosimétricos porcentagem de dose em profundidade e perfil de campo determinado utilizando o dosímetro MAGIC- $f$ gel, simulação Monte Carlo PENELOPE e TPS Eclipse ${ }^{\circledR}$, os resultados foram analisados com um determinados com o auxílio de desenvolvido na plataforma MATLAB ${ }^{\circledR}$.

\subsubsection{Porcentagem de dose em profundidade}

Para a determinação das curvas de PDP para os feixes de elétrons de 6, 9, 12 e $15 \mathrm{MeV}$, primeiramente, com o TPS Eclipse ${ }^{\circledR}$ foram obtidos dados da distribuição de dose no eixo central do plano de irradiação, para todos os feixes utilizados, em condição de referência, campo de 10 x $10 \mathrm{~cm}^{2}$ e DFS de $100 \mathrm{~cm}$. Nas mesmas configurações planejadas foram realizadas simulações com o código PENELOPE. Para a irradiação do dosímetro MAGIC- $f$ uma amostra de gel foi preparada e acondicionada em um objeto simulador de vidro de $50 \mathrm{ml}$, ver seção 3.1. O objeto simulador foi colocado dentro de um cubo de PMMA de $50 \times 50 \times 50 \mathrm{~cm}^{3}$, preenchido com água e irradiado com 5 Gy na profundidade de máxima dose nas mesmas condições planejadas e simuladas. A geometria de irradiação é apresentada na figura 15. 


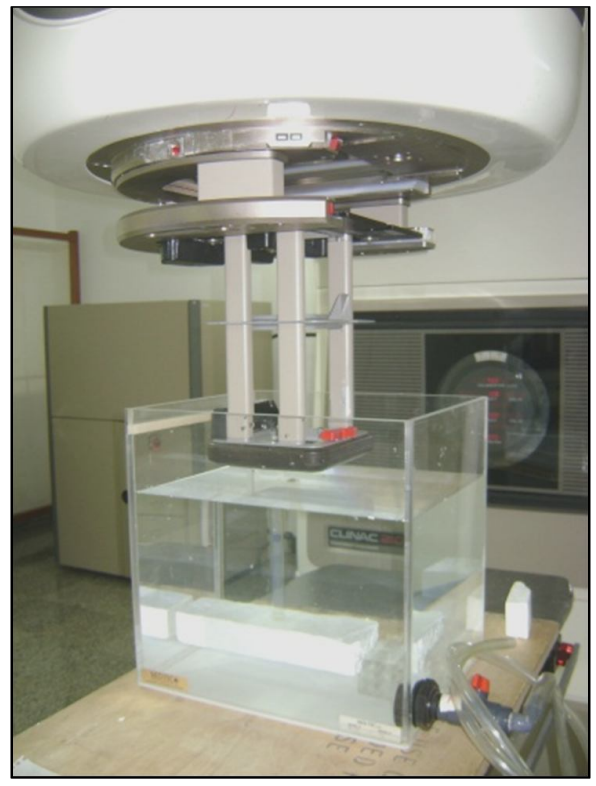

Figura 15: Geometria de irradiação utilizada para a determinação das curvas PDP para feixes de elétrons de 6, 9, 12 e $15 \mathrm{MeV}$ em um campo de 10 x $10 \mathrm{~cm}^{2}$ e DFS $100 \mathrm{~cm}$.

Depois de realizados os procedimentos de leitura do dosímetro MAGIC-f, obtém-se as distribuições de dose do eixo central. Os dados encontrados para os métodos dosimétricos utilizados (MAGIC- $f$, PENELOPE e TPS Eclipse ${ }^{\circledR}$ ) foram comparados com dados de câmara de ionização fornecidos pelo serviço de Radioterapia do HCB por meio das curvas de PDP para cada energia.

\subsubsection{Perfil de campo}

Para a determinação das curvas de perfil de campo para os feixes de elétrons de 6, 9, 12 e $15 \mathrm{MeV}$, primeiramente, utilizando TPS Eclipse ${ }^{\circledR}$ foram obtidos dados da distribuição de dose no eixo central do plano de irradiação, para todos os feixes utilizados, em condição de referência, campo de 10 x $10 \mathrm{~cm}^{2}$ e DFS de $100 \mathrm{~cm}$. Nas mesmas configurações planejadas foram realizadas simulações com o código PENELOPE.

Os procedimentos de irradiação, seguiram a mesma geometria planejada e simulada. Para a irradiação, uma amostra de gel foi preparada e acondicionada em objetos simuladores retangulares, seção 3.1., Para a irradiação, o objeto simulador foi colocado dentro de um cubo de PMMA de 50 x 50 x $50 \mathrm{~cm}^{3}$, preenchido com água e irradiado com 5 Gy na profundidade de máxima dose. A geometria de irradiação é apresentada na figura 14. 
Depois de realizado os procedimentos de leitura do dosímetro MAGIC- $f$ as distribuições de dose do eixo central foram obtidas e as curvas de perfil de campo foram determinadas para a profundidade de máxima dose. As curvas determinadas para os métodos dosimétricos utilizados (MAGIC- $f$, PENELOPE e TPS Eclipse ${ }^{\circledR}$ ) foram comparados as curvas de perfil de campo obtidas com dados de câmara de ionização fornecidos pelo serviço de Radioterapia do HCB.

\subsection{Avaliação de condições de irradiação com MAGIC- $f$ gel}

Estudos foram realizados para determinar distribuições de doses para diferentes condições de irradiação com feixes de elétrons. As irradiações foram feitas com diferentes configurações de campos, utilizando-se campos pequenos, campos somados e campos adjacentes.

Inicialmente, foram adquiridos dados de dose do plano central paralelo ao feixe de irradiação com o TPS Eclipse ${ }^{\circledR}$ para todos as condições estudadas. Nas mesmas configurações planejadas foram realizadas simulações com o código PENELOPE e procedimentos experimentais com MAGIC-f.

\subsubsection{Campos pequenos}

Para irradiar campos pequenos em aceleradores lineares com feixes de elétrons, deve-se confeccionar colimadores adicionais para limitar os campos pequenos, pois para feixes de elétrons os tamanhos de campos são determinados por colimadores padrão que possuem dimensões de 10 x $10 \mathrm{~cm}^{2}, 15$ x $15 \mathrm{~cm}^{2}, 20 \times 20 \mathrm{~cm}^{2}$ e $25 \times 25 \mathrm{~cm}^{2}$. Para o estudo de campos pequenos, avaliou-se a equivalência do uso de dois materiais: cerrobend e acrílico. Uma vez avaliado o tipo de material para a colimação dos campos pequenos, o cerrobend foi utilizado para determinar distribuições de dose para campo de $1 \times 1 \mathrm{~cm}^{2}$ e 5 x $5 \mathrm{~cm}^{2}$ para as energias de 6,9 e $12 \mathrm{MeV}$.

3.7.1.1. Determinação do material para confecção do colimador adicional utilizando simulação Monte Carlo

As diferenças nas distribuições de dose para irradiação feitas com colimadores adicionais de diferentes matérias foram avaliadas através de simulação Monte Carlo com o código PENELOPE. 
Neste estudo, foram utilizados espectros de feixe de elétrons de 6 e $12 \mathrm{MeV}$, um objeto simulador de $20 \times 20 \times 20 \mathrm{~cm}^{3}$ preenchido com água. A DFS utilizada foi de $100 \mathrm{~cm}$, com um campo de radiação de $10 \times 10 \mathrm{~cm}^{2}$ sendo colimado em um campo de $1 \times 1 \mathrm{~cm}^{2}$ por aplicadores adicionais de cerrobend ou acrílico.

As curvas de PDP e os perfis de dose, na profundidade de tratamento (isodose de $85 \%$ ), foram determinadas através do código, para ambos os materiais e energias, com tamanho de pixel de $1 \mathrm{~mm}$.

As espessuras dos colimadores adicionais de cerrobend e acrílico foram determinadas considerando a mesma atenuação nos diferentes materiais e nas diferentes energias. Na tabela 2 estão apresentadas as espessuras utilizadas na simulação.

Tabela 2: Espessuras dos colimadores adicionais.

\begin{tabular}{c|c|c} 
& \multicolumn{2}{|c}{ Espessura do colimador adicional (cm) } \\
\hline Energia $(\mathrm{MeV})$ & cerrobend & acrílico \\
\hline 6 & 1,8 & 6,0 \\
\hline 12 & 3,3 & 10,9
\end{tabular}

\subsubsection{Distribuição de dose com campos pequenos}

Os métodos dosimétricos utilizados nesse trabalho foram utilizadas para determinação de distribuições de dose em irradiações com campo pequeno com feixes de elétrons. Para a realização do planejamento, foi realizada uma tomografia computacional dos objetos simuladores retangulares, 5 × 5 x $5 \mathrm{~cm}^{2}$ e $10 \times 5 \times 5 \mathrm{~cm}^{2}$, preenchidos com gel. Com o TPS Eclipse ${ }^{\circledR}$ foram planejados campos de irradiação, para feixes de 6, 9 e 12 $\mathrm{MeV}$ com DFS de $100 \mathrm{~cm}$. Esse planejamento foi reproduzido utilizando simulação com o código PENELOPE, nas mesmas condições e geometria de irradiação, com tamanho de pixel de $1 \mathrm{~mm}$.

Nas mesmas condições planejadas e simuladas foram feitas medidas experimentais com o dosímetro MAGIC- $f$ gel. Através dos métodos de leituras por ressonância magnética foram obtidas as distribuições de dose do plano central de irradiação. Como descrito anteriormente, para o procedimento experimental, colimadores adicionais de cerrobend foram confeccionados e acoplados aos colimadores padrão de elétrons para obtenção dos campos pequenos, como mostrado na figura 16. 


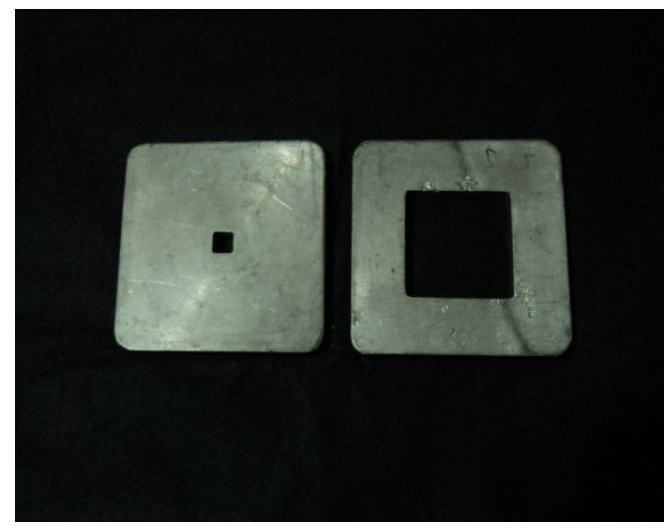

(a)

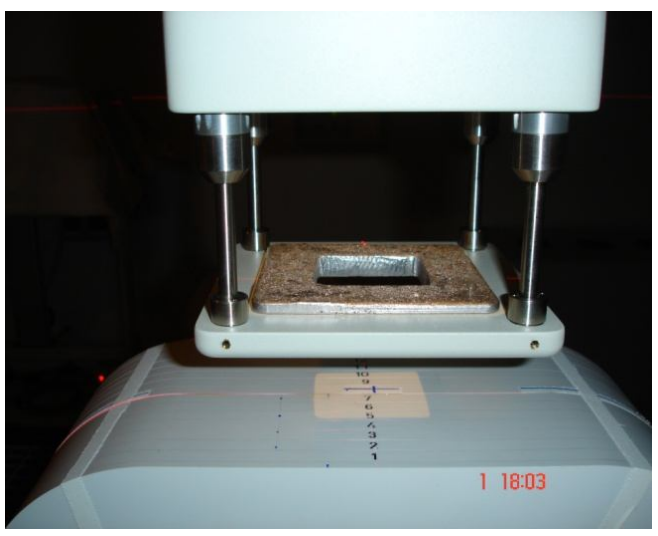

(b)

Figura 16: Acessório utilizado para irradiação de campos pequenos para feixes de elétrons: (a) colimador adicional, (b) colimador adicional acoplado ao colimador padrão para elétrons.

As distribuições de dose obtidas com os três métodos dosimétricos foram comparados por meio da análise das curvas de PDP para os diferentes tamanhos de campo e feixes estudados.

\subsubsection{Campos somados}

Para analisar a influência na dose depositada por diferentes geometrias de irradiação, duas configurações foram estudadas: primeiramente utilizando simulação Monte Carlo, comparou-se um campo único e uma irradiação na qual o campo total é a soma de vários campos pequenos, para os feixes de 6,9 e $12 \mathrm{MeV}$. Para o campo somado foram considerados 5 campos de irradiação adjacentes de $5 \times 1 \mathrm{~cm}^{2}$ e um campo único de $5 \times 5 \mathrm{~cm}^{2}$, ambos com DFS de $100 \mathrm{~cm}$, como mostrado na figura 17 . 


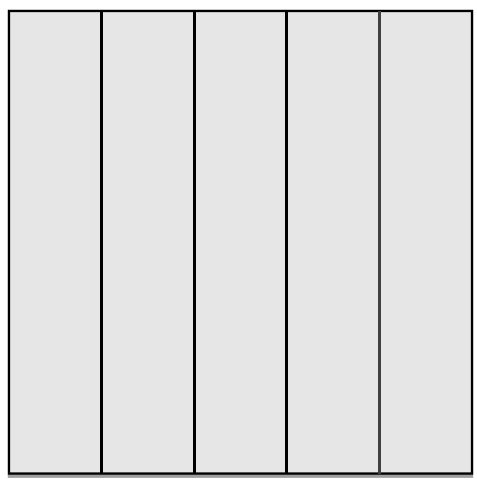

(a)

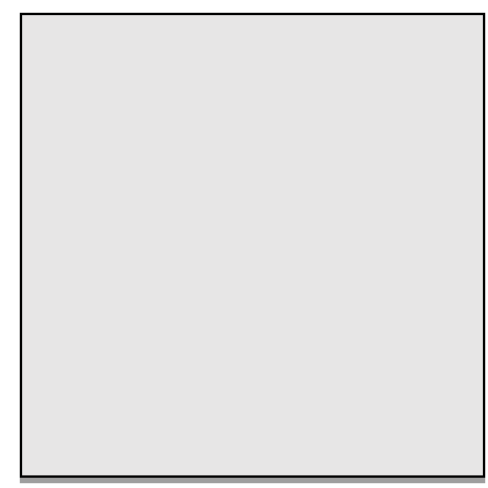

(b)

Figura 17: Esquema da configuração dos campos de irradiação para o estudo dos campos adjacentes somados: (a) 5 campos de $5 \times 1 \mathrm{~cm}^{2}$, (b) campo de $5 \times 5 \mathrm{~cm}^{2}$.

As distribuições de dose para os campos somados e único obtidas com código PENELOPE foram avaliadas através das curvas de perfil de dose em diferentes profundidades: na entrada do campo, na profundidade de máxima dose e na profundidade de tratamento (isodose de $85 \%$ ).

Nas mesmas condições simuladas, o planejamento utilizando a tomografia do objeto simulador retangular, $10 \times 5 \times 5 \mathrm{~cm}^{2}$, foi realizada com o TPS Eclipse ${ }^{\circledR}$ para o feixe de $6 \mathrm{MeV}$ e o procedimento experimental com o dosímetro MAGIC- $f$ foi realizado utilizando o colimador adicional mostrado na figura 18.

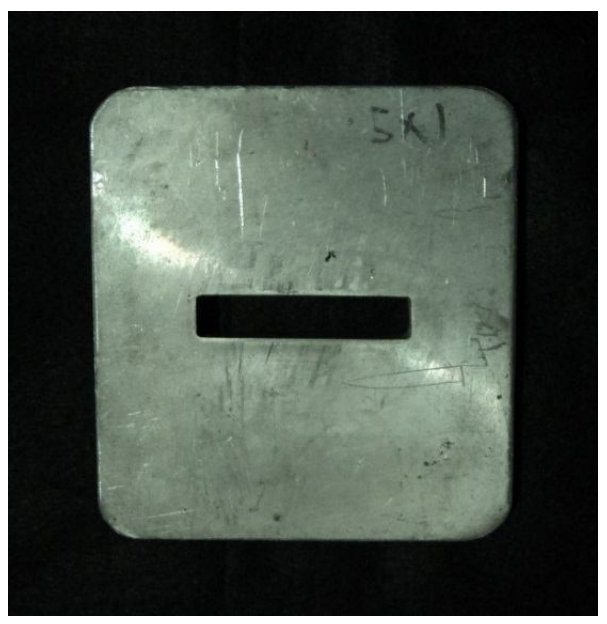

Figura 18: Colimador adicional utilizado para colimação de um campo de 5 x $1 \mathrm{~cm}^{2}$ para feixe de elétrons de $6 \mathrm{MeV}$. 
Nas mesmas condições planejadas e simuladas foram feitas medidas experimentais com o dosímetro MAGIC- $f$ gel. Através dos métodos de leituras por ressonância magnética foram obtidas as distribuições de dose do resultantes.

As distribuições de dose obtidas com os três métodos dosimétricos para o feixe de $6 \mathrm{MeV}$ foram comparadas por meio da análise do perfil de dose em diferentes profundidades: na entrada do campo, na profundidade de máxima dose e na profundidade de tratamento (isodose de $85 \%$ ).

\subsubsection{Campos adjacentes}

Uma composição com dois campos adjacentes foi utilizada para avaliar a possibilidade da utilização dos métodos dosimétricos desse trabalho, PENELOPE e MAGIC- $f$, em determinar a distribuição de dose em casos de tratamentos que necessitem de espaços entre os campos de irradiação.

Dois campos adjacentes de 5 x $5 \mathrm{~cm}^{2}$ com espaçamento de $1,2 \mathrm{~cm}$, para o feixe de elétrons de $6 \mathrm{MeV}$ com DFS de $100 \mathrm{~cm}$, foram planejados com TPS Eclipse ${ }^{\circledR}$ utilizando a tomografia do objeto simulador retangular $15 \times 5 \times 5 \mathrm{~cm}^{2}$. O planejamento foi reproduzido utilizando simulação com o código PENELOPE e dosímetro gel, nas mesmas condições e geometria de irradiação, com tamanho de pixel de $1 \mathrm{~mm}$.

As distribuições de dose obtidas com TPS Eclipse ${ }^{\circledR}$, PENELOPE e MAGIC- $f$ foram comparados e analisadas através dos perfis de campo.

\subsection{Verificação de tratamentos}

Estudos foram realizados para determinar distribuições de doses para diferentes condições de irradiação clínicas com feixes de elétrons. Foram consideradas condições de irradiação com diferentes configurações de campos de irradiação mostrados anteriormente. Os casos clínicos avaliados foram um caso de linfoma conjuntival, um caso de uma doença subclínica de linfonodos, e uma combinação de feixes de elétrons e fótons utilizado para tratamentos de cabeça e pescoço.

Inicialmente, foram adquiridos dados de dose do plano central ao longo da direção do feixe de irradiação com o TPS Eclipse ${ }^{\circledR}$ para todos as condições estudadas. Nas mesmas configurações planejadas foram realizadas simulações com o código PENELOPE e o procedimento de irradiação com MAGIC- $f$. 


\subsubsection{Linfoma conjuntival}

Nessa etapa do trabalho, uma geometria de tratamento para linfoma conjuctival da literatura (BRUALLA et al, 2009) foi reproduzida experimentalmente sendo irradiada com um feixe de $6 \mathrm{MeV}$. Nessa geometria utiliza-se um aplicador adicional de cerrobend na saída do campo de irradiação sobre o aplicador padrão de feixes de elétrons. O aplicador adicional é constituído de um bloco de cerrobend de $15 \times 15 \mathrm{~cm}^{2}$ com espessura de $1,8 \mathrm{~cm}$ e possui um orifício central de $3,5 \mathrm{~cm}$ de diâmetro com uma haste, também de cerrobend, com $1 \mathrm{~cm}$ de diâmetro e 1,8 cm de altura, posicionada na região central do orifício, sendo o bloco mais haste presos a uma placa de PMMA de $1 \mathrm{~mm}$ de espessura, como mostrado na figura $19 \mathrm{a}$.

Uma amostra de gel foi preparada e acondicionada em um objeto simulador retangular de acrílico de 20 x $5 \times 5 \mathrm{~cm}^{3}$. A irradiação foi feita com as mesmas condições em um acelerador linear Varian $2100 \mathrm{C}$ do HCB em um feixe de elétrons de $6 \mathrm{MeV}$, distância fonte-superfície $100 \mathrm{~cm}$, condições estas descrita por Brualla e colaboradores (BRUALLA et al, 2009), como mostrado na figura 19b.

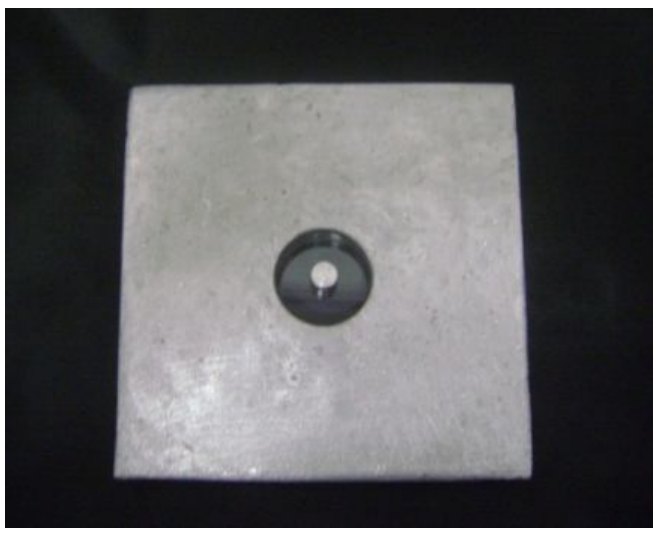

(a)

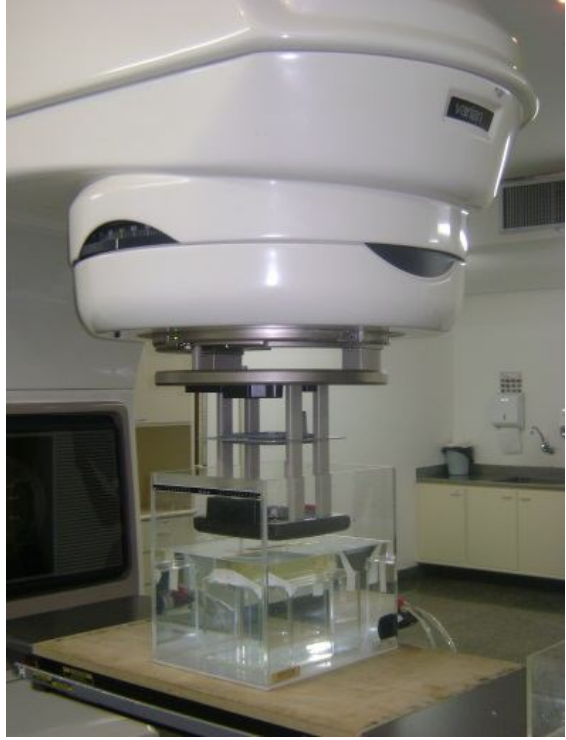

(b)

Figura 19: Irradiação do dosímetro MAGIC- $f$ para verificação da distribuição de dose de uma geometria de tratamento de linfoma conjunctival: (a) aplicador adicional de cerrobend utilizado no tratamento, (b) geometria de irradiação para o tratamento.

Os resultados encontrados com MAGIC- $f$ foram comparados com dados de PENELOPE da literatura, desenvolvidos por Brualla e colaboradores (BRUALLA et al, 2009) através da determinação do perfil de campo. 


\subsubsection{Doença subclínica de linfonodo}

Foi avaliado um caso clínico de doença subclínica de linfonodos localizado. O planejamento utilizou feixe de elétrons de $6 \mathrm{MeV}$, campo de $6 \times 6 \mathrm{~cm}^{2}$, distância fontesuperfície de $100 \mathrm{~cm}$, com "taxa de dose de $400 \mathrm{cGy} / \mathrm{min}$ " e dose total de $10 \mathrm{~Gy}$. A figura 20 mostra a tela do TPS Eclipse ${ }^{\circledR}$ para o planejamento realizado.

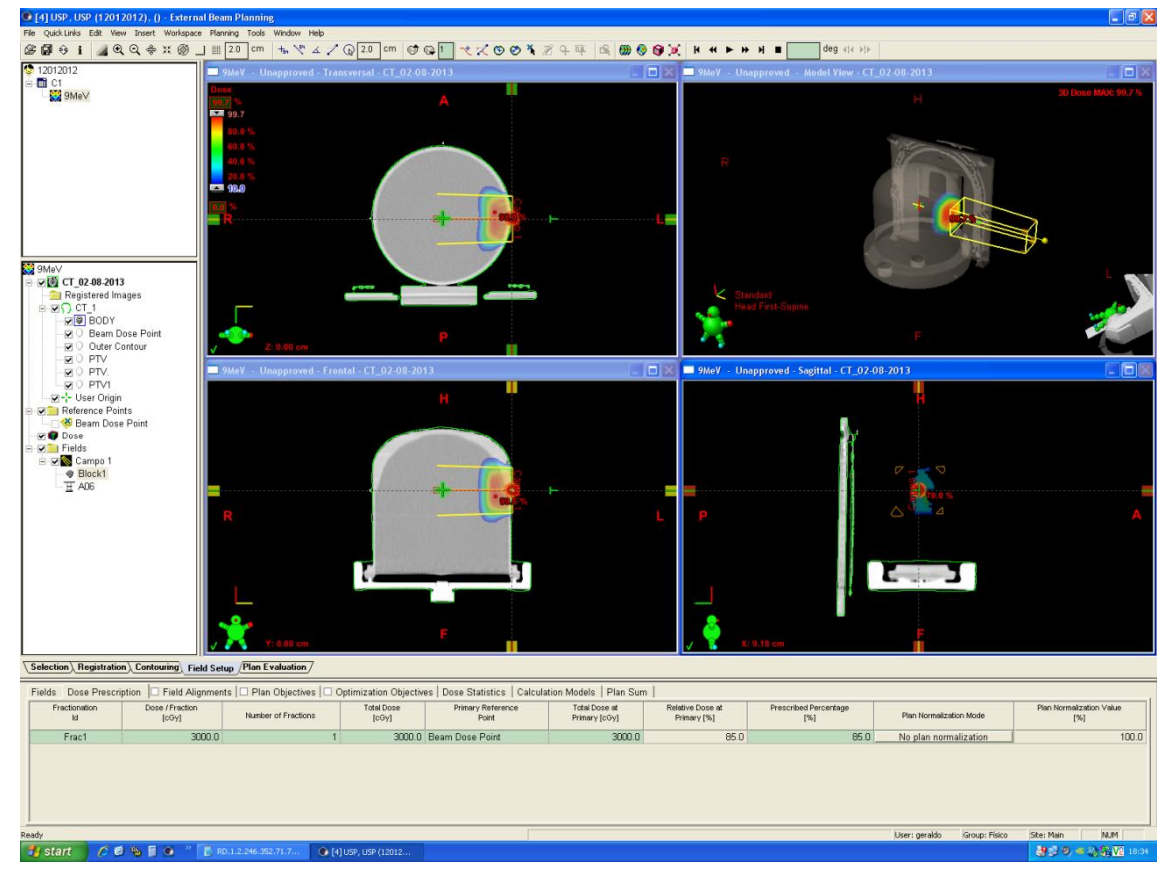

Figura 20: Tela do sistema de planejamento Eclipse ${ }^{\circledR}$ para o caso de doença subclínica de linfonodos localizados tratado com feixe de elétrons de $6 \mathrm{MeV}$.

Para a irradiação dessa simulação de caso clínico, as imagens de CT do objeto simulador foram adquiridas em um tomógrafo LightSpeed VCT, multislice de 64 canais, da marca GE, também, do serviço de radioterapia do HCB como mostrado na figura 21. As imagens do CT foram utilizadas no planejamento dos casos estudados. 


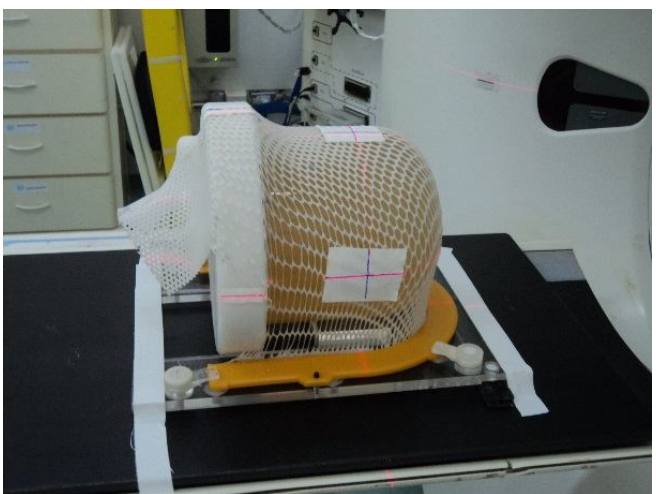

(a)

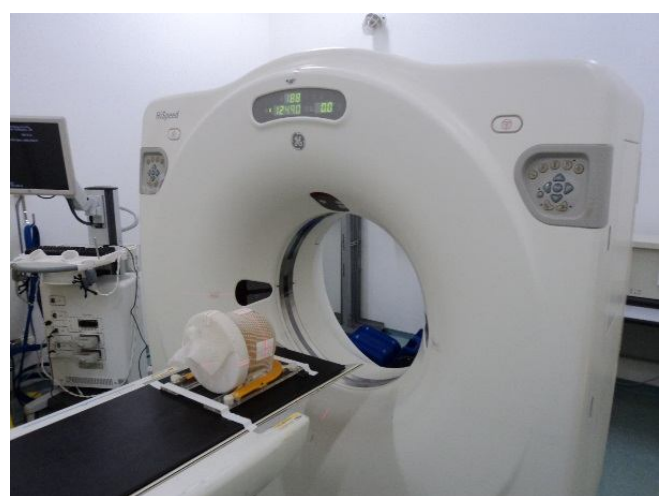

(b)

Figura 21: Posicionamento do objeto simulador para obtenção das imagens de CT que foram utilizadas para o planejamento: (a) objeto simulador de cabeça com a máscara termoplástica e suporte de cabeça e pescoço, (b) objeto simulador posicionado no CT.

Nas mesmas condições planejadas, o dosímetro polimérico MAGIC- $f$ gel foi irradiado para determinação das distribuição de dose desse tratamento clínico utilizando feixe de elétrons, como mostrado na figura 22.

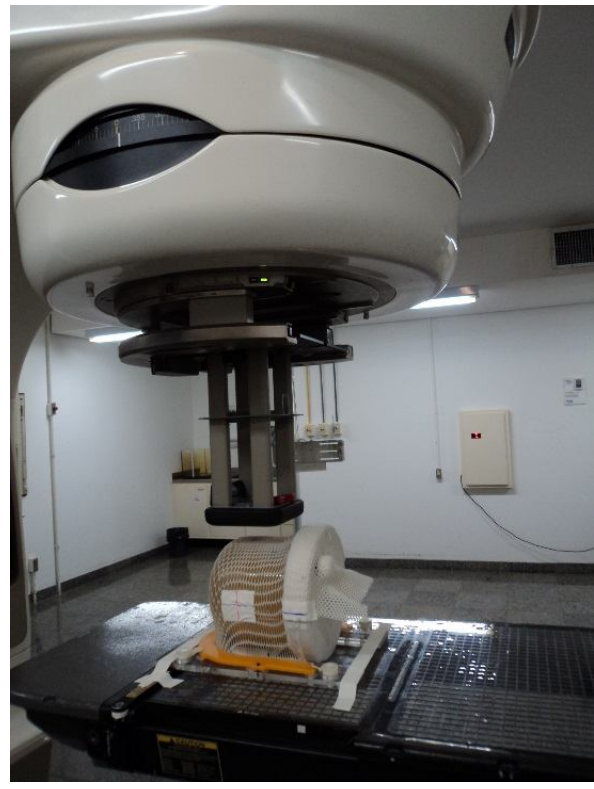

Figura 22: Geometria de irradiação do dosímetro MAGIC- $f$ gel para determinação das distribuições de dose de um caso clínico utilizando feixe de elétrons.

Nas mesmas condições planejadas e irradiadas, o tratamento foi simulado com o código PENELOPE. 
As distribuições de dose obtidas para os três métodos dosimétricos foram obtidas por um programa desenvolvido na plataforma MatLab ${ }^{\circledR}$, que carrega as informações, cria as imagens das distribuições de dose individuais e as compara utilizando o método do índice gama. No programa, os critérios do índice gama foram considerados 3\% de DD e $3 \mathrm{~mm}$ de DTA.

\subsubsection{Cabeça e pescoço}

Nesse caso foi simulado um tratamento clínico de um caso de cabeça e pescoço irradiado com feixe de fótons de $6 \mathrm{MV}$ e elétrons de $9 \mathrm{MeV}$, em um objeto simulador de cabeça. A distância fonte-superfície utilizada foi de $100 \mathrm{~cm}$ "taxa de dose de 400 cGy/min" e 10 Gy. Os campos de irradiação utilizados para feixes de elétrons foram dois campos paralelos opostos de $6 \times 6 \mathrm{~cm}^{2}$, com angulações de $90^{\circ}$ e $270^{\circ}$, no qual o centro do campo de irradiação foi posicionado a uma distância de 12,27 cm da base do objeto simulador e dois campos de fótons de $11 \times 7 \mathrm{~cm}^{2}$, também, paralelos opostos, com angulações de $90^{\circ}$ e $270^{\circ}$, no qual o centro do campo de irradiação foi posicionado a uma distância de 12,27 cm da base do objeto simulador e descolocados $6,72 \mathrm{~cm}$ do centro do campo de elétrons. A figura 23 mostra a tela do TPS Eclipse ${ }^{\circledR}$ para o planejamento realizado.

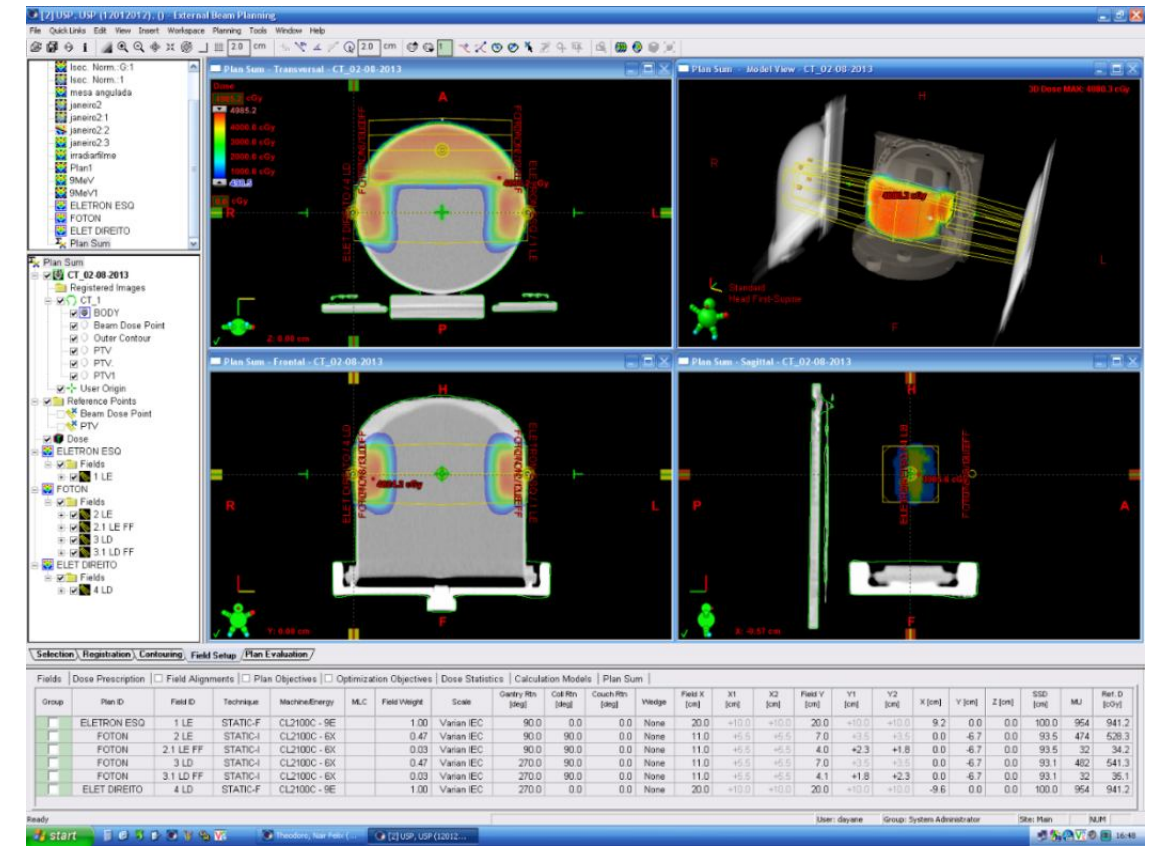

Figura 23: Tela do sistema de planejamento Eclipse ${ }^{\circledR}$ para um caso de cabeça e pescoço irradiado com feixe clínico de elétrons de $9 \mathrm{MeV}$ e de fótons de $6 \mathrm{MV}$. 
Nas mesmas condições planejadas, o dosímetro MAGIC- $f$ gel foi irradiado e a simulado com o código PENELOPE. As distribuições de dose obtidas para os três métodos dosimétricos foram comparadas utilizando o método do índice gama, com os critérios de $3 \%$ de DD e 3 mm de DTA. 


\section{RESULTADOS E DISCUSSÕES}

Nesse capítulo são apresentados e discutidos os resultados obtidos para a caracterização da resposta do dosímetro gel polimérico MAGIC- $f$, assim como os resultados de determinação dos parâmetros dosimétricos com os métodos dosimétricos utilizados nesse trabalho. São apresentados, também, os resultados de distribuição de dose para avalição de condições de irradiações e de tratamentos clínicos com feixes de elétrons.

\subsection{Testes preliminares}

Nesta seção são apresentados os resultados obtidos dos testes preliminares à utilização do dosimétrico polimérico MAGIC- $f$ gel, que estão relacionados com a homogeneidade do campo magnético da bobina de cabeça, do tomógrafo de ressonância magnética, utilizada para leitura do mesmo. Assim, como também a avaliação da equivalência em água do dosímetro.

\subsubsection{Homogeneidade da bobina de ressonância magnética}

As avaliações da homogeneidade de campo magnético da bobina de cabeça do tomógrafo de ressonância magnética de $3 \mathrm{~T}$ do HC-RP foram realizados em cortes axiais de um objeto simulador cilindro de PMMA, contendo uma solução composta por 99,5\% de água destilada, $0,2 \%$ de $\mathrm{NaCl}$ e $0,3 \%$ de $\mathrm{MnCl} .4 \mathrm{H}_{2} \mathrm{O}$, com descrito na seção 3.4.1. A figura 24 mostra as imagens das intensidades do sinal de tempo de relaxação (T2) nas regiões avaliadas do objeto simulador: superior, central e inferior. 


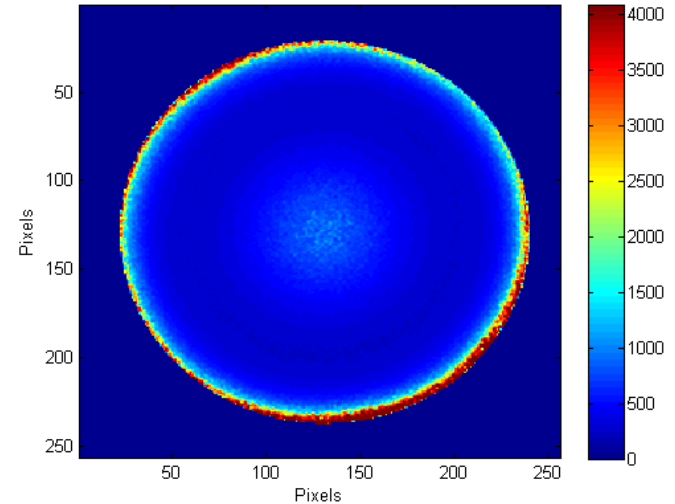

(a)

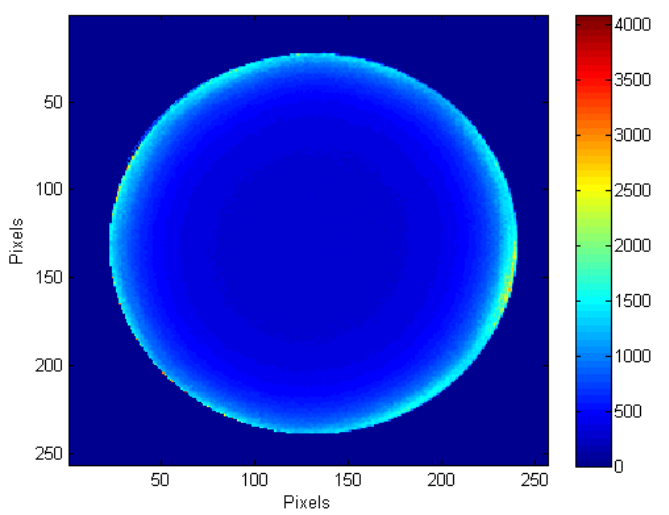

(b)

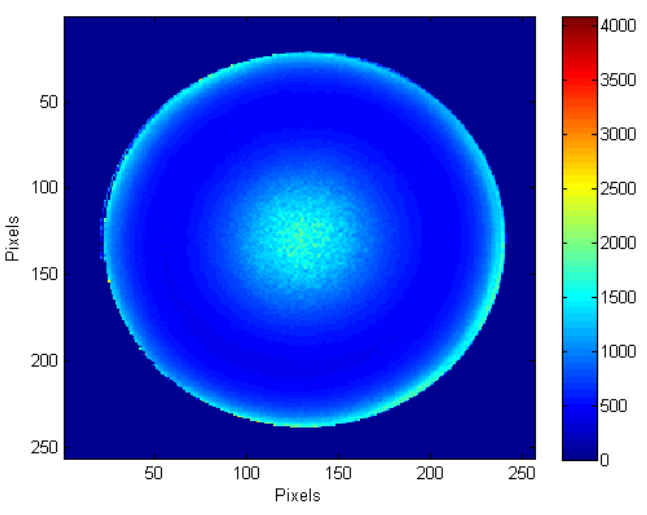

(c)

Figura 24: Mapas das intensidades do sinal de tempo de relaxação (T2) nos cortes axiais para o estudo da homogeneidade da bobina de cabeça de um tomógrafo de ressonância magnética de 3,0 T em diferentes posições do objeto simulador: (a) corte axial superior, (b) corte axial central e (c) corte axial inferior.

As imagens de ressonância magnética foram obtidas em formato DICOM e analisadas em um programa desenvolvido na plataforma de Matlab ${ }^{\circledR}$ que gera os histogramas das intensidades dos sinas nas regiões selecionadas. Em cada um dos cortes estudados foram feitos dois histogramas, um analisou a homogeneidade do corte todo e outro a homogeneidade de uma região central de $9,5 \mathrm{~cm}$ de diâmetro, determinado para abranger as dimensões dos objetos simuladores utilizados na caracterização do dosímetro a base de gel. As figuras 25, 26 e 27 mostram os histogramas de cada corte axial para as duas regiões avaliadas. 

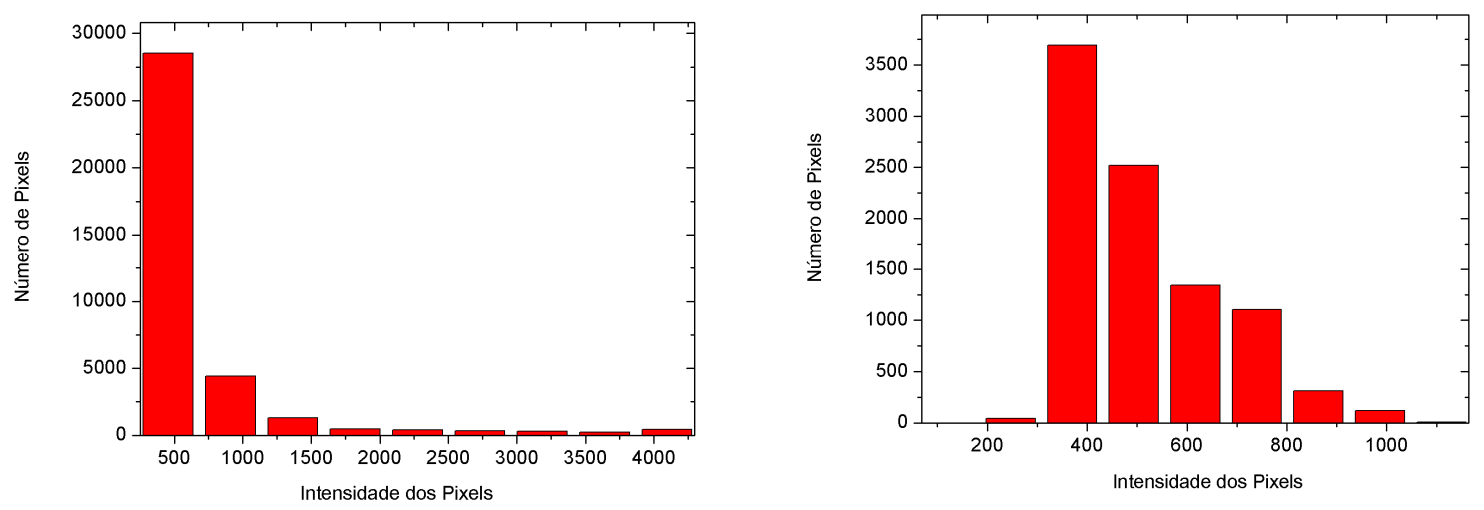

(a)

(b)

Figura 25: Histogramas das intensidades do sinal no corte axial superior em regiões distintas: (a) corte todo, (b) região central com $9,5 \mathrm{~cm}$ de diâmetro.

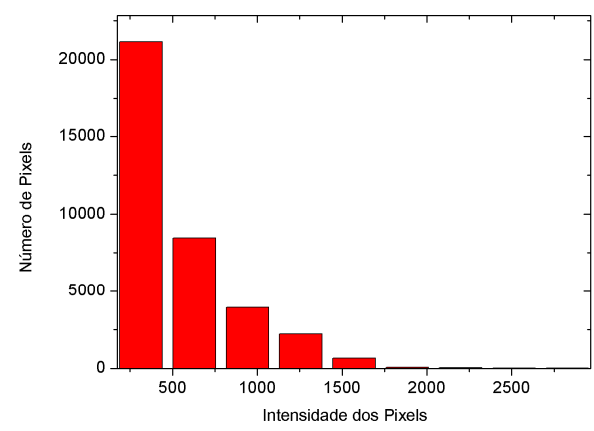

(a)

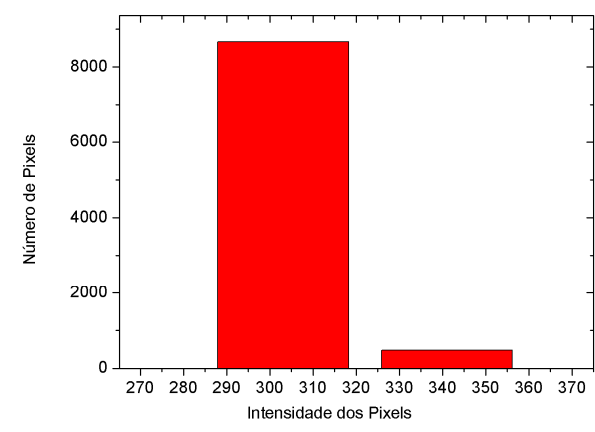

(b)

Figura 26: Histogramas das intensidades do sinal no corte axial central em regiões distintas: (a) corte todo, (b) região central com $9,5 \mathrm{~cm}$ de diâmetro.

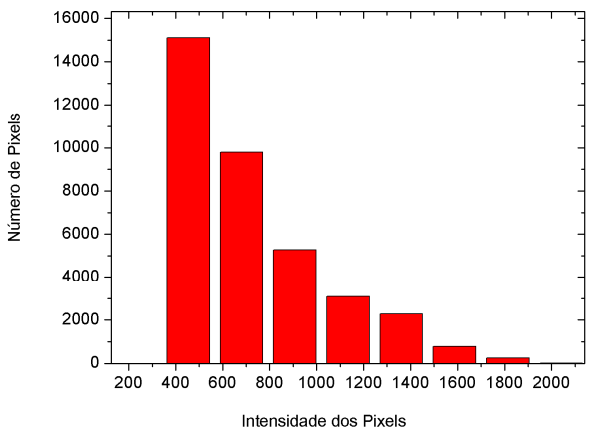

(a)

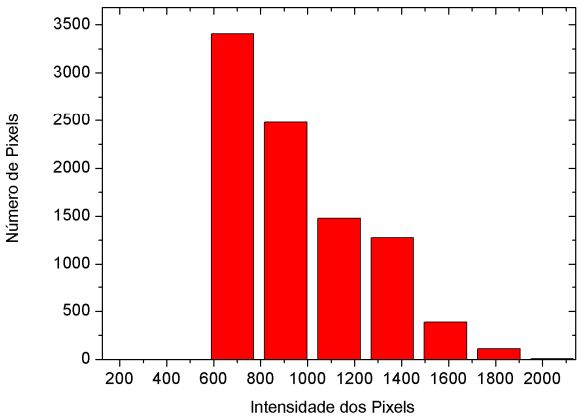

(b)

Figura 27: Histogramas das intensidades do sinal no corte axial inferior em regiões distintas: (a) corte todo, (b) região central com 9,5 cm de diâmetro. 
De acordo com os resultados encontrados no estudo da homogeneidade observa-se uma variação significativa para os valores das intensidades do sinal. Dessa forma, para minimizar artefatos causados por esse fator, o corte axial da região de interesse sempre foi feito na posição central da bobina.

\subsubsection{Simulação do material MAGIC- $f$ gel}

De acordo com o protocolo TRS-398 da IAEA a dosimetria de referência para um feixe clínico de elétrons, assim como para fóton, baseia-se na dose absorvida na água (IAEA, 2000b). Dessa maneira, se o dosímetro utilizado para as medidas em condições de referência apresentar número atômico efetivo equivalente em água, eliminam-se alguns fatores de correção devido a perturbações no feixe produzidas elo material do dosímetro. Assim, o estudo da equivalência da composição do dosímetro MAGIC- $f$ com água, para feixes de elétrons, foi realizado utilizando simulação Monte Carlo com o código PENELOPE. Para realização desse estudo foram construídos os dois arquivos de materiais, "agua.mat" e "magicf.mat".

Primeiramente, utilizando uma ferramenta auxiliar do código PENELOPE, table.f, foram gerados valores de stopping power mássicos para os dois arquivos de materiais e comparados com valores da literatura (NIST, 2013) como mostrado na figura 28.

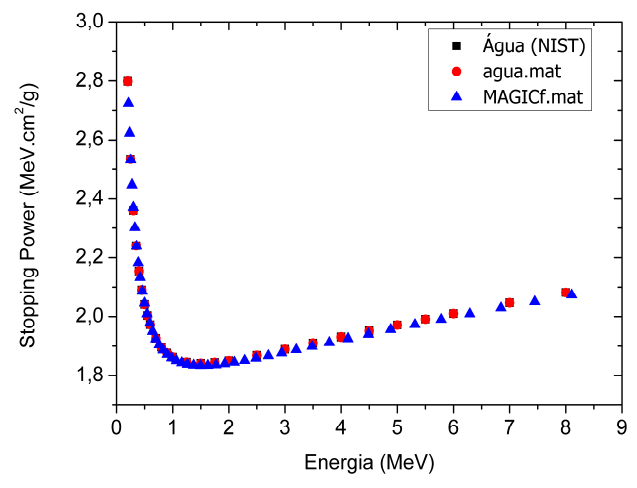

Figura 28: Comparação entre valores stopping power para os materiais gerados pelo código de simulação PENELOPE e dados da literatura (NIST, 2013).

Como mostrado na figura 28, as curvas contendo os valores do stopping power mássico, em função da energia, para os materiais gerados pelo código PENELOPE e dados da literatura (NIST) mostraram-se equivalentes, com diferença máxima de 0,4\%, para energias maiores de $6 \mathrm{MeV}$. A partir desta comparação pode-se afirmar que os 
materiais gerados como "agua.mat" e "magicf.mat" interagem de modo similar para uma certa geometria de um objeto simulador contendo água. A partir deste contexto, pode-se concluir que o dosímetro MAGIC- $f$ gel tem um comportamento similar com a água, com número atômico efetivo equivalente ao da água.

Os materiais gerados, "agua.mat" e "magicf.mat", foram utilizados para simular um cubo de $30 \mathrm{~cm}$ de aresta, em condições de irradiação, com campo de $10 \times 10 \mathrm{~cm}^{2}$ e distância fonte superfície de $100 \mathrm{~cm}$, para as energias de 6 a $15 \mathrm{MeV}$. A partir dos dados obtidos da simulação, foram gerados kernels de dose relativa, por meio de um programa desenvolvido na plataforma de MatLab ${ }^{\circledR}$. Assim, os dados obtidos foram comparados por meio de curvas de porcentagem de dose em profundidade. As curvas de PDP para os dois materiais simulados, água e MAGIC- $f$, para diferentes feixes de elétrons são apresentadas na figura 29 .

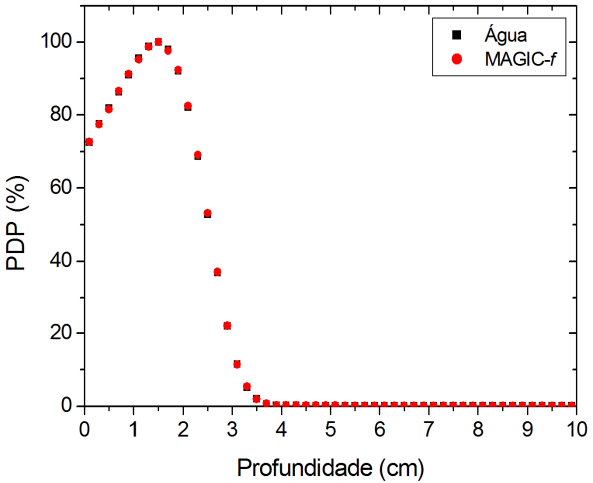

(a)

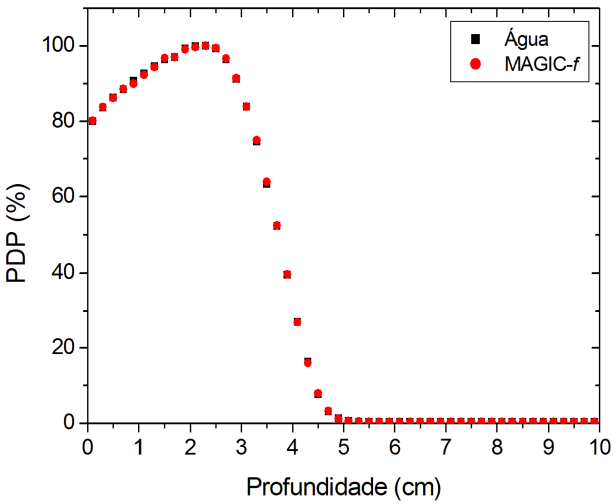

(b)

Figura 29: PDPs obtidas com simulação utilizando o código PENELOPE para os materiais "agua.mat" e "magicf.mat" para os feixes clínicos de elétrons de: (a) $6 \mathrm{MeV}$; (b) $9 \mathrm{MeV}$; (c) $12 \mathrm{MeV}$ e (d) $15 \mathrm{MeV}$, continuação. 


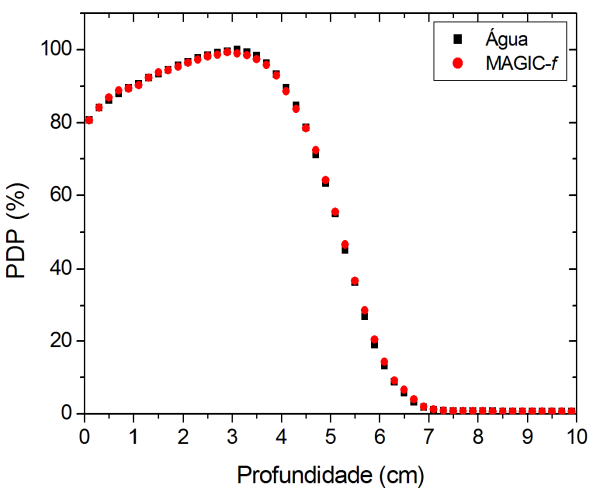

(c)

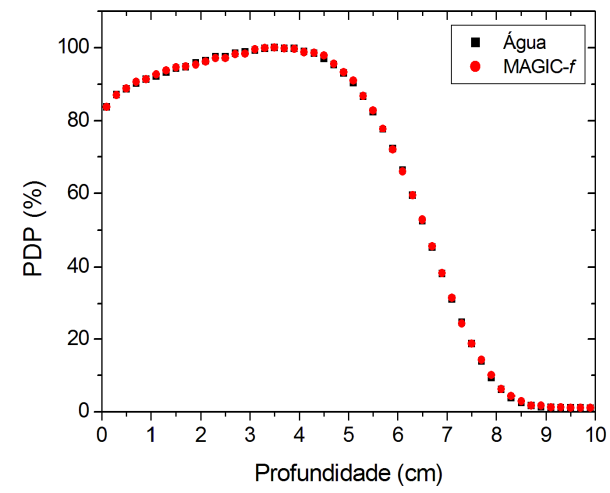

(d)

Figura 29: PDPs obtidas com simulação utilizando o código PENELOPE para os materiais "agua.mat" e "magicf.mat" para os feixes clínicos de elétrons de: (a) $6 \mathrm{MeV}$; (b) $9 \mathrm{MeV}$; (c) $12 \mathrm{MeV}$ e (d) $15 \mathrm{MeV}$.

As curvas de PDP, obtidas por meio do código simulação, para os materiais "agua.mat" e "magicf.mat", nas energias estudadas, mostram comportamentos similares. Comparando-se quantitativamente as curvas PDP, de ambos os materiais criados, foram encontradas diferenças menores que $0,9 \%$, para as porcentagens de dose acima de $50 \%$, em todas as energias simuladas. Para as porcentagens de dose menores que $50 \%$, as diferenças chegam a 2,0\% para a energia $12 \mathrm{MeV}$, na profundidade de $5,75 \mathrm{~cm}$, concluindo-se que o dosímetro MAGIC- $f$ gel tem o mesmo comportamento que a água.

Com a concordância entre os materiais simulados e dados literatura, pode-se inferir que a composição química do material utilizado para simular o dosímetro polimérico MAGIC-f é equivalente à água, resultado que concorda com a literatura em experimentos feitos para feixes de fótons que mostram também essa equivalência em água (ALVA, 2012).

Assim, para a determinação das distribuiçõos de dose para casos de tratamentos clínicos com feixes de elétrons foram utilizadas simulações com o material "magic.mat".

\subsection{Caracterização do dosímetro MAGIC- $f$}

Nessa seção são apresentados os resultados de caracterização para o dosímetro MAGIC- $f$, de número atômico efetivo de 7,41 e densidade de $1,06 \mathrm{~g} / \mathrm{cm}^{3}$, para feixes clínicos de elétrons. eEtudos de reprodutibilidade e estabilidade temporal da resposta do 
dosímetros foram realizados, assim como análises sobre sua dependência em função da dose, taxa de dose e energia.

\subsubsection{Reprodutibilidade}

A figura 30 mostra o resultado do estudo da reprodutibilidade do dosímetro MAGIC- $f$ para um feixe de elétrons de $6 \mathrm{MeV}$. Cada medida é a média das leituras dentro de uma região de interesse com seu respectivo desvio padrão, que foi menor que $2 \%$ em todas as medidas. As diferenças máximas percentuais entre os valores de R2 obtidos são apresentados na tabela 3 .

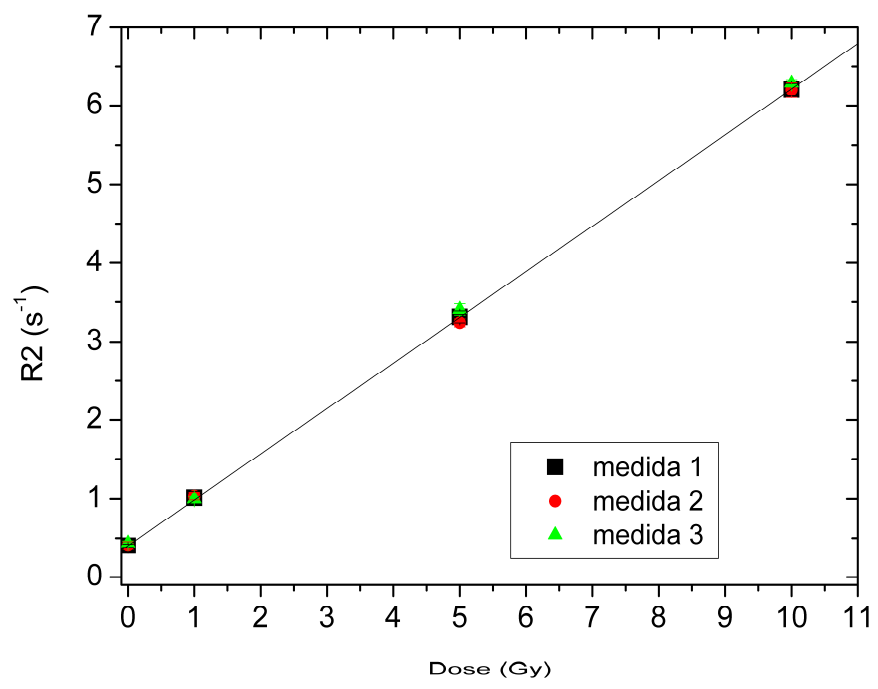

Figura 30: Resposta do dosímetro MAGIC- $f$ em função da dose absorvida para o teste de reprodutibilidade para um feixe de elétrons de $6 \mathrm{MeV}$.

Tabela 3: Diferenças percentuais máximas entre as respostas do dosímetro MAGIC- $f$ para teste de reprodutibilidade.

\begin{tabular}{c|c}
\hline Dose (Gy) & $\begin{array}{c}\text { Diferenças percentuais } \\
\text { máximas entre as medidas }(\%)\end{array}$ \\
\hline 0 & 3,0 \\
\hline 1 & 2,2 \\
\hline 5 & 2,8 \\
\hline 10 & 1,4
\end{tabular}

A tabela 3 mostra que a diferença percentual encontrada em R2 é maior para amostras não irradiadas, tendo uma variação máxima de $3 \%$, enquanto que a menor diferença foi encontrada para a amostra irradiada com a dose mais alta. Isso pode ser explicado pela 
relação sinal ruído, para a amostra não irradiada o sinal de leitura é baixo, então pequenas variações do sinal de fundo, intrínsecas do próprio dosímetro, influênciam na leitura da amostra, aumentando dessa forma as diferenças percentuais das leituras para doses menores que 1,0 Gy. Consequentemente, fato contrário acontece para doses altas, com a melhora da relação sinal-ruído. Os valores de leitura do dosímetro para doses altas são maiores, e assim as variações do sinal de fundo do dosímetro não irão influenciar significativamente o valor final de leitura do dosímetro, diminuindo a variação da resposta associada a essas doses.

\subsubsection{Estabilidade temporal da resposta do MAGIC- $f$ gel}

No estudo da estabilidade temporal da resposta do dosímetro após a irradiação, para diferentes doses em um feixe de cobalto 60, as amostras foram lidas em um intervalo de tempo de 0 a 96 horas após a irradiação, e os resultados são apresentados na figura 31.

Para todas as doses, a resposta do dosímetro é menor para as medidas iniciais, evidenciando que o dosímetro necessita de um tempo para completar o processo de polimerização. Além disso, depois de um tempo adequado, a resposta estabiliza, indicando a finalização do processo de polimerização. A partir de 24 horas, a informação de dose absorvida é mantida após do término das reações poliméricas, pelo intervalo de tempo considerado.

Assim, observa-se que o processo de polimerização se completa em um intervalo de tempo depois da amostra ser irradiada, e quando a polimerização é finalizada, a informação de dose absorvida é conservada. Esse comportamento é similar ao apresentado na literatura, no qual as curvas de estabilidade de resposta do gel em função do tempo de leitura, também mostram que a polimerização precisa de um tempo para ser finalizada e que a informação de dose é preservada (PAVONI, 2009). 


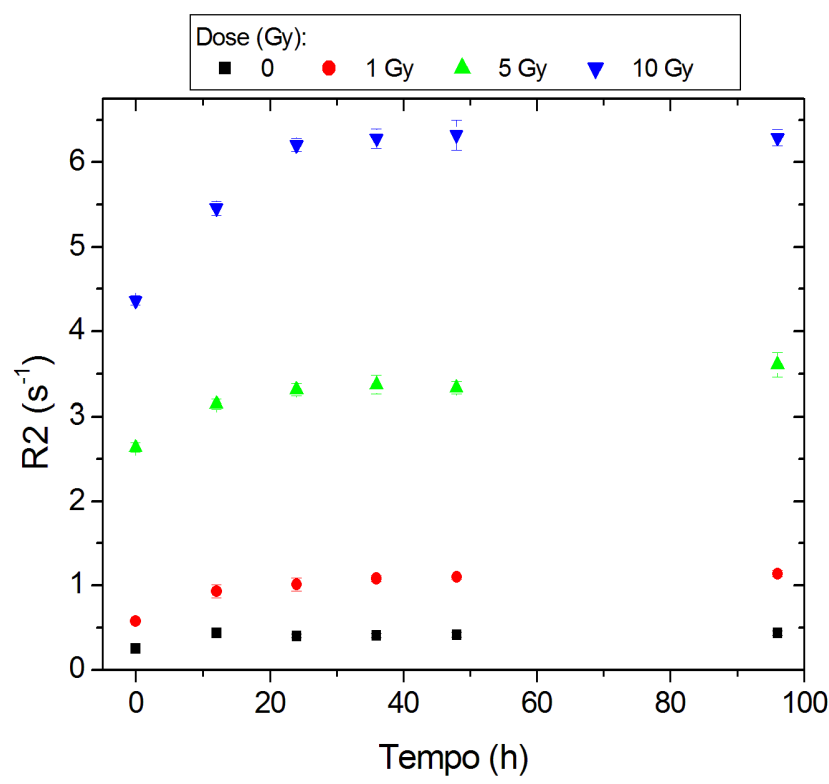

Figura 31: Resposta do dosímetro MAGIC- $f$ em função da dose absorvida e do tempo de leitura após a irradiação.

De acordo com o resultado apresentado nesse estudo, para doses baixas o processo de polimerização é finalizado em torno de 12 horas após a irradiação, porém para doses mais altas, como 10 Gy, o tempo necessário para a finalização da polimerização é aumentado para, aproximadamente, 24 horas.

Assim como os outros géis poliméricos, a leitura das amostras do MAGIC- $f$ gel não deve ser realizada logo após a irradiação, pois devido a não finalização do processo de polimerização o sinal de R2 é menor. Dessa forma, considerando que neste estudo as amostras também seriam irradiadas com doses altas, o tempo padrão de leitura após a irradiação foi estabelecido em $24 \mathrm{~h}$.

\subsubsection{Dependência de resposta do MAGIC- $f$ gel com a dose absorvida e} energia para feixes clínicos de elétrons

Os resultados para a resposta do dosímetro em função da dose para os feixes clínicos de elétrons de 6, 9, 12 e $15 \mathrm{MeV}$, irradiados de 0,5 a 20 Gy, com taxa de dose de 400 cGy/min, são apresentados na figura 32a. Observa-se que o sinal de R2 apresenta um comportamento crescente com o aumento de dose absorvida, tendendo a um saturação para altas doses. Na figura $32 \mathrm{~b}$ os resultados foram normalizados para a energia de 6 $\mathrm{MeV}$. 


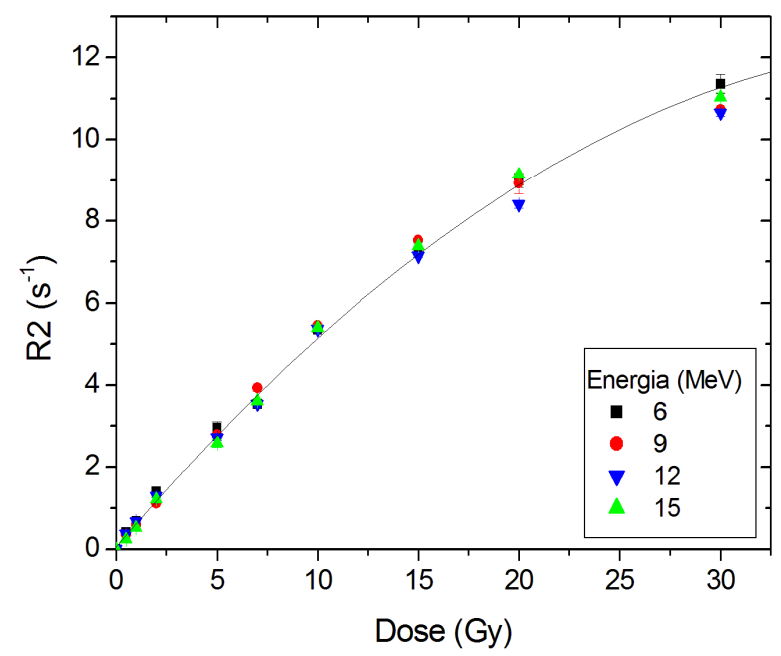

(a)

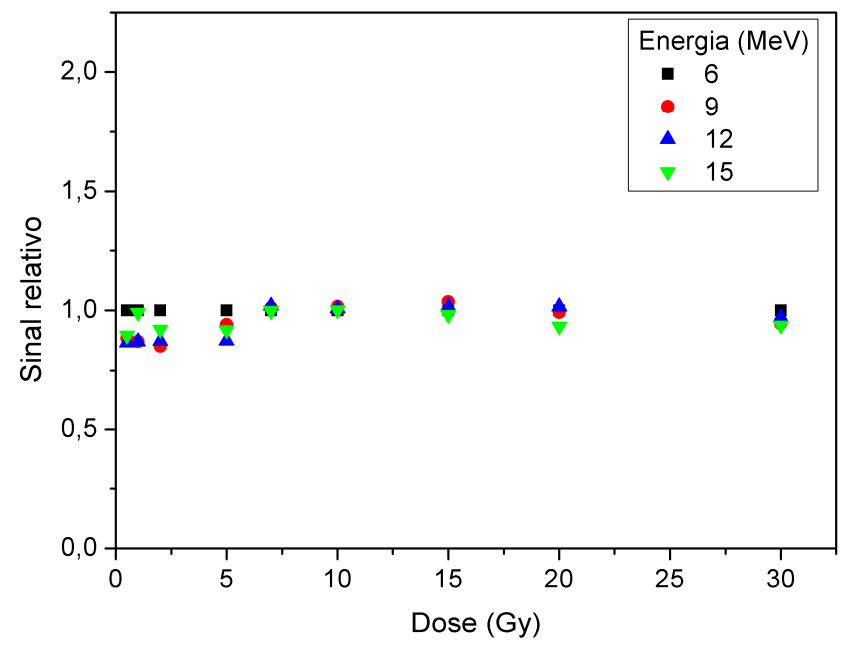

(b)

Figura 32: Resposta do dosímetro MAGIC- $f$ em função da dose absorvida para os feixes de elétrons de 6, 9, 12 e $15 \mathrm{MeV}$ (a) valores de R2 absolutos; (b) valores de R2 normalizados para a energia de $6 \mathrm{MeV}$.

Resultados da literatura para a resposta do dosímetro em função da dose (MARYANSKI et al, 1994; DE DEENE et al, 2007) mostram um comportamento nãolinear de dosímetros poliméricos quando irradiados até altas doses. Assim, o resultado encontrado nesse trabalho, com o dosímetro MAGIC- $f$ para feixes de elétrons, apresentam o mesmo comportamento da literatura, uma não-linearidade para intervalos até altas 
doses. Um ajuste polinomial de segunda ordem dos dados da figura 32 apresenta um coeficiente de correlação de 0,997. Porém, considerando um intervalo de dose específico, no caso desse trabalho, de 1 a 10 Gy, observa-se uma faixa de linearidade em função da dose, como apresentado na figura 33.

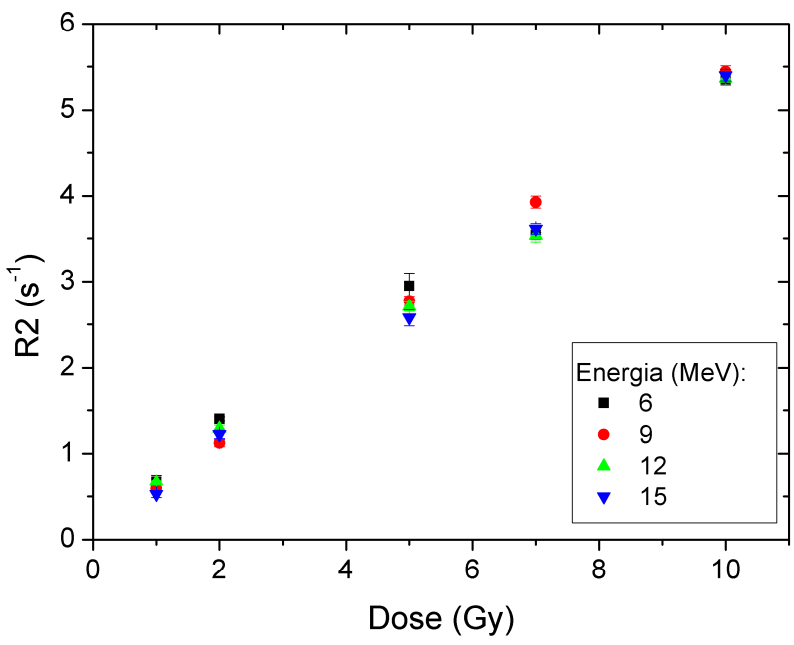

Figura 33: Resposta do dosímetro MAGIC- $f$ em função da dose absorvida para os feixes de 6, 9, 12 e $15 \mathrm{MeV}$ para um intervalo de dose absorvida restrito, 1 a $10 \mathrm{~Gy}$.

Com os dados da figura 33 foi feito um ajuste linear para a dependência da reposta do dosímetro MAGIC- $f$ em um intervalo de dose absorvida para um intervalo de dose 1 a 10 Gy e o coeficiente de correlação encontrado foi de 0,$995 ; 0,999 ; 0998$ e 0,997 para os feixes de 6, 9, 12 e $15 \mathrm{MeV}$, respectivamente. Assim, para esse intervalo de dose, podese considerar que o dosímetro polimérico MAGIC- $f$ apresenta um comportamento linear para feixes de elétrons.

Nessa mesma figura, também se pode avaliar a dependência energética do dosímetro MAGIC- $f$ em relação ao feixe de irradiação. Os coeficientes angulares encontrados para os ajustes dos dados foram de 0,46;0,54;0,53 e $0,51 \mathrm{~s}^{-1} \mathrm{~Gy}^{-1}$, respectivamente para os feixes de 6, 9, 12 e $15 \mathrm{MeV}$, mostrando que o coeficiente angular aumenta com o aumento da energia até $9 \mathrm{MeV}$ voltando a diminuir para os feixes de 12 e $15 \mathrm{MeV}$.

Vários trabalhos na literatura (ALVA, 2012; PAVONI, 2009; DE DEENE et al, 2006) mostram que existe uma dependência energética para dosímetros poliméricos. Esses resultados são para feixes de fótons e apresentam um aumento dos valores de R2 com o aumento da energia do feixe para todas as doses absorvidas. Nos resultados para feixes de elétrons, não encontramos a mesma tendência ponto a ponto, entretanto, se 
avaliarmos a forma funcional da curva pelo coeficiente angular, encontramos o mesmo comportamento, um aumento do coeficiente angular com o aumento da energia do feixe, com exceção da energia de $15 \mathrm{MeV}$.

Para determinação da dependência energética, os resultados obtidos com as energias 9, 12 e $15 \mathrm{MeV}$ foram comparados com a energia de $6 \mathrm{MeV}$ e as diferenças percentuais máximas foram de $2 \%$ para 10 Gy e $16 \%$ para a dose de 0,5 Gy.

Os efeitos de dependência energética podem ser minimizados determinando-se curvas de calibração em dose para cada energia do feixe.

Uma outra análise a ser feita é referente à reprodutibilidade de manufatura do gel, que pode ser analisada utilizando as figuras 31,32 e 33 mostrando uma diferença máxima de $2 \%$. As figuras apresentam valores de R2 ligeiramente diferentes para uma mesma dose, mostrando assim que o dosímetro apresenta uma pequena variação de sensibilidade de $1,3 \mathrm{~s}^{-1} / \mathrm{Gy}$. Esse fato pode ser explicado pelo próprio processo de manufatura das amostras, pois é um processo totalmente manual e a sensibilidade depende significativamente das concentrações dos componentes como encontrado na literatura (LUCI et al, 2007). Dessa forma, uma variação na concentração dos componentes pode levar a uma resposta do dosímetro. Para minimizar os efeitos da variação de sensibilidade dos diferentes lotes do dosímetro, foram feitas curvas de recalibração para cada lote de gel manufaturado.

\subsubsection{Dependência de resposta do MAGIC-f $f$ gel com a taxa de dose para feixes clínicos de elétrons}

Os resultados para a resposta do dosímetro em função da taxa de dose para os feixes clínicos de elétrons de 6, 9, 12 e $15 \mathrm{MeV}$ irradiados com 5 Gy, são apresentados na figura 34 . 


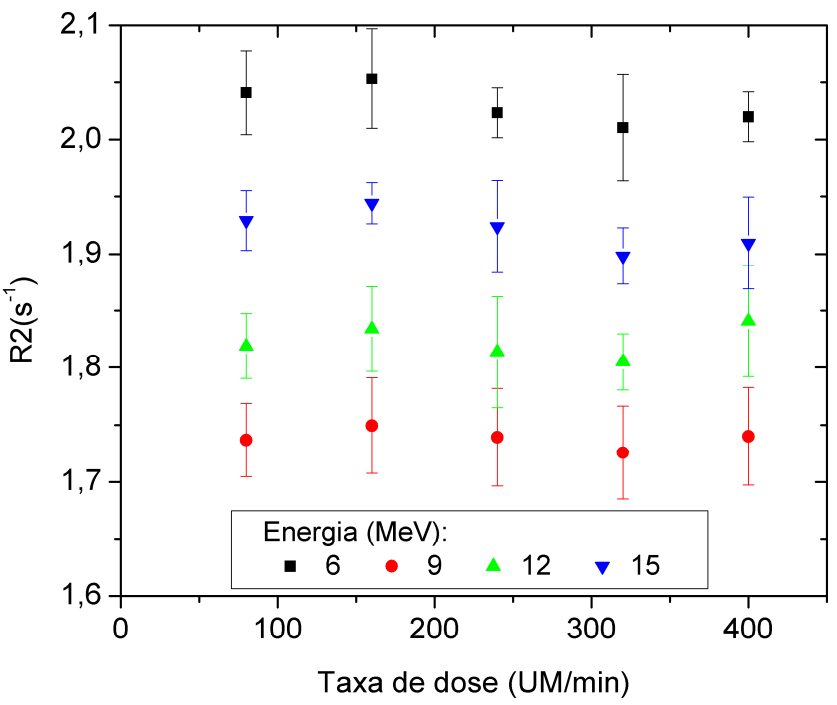

Figura 34: Resposta do dosímetro MAGIC- $f$ em função da taxa de dose para os feixes de $6,9,12$ e $15 \mathrm{MeV}$.

Os resultados encontrados nesse trabalho mostram que o dosímetro MAGIC- $f$ apresenta dependência com as taxas de dose utilizadas, resultado semelhante a encontrados na literatura para esse dosímetro (DE DEENE et al, 2006).

A taxa de dose considerada como padrão pelo HCB é de 400 "UM/min". Assim, os valores de $\mathrm{R} 2$ obtidos com essa taxa de dose foram comparados com os valores R2 para as outras taxas de dose e as variações percentuais máximas encontradas são apresentadas na tabela 4.

Tabela 4: Diferenças percentuais máximas da resposta do dosímetro MAGIC- $f$ em função da taxa de dose.

\begin{tabular}{c|c} 
Energia (MeV) & $\begin{array}{r}\text { Diferenças percentuais máxima da resposta do } \\
\text { dosímetro MAGIC- } f \text { em função da taxa de dose }(\%)\end{array}$ \\
\hline 6 & 1,6 \\
\hline 9 & 1,8 \\
\hline 12 & 2,1 \\
\hline 15 & 1,1
\end{tabular}

Na figura 34 observa-se uma dependência energética similar àquela mostrada na figura 33 mostrando que a dependência energética do dosímetro não é alterada pela alteração da taxa de dose. A diferença máxima de 13,8\% foi obtida, quando comparados 
os valores entre as energias de 6 e $15 \mathrm{MeV}$, para uma dose de 5 Gy e para todos os valores das taxas de dose.

Para minimizar os efeitos da taxa de dose do dosímetro nesse trabalho, todos os processos de irradiações foram feitos com a taxa de dose padrão do HCB, 400 "UM/min".

\subsection{Avaliação dos parâmetros dosimétricos com MAGIC- $f$ gel}

Para assegurar a acurácia na entrega de dose em um tratamento de radioterapia é necessário que seja realizada a dosimetria do feixe de radiação. Protocolos recomendam que a dosimetria seja feita em um objeto simulador de água, em uma determinada energia, tipo de radiação e geometria utilizando câmaras de ionização e que assim sejam determinados os parâmetros dosimétricos.

Como uma ferramenta auxiliar, esses parâmetros dosimétricos poderiam ser determinados utilizando dosimetria gel polimérica. Nessa seção são apresentados os resultados para determinação dos parâmetros dosimétricos, porcentagem de dose em profundidade e perfil de campo, com MAGIC- $f$ gel para feixes de elétrons.

\subsubsection{Porcentagem de dose em profundidade}

A figura 35 mostra os objetos simuladores que foram irradiados com 5 Gy em feixes clínicos de elétrons de 6, 9, 12 e $15 \mathrm{MeV}$ para determinação das curvas de PDP.

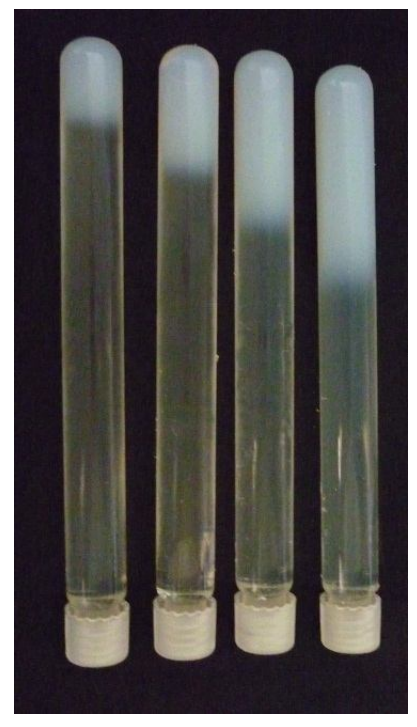

Figura 35: MAGIC- $f$ gel depois de irradiado para determinação das curvas de PDP nas energias de 6, 9, 12 e $15 \mathrm{MeV}$, como mostrado na figura da esquerda para direita. 
Os dados clínicos utilizados nesse trabalho foram fornecidos pelo serviço de radioterapia do $\mathrm{HCB}$ e foram obtidos com uma câmara de ionização na água, em condições de referência campo 10 x 10 cm², DFS de $100 \mathrm{~cm}$ utilizando o aplicador padrão de elétrons. Assim, as curvas de PDP experimentais obtidas com MAGIC- $f$ são comparadas as curvas obtidas por simulação e com dados clínicos, como mostrado na figura 36.

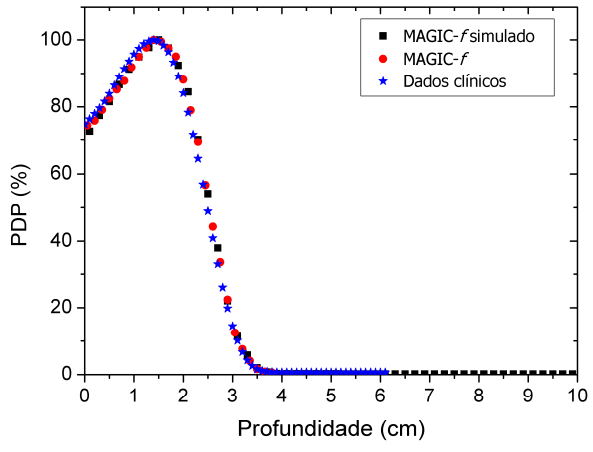

(a)

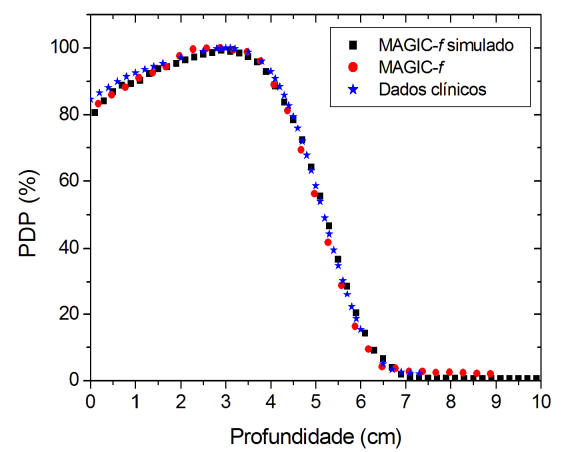

(c)

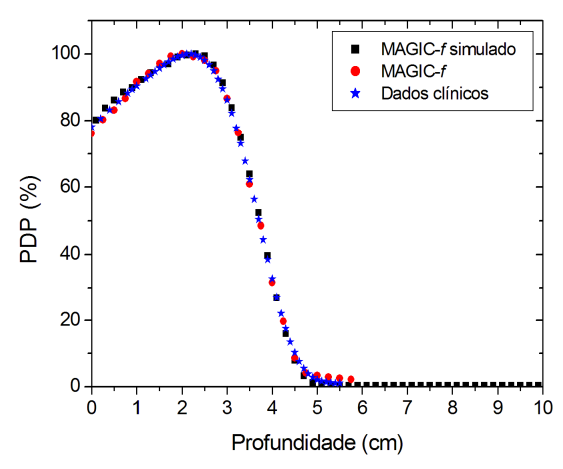

(b)

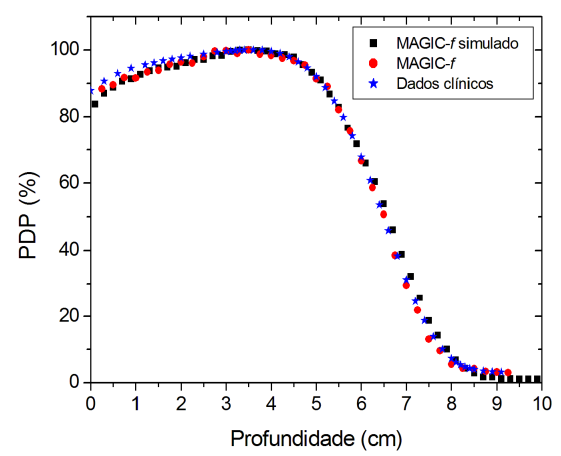

(d)

Figura 36: Curvas de PDP obtidas com PENELOPE, MAGIC- $f$ e dados clínicos para feixes clínicos de elétrons de: (a) $6 \mathrm{MeV}$; (b) $9 \mathrm{MeV}$; (c) $12 \mathrm{MeV}$ e (d) $15 \mathrm{MeV}$.

A tabela 5 mostra as diferenças percentuais máximas, em todas as energias, comparando PENELOPE, MAGIC- $f$ e dados clínicos do HCB, ressaltando que essas diferenças máximas foram determinadas em profundidades maiores que a profundidade de máxima dose para todas as energias. 
Tabela 5: Diferenças percentuais máximas entre as curvas de PDP determinadas com PENELOPE, MAGIC-f e dados clínicos do HCB.

\begin{tabular}{l|c|c|c|c} 
& \multicolumn{5}{|c}{$\begin{array}{c}\text { Diferenças percentuais máximas entre } \\
\text { as curvas de PDP (\%) }\end{array}$} \\
\hline \multicolumn{1}{c|}{ Energia (MeV) } & 6 & 9 & 12 & 15 \\
\hline PENELOPE e dados clínicos & 3,5 & 2,0 & 3,0 & 3,5 \\
\hline MAGIC-f e dados clínicos & 4,0 & 3,5 & 3,5 & 4,0 \\
\hline MAGIC- $f$ e PENELOPE & 1,7 & 3,2 & 7,0 & 6,5
\end{tabular}

Dos resultados obtidos, para todas as energias, observa-se que as curvas de PDP obtidas com PENELOPE e MAGIC- $f$ possuem o mesmo comportamento da curva obtida com os dados clínicos do HCB, com pouca diferença entre os valores de dose, a partir da dose máxima. Nas profundidades antes de alcançar a dose máxima, diferenças percentuais de até $4 \%$ foram obtidas, quando comparadas os valores entre o MAGIC- $f$ gel e os dados clínicos, como mostrado na tabela 5. Apesar, dessa diferença, pode-se inferir a validação dois métodos dosimétricos utilizados, devido a que no planejamento, é considerada que o volume alvo encontre-se dentro de uma isodose entre $85 \%$ até $95 \%$, região onde os valores dos métodos tiveram uma máxima diferença de 2,2\%.

A partir das curvas de dose em profundidade obtidas como o dosímetro MAGIC- $f$ gel, simulação PENELOPE e dados clínicos, mostradas na figura 36, foram obtidos os valores dos índices de qualidade para feixes de elétrons, como o parâmetro $R_{50}$, para as energias de $6 \mathrm{MeV}$ a $15 \mathrm{MeV}$ (AIEA, 2000b). Os valores da profundidade são mostrados na tabela 6, os quais foram obtidos relacionando o ponto em que o valor da dose em profundidade alcança $50 \%$.

Tabela 6: Valores de R50 nas energias de $6 \mathrm{MeV}$ a $15 \mathrm{MeV}$.

\begin{tabular}{l|c|c|c|c}
\multicolumn{1}{c|}{ Energia $(\mathrm{MeV})$} & \multicolumn{4}{|c}{ Valores de $\mathrm{R}_{50}(\mathrm{~cm})$} \\
\hline PENELOPE & 6 & 9 & 12 & 15 \\
\hline MAGIC- $f$ gel & 2,59 & 3,80 & 5,20 & 6,50 \\
\hline Dados Clínicos & 2,51 & 3,80 & 5,05 & 6,48 \\
\hline
\end{tabular}

Os valores de $\mathrm{R}_{50}$ para as diversas energias estudadas apresentaram-se próximos. Quando os valores obtidos com MAGIC- $f$ gel são comparados com dados uma diferença 
máxima de $0,98 \%$ foi encontrado, para a energia de $12 \mathrm{MeV}$. Uma diferença de 1,95\% foi encontrada quando comparados os valores clínicos de $\mathrm{R}_{50}$ para a energia de $12 \mathrm{MeV}$ são comparados com valores de encontrados por simulação.

Com os índices de qualidade dos feixes de elétrons, $\mathrm{R}_{50}$, foram determinadas as energias médias dos feixes através da relação $\overline{E_{0}}=C R_{50}$ (AIEA 2000 TRS 398), onde C $=2,33 \mathrm{MeV} / \mathrm{cm}$ para água. Considerando que tanto o dosímetro MAGIC- $f$ gel quanto o material utilizado na simulação são equivalentes à água, o valor da energia pode ser determinado. Dessa maneira, com os valores de $\mathrm{R}_{50}$, mostrados na tabela 6, obteve-se valores de energia média de 5,80; 8,83;11;76 e 14,97 MeV, relativos as energias nominais do aparelho de irradiação utilizado, de 6, 9, 12 e $15 \mathrm{MeV}$. Os valores médios da energia encontrados diferem em no máximo, 3,3\% daqueles valores nominais de energia.

Além dos valores de $\mathrm{R}_{50}$, também foram determinados valores de profundidade na máxima dose, $d_{\max }$, mostrados na tabela 7 . Os valores $d_{\max }$ foram determinados a partir da distância em profundidade, para todas as curvas mostradas na figura 36 e para todas as energias estudadas no presente trabalho.

Tabela 7: Valores de $d_{\max }$, para as energias de $6 \mathrm{MeV}$ a $15 \mathrm{MeV}$.

\begin{tabular}{l|r|r|r|r}
\multicolumn{1}{c|}{ Energia $(\mathrm{MeV})$} & \multicolumn{4}{|c}{ Valores de $\mathrm{d}_{\max }(\mathrm{cm})$} \\
\hline PENELOPE & 6 & 9 & 12 & 15 \\
\hline MAGIC- $f$ & 1,50 & 2,22 & 3,00 & 3,51 \\
\hline Dados Clínicos & 1,48 & 2,18 & 2,98 & 3,48 \\
\hline
\end{tabular}

Como mostrado na tabela 7 , os valores de $\mathrm{d}_{\max }$ mostram dados da mesma ordem quando comparados aos métodos dosimétricos utilizados para todas as energias. A comparação entre os dados do MAGIC- $f$ gel como os dados clínicos mostrou uma diferença máxima de $1,33 \%$, para a energia de $6 \mathrm{MeV}$.

Outro parâmetro determinado foi o alcance prático, $\mathrm{R}_{\mathrm{P}}$, parâmetro que também caracteriza os feixes de elétrons. A tabela 8 mostra os valores para $\mathrm{R}_{\mathrm{P}}$ para todas as energias avaliadas. 
Tabela 8: Valores $\mathrm{R}_{\mathrm{p}}$, para as energias de $6 \mathrm{MeV}$ a $15 \mathrm{MeV}$.

\begin{tabular}{c|c|c|c|c} 
& \multicolumn{4}{|c}{ Valores de $\mathrm{R}_{\mathrm{P}}(\mathrm{cm})$} \\
\hline Energia $(\mathrm{MeV})$ & 6 & 9 & 12 & 15 \\
\hline PENELOPE & 3,42 & 4,70 & 6,49 & 8,09 \\
\hline MAGIC- $f$ & 3,38 & 4,63 & 6,40 & 7,98 \\
\hline Dados Clínicos & 3,41 & 4,71 & 6,43 & 8,00
\end{tabular}

Os resultados mostrados dos alcances práticos assim como os outros parâmetros, mostras valores similares obtidos com os métodos dosimétricos para todas as energias. A diferença máxima entre todos os valores de $\mathrm{R}_{\mathrm{P}}$ foi de $1,7 \%$, quando comprados os valores do MAGIC- $f$ gel e os dados clínicos fornecidos pelo serviço de radioterapia do HCB, para a energia de $9 \mathrm{MeV}$.

O último parâmetro determinado a partir da curva de dose em profundidade foram as porcentagens de dose na entrada da pele, um parâmetro importante, pois a pele é considerado um órgão de risco para tratamentos com feixes de elétrons. Na tabela 9 são mostradas as porcentagens de dose na entrada da pele, obtida por meio das curvas mostradas na figura 36, para as energias estudadas. A tabela 10 mostra as diferenças entre os valores de dose na superfície entre os dados clínicos e os dados da simulação e do MAGIC- $f$ gel.

Tabela 9: Valores de porcentagem de dose na superfície para nas energias de $6 \mathrm{MeV}$ a 15 $\mathrm{MeV}$.

\begin{tabular}{l|c|c|c|c}
\multicolumn{1}{c|}{} & \multicolumn{4}{|c}{ Valores de dose na superfície (\%) } \\
\hline \multicolumn{1}{c|}{ Energia (MeV) } & 6 & 9 & 12 & 15 \\
\hline PENELOPE & 72,1 & 80,0 & 80,0 & 83,0 \\
\hline MAGIC- $f$ & 72,2 & 75,4 & 81,9 & 87,6 \\
\hline Dados Clínicos & 73,0 & 78,0 & 82,5 & 88,1
\end{tabular}

Tabela 10: Diferença entre os valores dose na superfície para as nas energias de $6 \mathrm{MeV}$ a $15 \mathrm{MeV}$.

\begin{tabular}{c|c|c|c|c} 
& \multicolumn{4}{|c}{ Diferença das doses na superfície (\%) } \\
\hline Energia (MeV) & 6 & 9 & 12 & 15 \\
\hline PENELOPE e dados clínicos & 1,15 & 3,33 & 0,76 & 0,53 \\
\hline MAGIC- $f$ e dados clínicos & 1,26 & 2,52 & 3,03 & 5,81
\end{tabular}


As doses na entrada da pele mostradas na tabela 9 foram comparadas com dados clínicos de referência. A máxima diferença percentual foi de 5,8\%, quando comparado o MAGIC- $f$ gel e os dados clínicos para a energia de $15 \mathrm{MeV}$.

Com o aumento da energia pode-se observar um aumento na dose na superfície, no $d_{\max }$ e consequentemente, o aumento dos parâmetros $\mathrm{R}_{50}$ e $\mathrm{R}_{\mathrm{P}}$, assim como também, observa-se um aumento na contaminação por feixe de fótons. Os parâmetros como $\mathrm{R}_{50}$, $d_{\max }, R_{P}$. Os três alcances $R_{50}, d_{\max }, R_{P}$ mostraram diferenças menores que o $2 \%$, entre os três métodos, podendo-se inferir que estes podem ser utilizados como métodos auxiliares nas medidas destes parâmetros, já que conforme as recomendações do ICRU, IAEA e AAMP o dosímetro de referência é a câmara de ionização.

\subsubsection{Perfil de campo}

Os métodos PENELOPE e MAGIC- $f$ foram utilizados para determinar curvas de perfil de campo para os feixes clínicos de elétrons de 6, 9, 12 e $15 \mathrm{MeV}$ para um campo de irradiação de $10 \times 10 \mathrm{~cm}^{2}$. As curvas de perfil de campo foram feitas na profundidade de máxima dose para todos os feixes, isto é, nas profundidades de 1,5;2,2;2,8 e 3,2 cm para os feixes de 6, 9, 12 e $15 \mathrm{MeV}$, respectivamente.

A figura 37 mostra o objeto simulador utilizado para a determinação da curva de perfil de campo para o feixe de $6 \mathrm{MeV}$.

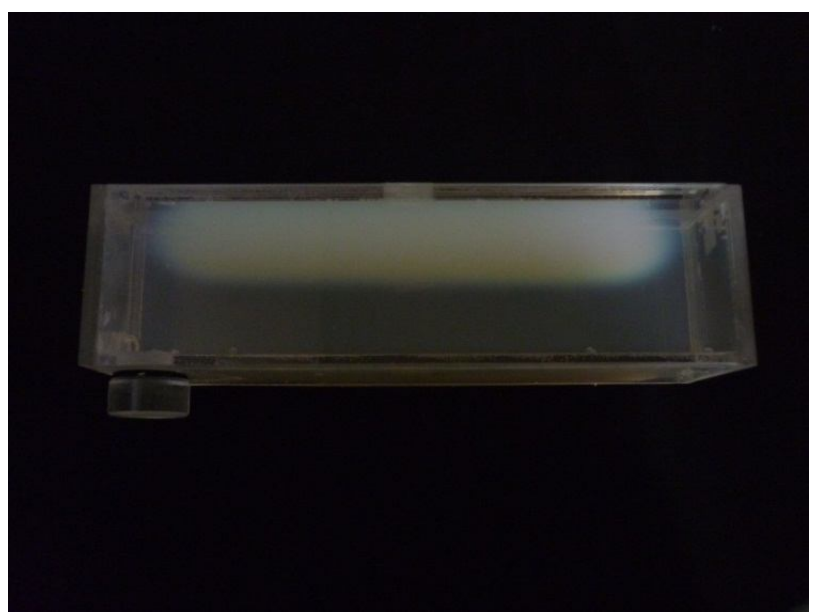

Figura 37: MAGIC- $f$ gel depois de irradiado para determinação da curva de perfil de campo para a energia de $6 \mathrm{MeV}$. 
Assim, as curvas de perfil de campo experimentais obtidas com MAGIC- $f$ são comparadas as curvas obtidas PENELOPE e com dados clínicos, como mostrado na figura 38 .

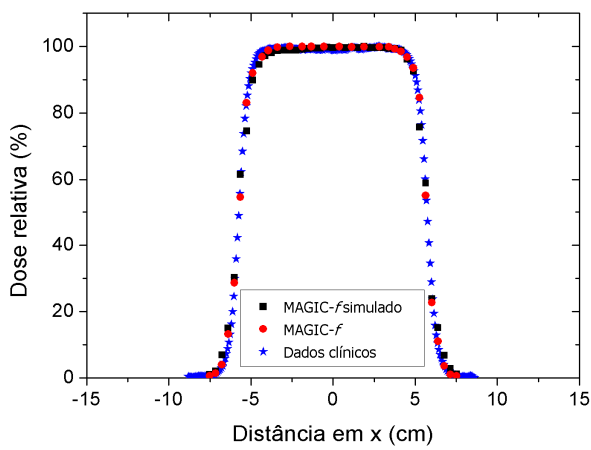

(a)

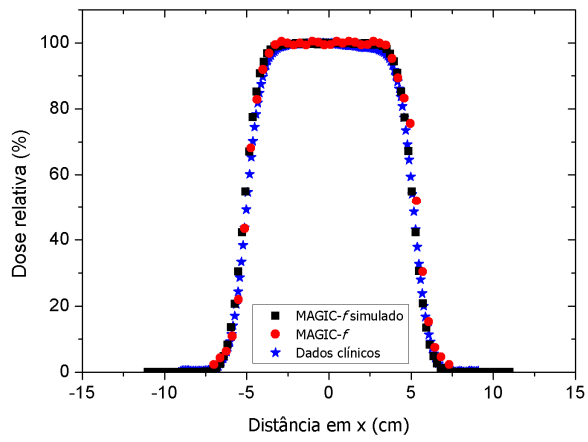

(c)

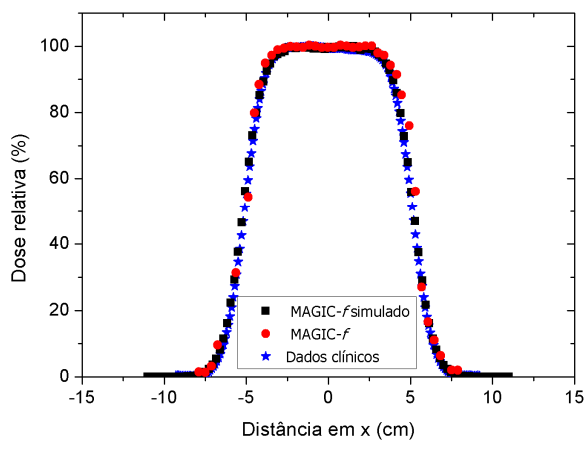

(b)

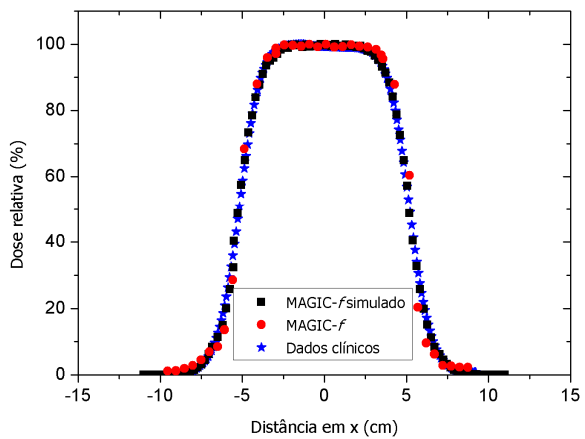

(d)

Figura 38: Curvas de perfil de campo obtidas com PENELOPE, MAGIC- $f$ e dados clínicos para feixes clínicos de elétrons de: (a) $6 \mathrm{MeV}$; (b) $9 \mathrm{MeV}$; (c) $12 \mathrm{MeV}$ e (d) $15 \mathrm{MeV}$.

A tabela 11 mostra as diferenças percentuais máximas, em todas as energias, comparando-se os resultados encontrados na determinação das curvas de perfil de campo para com PENELOPE, MAGIC- $f$ e dados clínicos do HCB.

Tabela 11: Diferenças percentuais máximas entre as curvas de perfil de campo determinadas com PENELOPE, MAGIC- $f$ e dados clínicos do HCB.

\begin{tabular}{l|c|c|c|c} 
& \multicolumn{5}{|c}{$\begin{array}{c}\text { Diferenças percentuais máximas entre } \\
\text { as curvas de perfil de campo (\%) }\end{array}$} \\
\hline \multicolumn{1}{c|}{ Energia (MeV) } & 6 & 9 & 12 & 15 \\
\hline PENELOPE e dados clínicos & 0,95 & 1,00 & 1,01 & 1,04 \\
\hline MAGIC- $f$ e dados clínicos & 1,26 & 1,37 & 1,35 & 1,39 \\
\hline MAGIC- $f$ e PENELOPE & 1,01 & 1,28 & 1,30 & 1,31
\end{tabular}


Assim, como para a determinação das curvas de PDP, as curvas de perfil de campo obtida com PENELOPE e MAGIC- $f$ para os feixes de 6, 9, 12 e $15 \mathrm{MeV}$, são próximas aos dados clínicos do $\mathrm{HCB}$, com diferenças percentuais máximas de 1,4\%, para a energia de $15 \mathrm{MeV}$, na região fora do tamanho de campo de $10 \times 10 \mathrm{~cm}^{2}$.

Por meio das curvas de perfil de campo foram obtidos os tamanhos do campo de irradiação, entre as distancias laterais relacionados com a porcentagem de dose em $80 \%$. Assim, valores do tamanho de campo foram comparados com o campo de $10 \times 10 \mathrm{~cm}^{2}$, definido pelos colimadores do aparelho para feixes de elétrons. As diferenças entre os tamanhos de campos determinados e aquele definido pelos colimadores mostraram uma diferença percentual máxima de $2,0 \%$, quando comparado os valores do tamanho do campo obtido com o dosímetro MAGIC- $f$ gel para a energia de $9 \mathrm{MeV}$, o que representa uma diferença de $0,2 \mathrm{~cm}$ do campo de referência.

\subsection{Avaliação de condições de irradiação com MAGIC- $f$ gel}

Para avaliação de alguns condições de irradiação, as distribuições de doses em três condições específicas foram determinadas utilizando MAGIC- $f$ gel: Um estudo com campos pequenos de elétrons, a irradiação de campos sobrepostos e, finalmente, a sobreposição de campos adjacentes de irradiação.

As três condições de irradiação foram planejadas com o sistema de planejamento, e nas mesmas condições do planejamento o dosímetro MAGIC- $f$ gel foi irradiado. Simulações dessas condições de irradiação foram realizadas por meio do código PENELOPE, nas mesmas condições do planejamento.

\subsubsection{Campos pequenos}

Feixes de elétrons em radioterapia são comumente empregados em lesões de pele, cabeça e pescoço, mama e olhos devido a sua habilidade de entrega de dose homogêneas na superfície e em uma profundidade específica. Em alguns casos dessas aplicações, campos pequenos ou irregulares tornam-se necessários. Entretanto, os colimadores padrões de elétrons, em geral, possuem dimensões pré-estabelecidas como $6 \times 6 \mathrm{~cm}^{2}, 10 \mathrm{x}$ $10 \mathrm{~cm}^{2}$ e $15 \times 15 \mathrm{~cm}^{2}$, sendo necessário dessa forma a confecção de colimadores adicionais para a conformação desses campos. 
Além disso, o uso de técnicas conformacionais para feixes de fótons corresponde aos procedimentos mais modernos em radioterapia, tendo como exemplo a radioterapia com modulação de intensidade de feixe (IMRT, do inglês intensity modulated radiation therapy). Para fótons, campos irregulares são obtidos por meio do uso de blocos de blindagens de alto número atômico, confeccionados especialmente para cada paciente, ou por meio de acessórios próprios das unidades de tratamento, como os colimadores multifolhas. Para o caso de feixes de elétrons, atualmente a maioria das unidades de terapia não são dotadas de acessórios específicos para técnicas conformacionais. Há trabalhos recentes que mostram a utilização de colimadores adicionais acoplados aos aplicadores padrões de feixes de elétrons (ALEXANDER et al, 2011; PAPACONSTADOPOULOS E SEUNTJENS, 2013).

Assim, a determinação de parâmetros dosimétricos para feixes de elétrons em campos pequenos podem ser utilizados nos planejamentos clínicos com radioterapia conformacional e em estudos de terapia com intensidade modulada para feixes de elétrons (MERT, do inglês modulated electron radiation therapy).

\subsubsection{Determinação do material para confecção do colimador adicional utilizando simulação Monte Carlo}

Inicialmente, utilizando simulação Monte Carlo, estudou-se o material para confecção do colimador adicional que é acoplado ao colimador padrão da unidade de terapia para feixes de elétrons. Os materiais estudados foram: cerrobend e acrílico. $\mathrm{O}$ cerrobend foi escolhido para ser o material mais comumente utilizado em oficinas de radioterapia para confecção dos blocos para blindagem de campos, e o acrílico por ser o material mais indicado para a blindagem de feixes de elétrons.

As distribuições de dose em campos pequenos, colimados com o acrílico e o cerrobend, foram determinadas e comparadas através das curvas de PDP e perfil de campo. A figura 39 mostra, qualitativamente, a diferença na distribuição de dose obtida para os colimadores de cerrobend e acrílico para o feixe de $6 \mathrm{MeV}$ para um campo de $1 \times 1 \mathrm{~cm}^{2}$. 


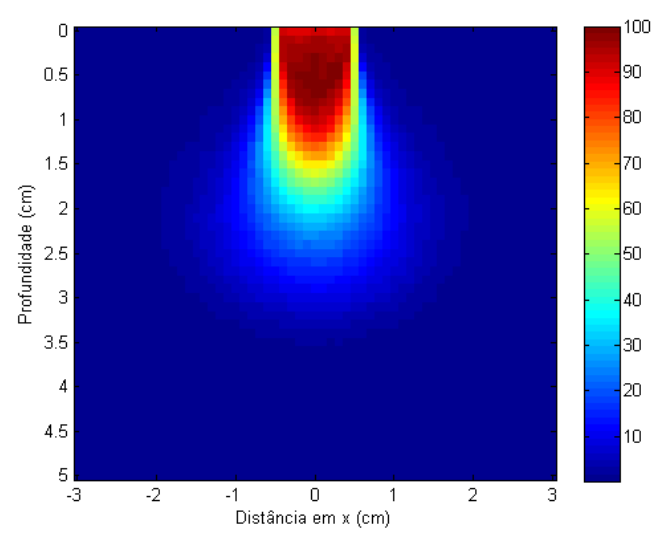

(a)

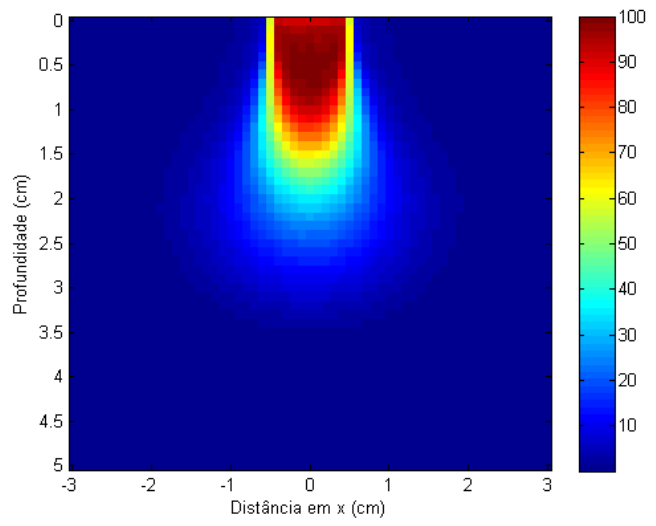

(b)

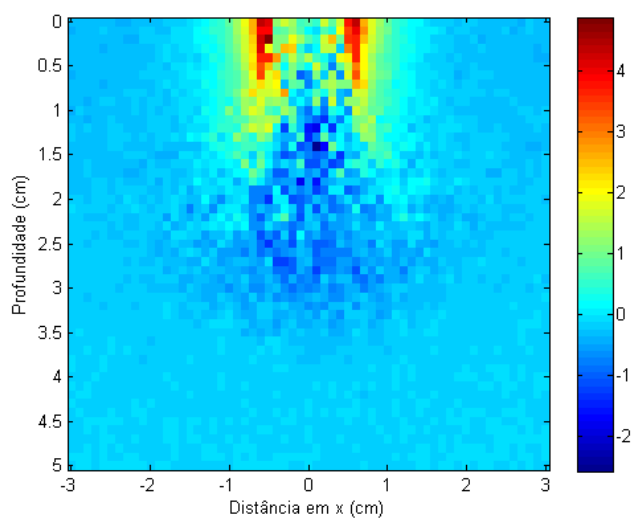

(c)

Figura 39: Distribuição de dose de um campo de 1 x $1 \mathrm{~cm}^{2}$ para a energias de $6 \mathrm{MeV}$ com colimação de: (a) cerrobend, (b) acrílico e (c) subtração das distribuições de dose de (a) e (b).

Para avaliar a influência na dose depositada em função dos materiais que colimam o campo de irradiação foram determinadas as distribuições de dose com as irradiações feitas com o colimador de cerrobend e acrílico. As respostas dosimétricas para os diferentes materiais e energias são apresentadas nas figuras 40 e 41 . 


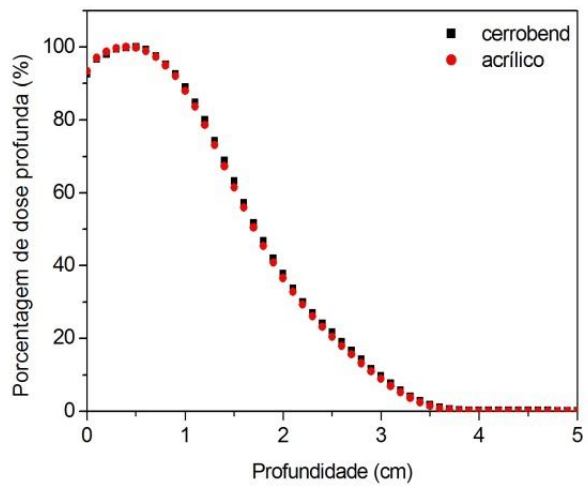

(a)

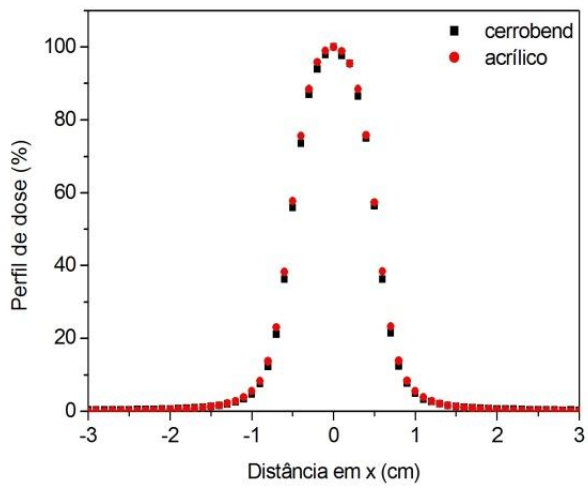

(b)

Figura 40: Comparação dos resultados com colimadores de cerrobend e acrílico para o feixe clínico de $6 \mathrm{MeV}$ para um campo de 1 x $1 \mathrm{~cm}^{2}$ : (a) PDP, (b) perfil de campo.

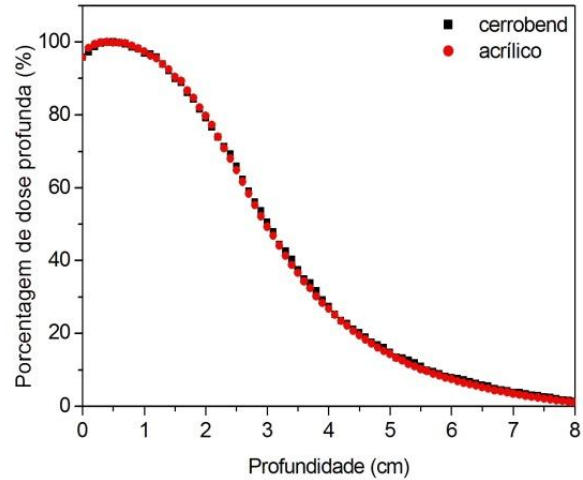

(a)

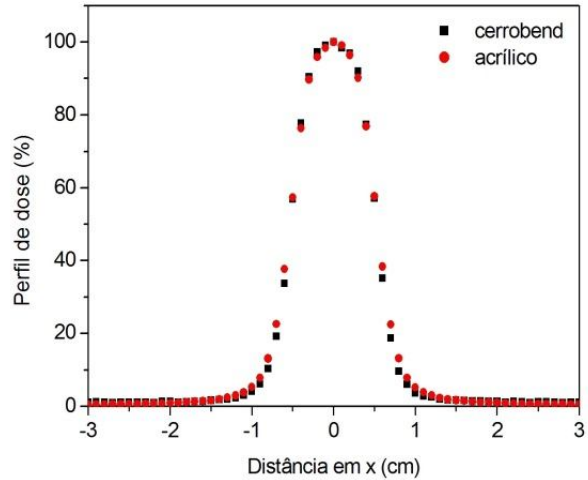

(b)

Figura 41: Comparação dos resultados com colimadores de cerrobend e acrílico para o feixe clínico de $12 \mathrm{MeV}$ para um campo de 1 x $1 \mathrm{~cm}^{2}$ : (a) PDP, (b) perfil de campo.

A tabela 12 mostra, quantitativamente, as maiores diferenças encontradas nos parâmetros dosimétricos, PDP e perfil de campo, para os colimadores de cerrobend e acrílico nas energias de $6 \mathrm{MeV}$ e $12 \mathrm{MeV}$ para um campo de $1 \times 1 \mathrm{~cm}^{2}$.

Tabela 12: Variação percentual máxima na comparação dos parâmetros dosimétricos para as irradiações com colimadores adicionais de cerrobend e acrílico, nas energias de $6 \mathrm{MeV}$ e $12 \mathrm{MeV}$ para um campo de $1 \times 1 \mathrm{~cm}^{2}$.

Diferenças percentuais máximas entre os parâmetros dosimétricos (\%)

\begin{tabular}{c|c|c}
\hline Energia $(\mathrm{MeV})$ & PDP & Perfil de campo \\
\hline 6 & 1,2 & 2,5 \\
\hline 12 & 1,5 & 3,2
\end{tabular}


Pelas características dosimétricas de um feixe de elétrons, era esperado que o colimador de cerrobend produzisse contaminação do feixe pela produção de fótons de Bremsstrahlung. Porém, os resultados das figuras 40 e 41 não mostram a presença dessa contaminação, indicando que os fótons produzidos foram atenuados pelo próprio colimador. Assim, materiais de alto número atômico podem ser usados para blindagem de feixes de elétrons, desde que tenham a espessura adequada para atenuar os fótons produzidos.

A pequena distância entre o aplicador padrão de elétrons e a superfície a ser irradiada, em torno de $5 \mathrm{~cm}$, privilegia a utilização de um colimador de maior número atômico, com espessura reduzida, que permite manter a distância fonte-superfície padrão de $100 \mathrm{~cm}$ sem aumentar a dose em profundidade por contaminação do feixe primário.

Os resultados mostram que o colimador adicional pode ser confeccionado com cerrobend ou acrílico, porém o primeiro tem a vantagem de possuir uma menor espessura em relação ao segundo, resolvendo o problema da curta distância entre o aplicador padrão de elétrons e a superfície irradiada e não alterando as condições padrão de irradiação.

\subsubsection{Distribuição de dose com campos pequenos obtidas com MAGIC-f}

Quando campos pequenos são utilizados em radioterapia, o dosímetro utilizado deve ter resolução espacial adequada para determinar a dose absorvida na regiões de interesse e nos órgãos de risco.

Dessa forma, o dosímetro polimérico MAGIC- $f$ foi utilizado para determinação das distribuições de dose para feixes de elétrons de 6,9 e $12 \mathrm{MeV}$ em campos de pequenos, de $1 \times 1 \mathrm{~cm}^{2}$ e $5 \times 5 \mathrm{~cm}^{2}$. A figura 42 mostra o dosímetro polimérico MAGIC- $f$ irradiado com diferentes tamanhos de campo para o feixe de $6 \mathrm{MeV}$. 


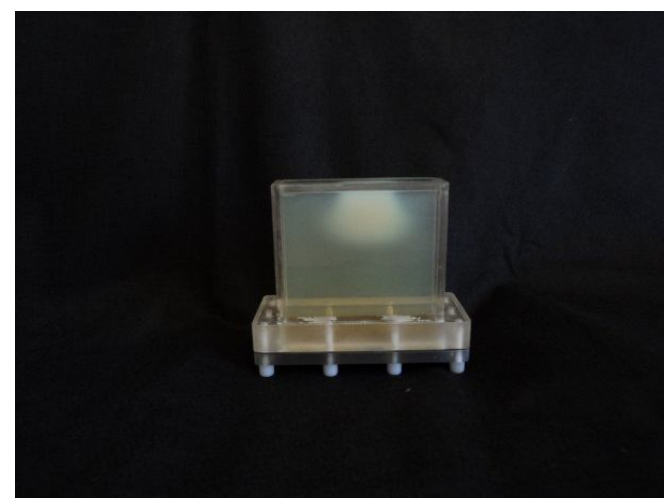

(a)

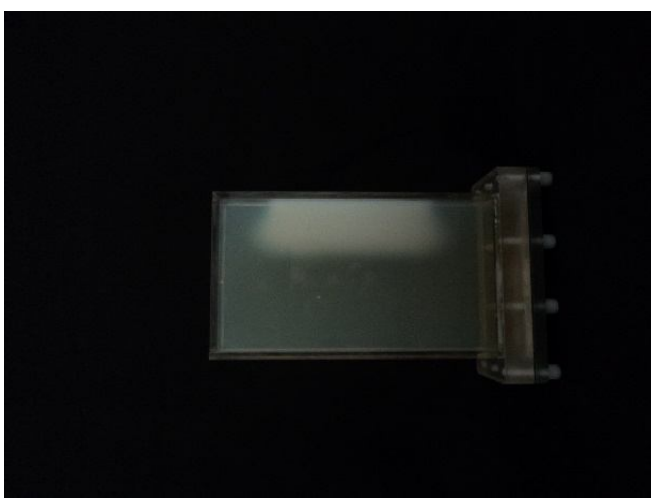

(b)

Figura 42: MAGIC- $f$ irradiado com um feixe de elétrons de $6 \mathrm{MeV}$ para determinação das curvas de PDP em função do tamanho de campo: (a) $1 \times 1 \mathrm{~cm}^{2}$, (b) $5 \times 5 \mathrm{~cm}^{2}$.

As distribuições de dose do plano central dos volumes irradiados para os campos de 1 x $1 \mathrm{~cm}^{2}$ e 5 x $5 \mathrm{~cm}^{2}$, obtidas com MAGIC-f, PENELOPE e TPS Eclipse ${ }^{\circledR}$, foram processadas e analisadas em um programa desenvolvido na plataforma Matlab $^{\circledR}$ e são apresentadas nas figuras 43 e 44 para o feixe de elétrons de $6 \mathrm{MeV}$.

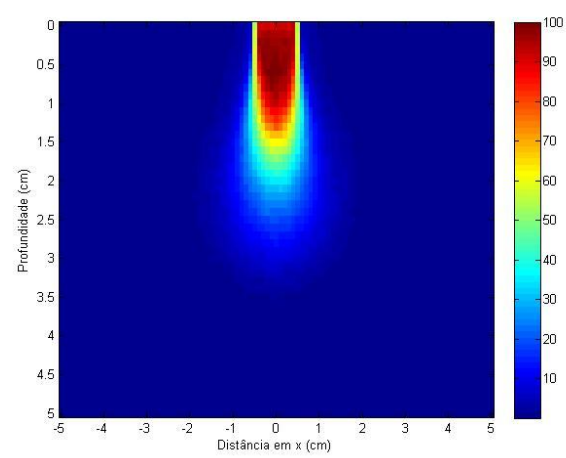

(a)

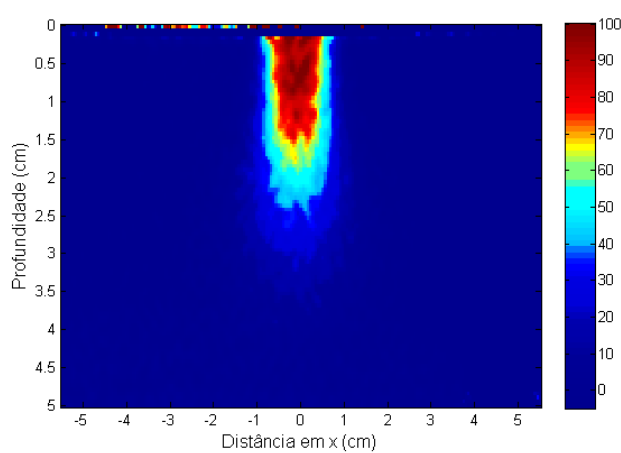

(b)

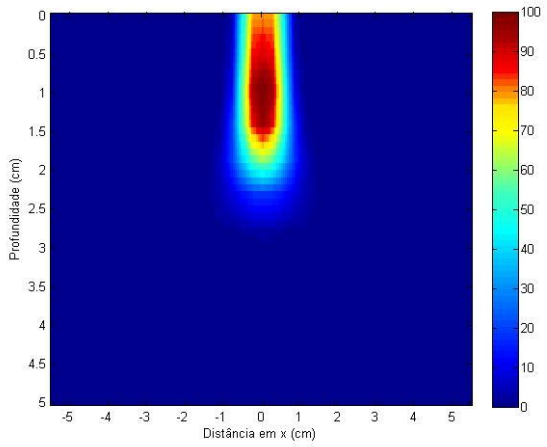

(c)

Figura 43: Distribuição de dose para um campo de $1 \times 1 \mathrm{~cm}^{2}$ para o feixe clínico de elétrons de $6 \mathrm{MeV}$ obtidas com: (a) PENELOPE, (b) MAGIC- $f$ e (c) TPS Eclipse ${ }^{\circledR}$. 


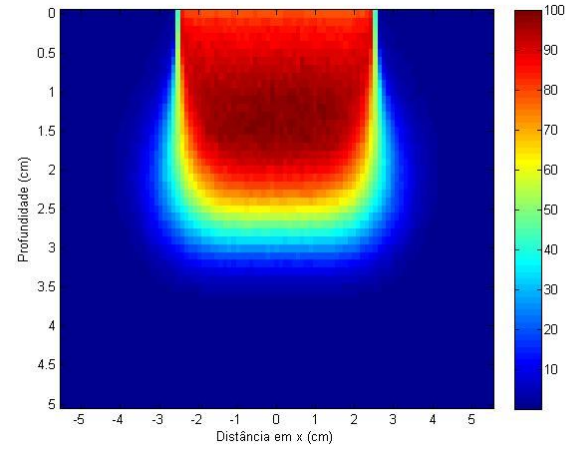

(a)

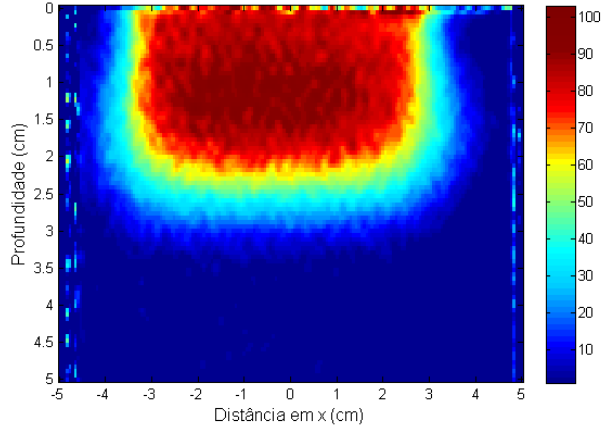

(b)

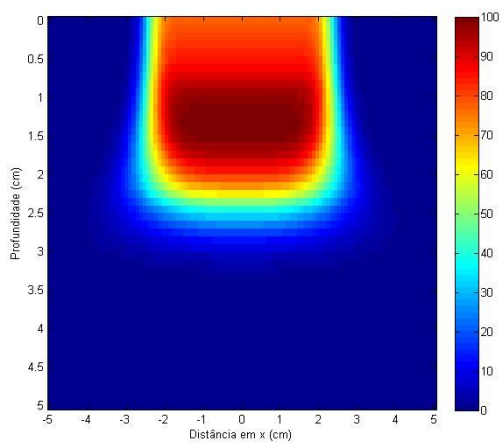

(c)

Figura 44: Distribuição de dose para um campo de $5 \times 5 \mathrm{~cm}^{2}$ para o feixe clínico de elétrons de $6 \mathrm{MeV}$ obtidas com: (a) PENELOPE, (b) MAGIC- $f$ e (c) TPS Eclipse ${ }^{\circledR}$.

Para avaliação das distribuições de dose, para os campos 1 x $1 \mathrm{~cm}^{2}$ e 5 x $5 \mathrm{~cm}^{2}$ obtidas com os métodos dosimétricos, as curvas de PDP foram determinadas e comparadas como mostrado na Figura 45 para o feixe de $6 \mathrm{MeV}$. As figuras 46 e 47 mostram os mesmos dados para os feixes de 9 e $12 \mathrm{MeV}$, respectivamente. 


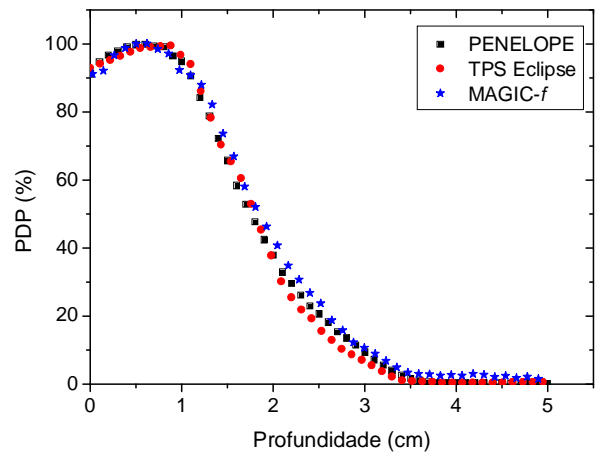

(a)

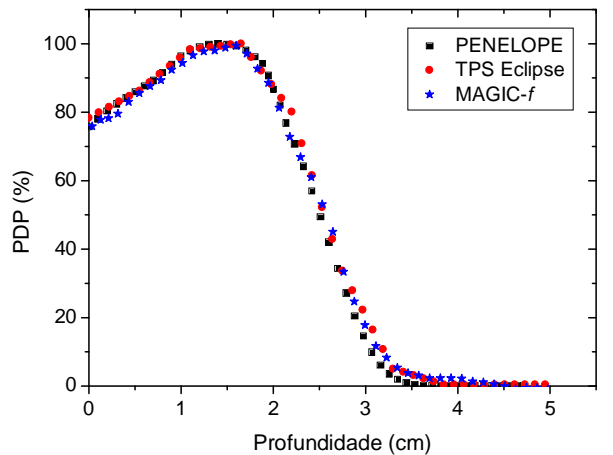

(b)

Figura 45: Curvas de PDP para o feixe clínico de elétrons de $6 \mathrm{MeV}$ obtidas com MAGIC- $f$, PENELOPE e TPS Eclipse ${ }^{\circledR}$ para os campos: (a) $1 \times 1 \mathrm{~cm}^{2}$ e (b) $5 \times 5 \mathrm{~cm}^{2}$.

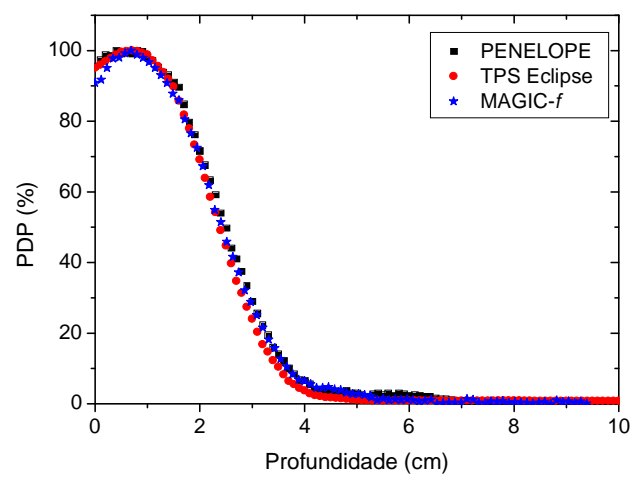

(a)

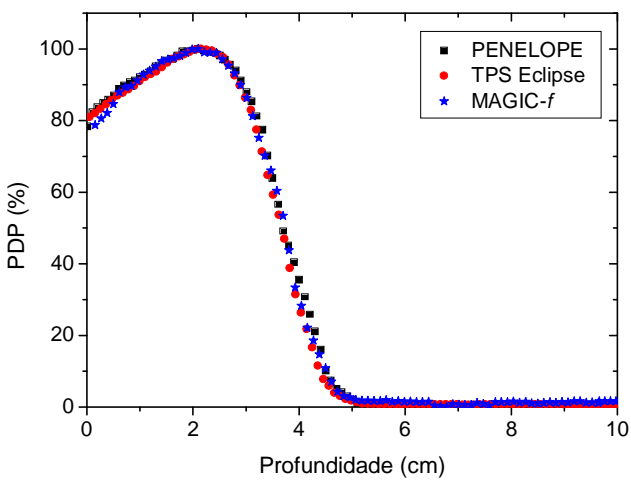

(b)

Figura 46: Curvas de PDP para o feixe clínico de elétrons de $9 \mathrm{MeV}$ obtidas com MAGIC- $f$, PENELOPE e TPS Eclipse ${ }^{\circledR}$ para os campos: (a) $1 \times 1 \mathrm{~cm}^{2}$ e (b) $5 \times 5 \mathrm{~cm}^{2}$. 


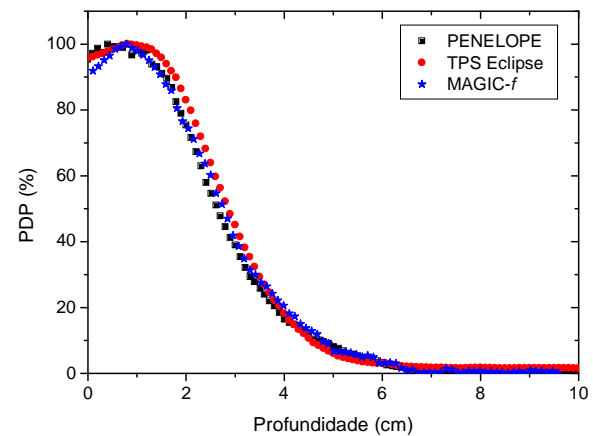

(a)

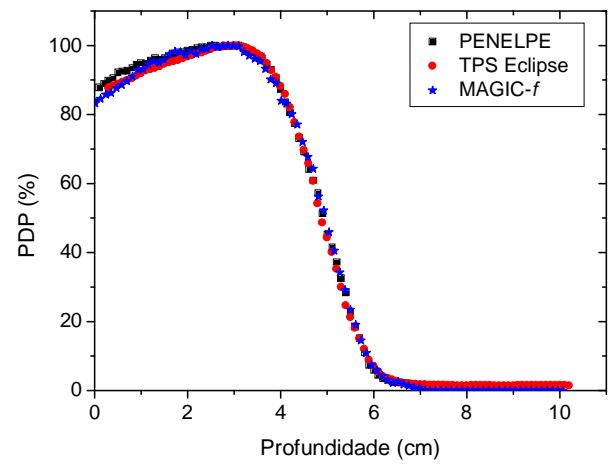

(b)

Figura 47: Curvas de PDP para o feixe clínico de elétrons de $12 \mathrm{MeV}$ obtidas com MAGIC-f, PENELOPE e TPS Eclipse ${ }^{\circledR}$ para os campos: (a) $1 \times 1 \mathrm{~cm}^{2}$ e (b) $5 \times 5 \mathrm{~cm}^{2}$.

Os resultados encontrados para as curvas de PDP e perfil de campo para os campos de 1 x 1 e 5 × $5 \mathrm{~cm}^{2}$ mostram que os métodos dosimétricos utilizadas nesse trabalho reproduzem a forma funcional dos parâmetros dosimétricos e podem ser utilizadas para determina-los, considerando as diferenças encontradas, de aproximadamente 5\%, na entrada da pele.

Parâmetros que caracterizam aos feixes de elétrons em condições de referência como, por exemplo $\mathrm{R}_{50}, \mathrm{~d}_{\max }$ e $\mathrm{R}_{\mathrm{p}}$, também foram determinados para campos pequenos de 1 x 1 $\mathrm{cm}^{2}$ e $5 \times 5 \mathrm{~cm}^{2}$. Além desses parâmetros foram determinadas as doses em profundidade para cada método dosimétrico avaliado. A seguir são mostrados os valores dos parâmetros avaliados para o campo de $1 \times 1 \mathrm{~cm}^{2}$, nas tabelas de 13 a 16, obtidos para as energias de 6, 9 e $12 \mathrm{MeV}$.

Tabela 13: Valores de $\mathrm{R}_{50}$ para o campo de $1 \times 1 \mathrm{~cm}^{2}$.

\begin{tabular}{l|c|c|c}
\multicolumn{1}{c|}{ Energia (MeV) } & \multicolumn{3}{c}{ Valores de $\mathrm{R}_{50}(\mathrm{~cm})$} \\
\hline PENELOPE & 6 & 9 & 12 \\
\hline MAGIC- $f$ & 1,78 & 2,20 & 2,60 \\
\hline TPS- Eclipse & 1,83 & 2,23 & 2,62 \\
\hline
\end{tabular}


Tabela 14: Valores de $\mathrm{d}_{\max }$ para o campo de $1 \times 1 \mathrm{~cm}^{2}$.

\begin{tabular}{l|c|c|c}
\multicolumn{1}{c|}{ Energia (MeV) } & \multicolumn{3}{|c}{ Valores de $\mathrm{d}_{\max }(\mathrm{cm})$} \\
\hline PENELOPE & 6 & 9 & 12 \\
\hline MAGIC-f & 0,65 & 0,67 & 0,71 \\
\hline TPS- Eclipse & 0,64 & 0,66 & 0,70 \\
\hline
\end{tabular}

Tabela 15: Valores de $R_{P}$ para o campo de $1 \times 1 \mathrm{~cm}^{2}$.

\begin{tabular}{l|c|c|c} 
& \multicolumn{3}{c}{ Valores de $\mathrm{R}_{\mathrm{P}}(\mathrm{cm})$} \\
\hline \multicolumn{1}{c|}{ Energia (MeV) } & 6 & 9 & 12 \\
\hline PENELOPE & 3,61 & 3,80 & 3,9 \\
\hline MAGIC- $f$ & 3,74 & 3,75 & 4,1 \\
\hline TPS- Eclipse & 3,57 & 3,78 & 4,0
\end{tabular}

Tabela 16: Valores de dose na superfície para o campo de $1 \times 1 \mathrm{~cm}^{2}$.

\begin{tabular}{l|c|c|c} 
& \multicolumn{3}{|c}{ Valores de dose na superfície (\%) } \\
\hline \multicolumn{1}{c|}{ Energia $(\mathrm{MeV})$} & 6 & 9 & 12 \\
\hline PENELOPE & 91,30 & 97,45 & 98,52 \\
\hline MAGIC- $f$ & 90,13 & 92,67 & 92,12 \\
\hline TPS- Eclipse & 91,50 & 96,35 & 98,02
\end{tabular}

Observando-se os valores obtidos dos parâmetros $\mathrm{R}_{50}, \mathrm{~d}_{\max }$ e $\mathrm{R}_{\mathrm{p}}$, para um campo de 1 x $1 \mathrm{~cm}^{2}$, encontram-se diferenças máximas de $10,9 \%$ entre os valores de $\mathrm{R}_{50}$ do PENELOPE e os dados clínicos (para o feixe de $9 \mathrm{MeV}$ ), de $2,9 \%$ entre os valores de $\mathrm{d}_{\max }$ do MAGIC- $f$ gel e os dados clínicos para o feixe de $15 \mathrm{MeV}$, de 4,8\% entre os valores de $\mathrm{R}_{\mathrm{P}}$ do PENELOPE e os dados clínicos (para o feixe de $6 \mathrm{MeV}$ ), e uma diferença máxima de 6,0\% foi encontrada entre os valores de dose na superfície quando comparados os valores do PENELOPE e os dados clínicos, para $15 \mathrm{MeV}$.

As tabelas 17 a 20 mostram os valores dos parâmetros avaliados para o campo de $5 \times 5 \mathrm{~cm}^{2}$, obtidos para as energias de 6,9 e $12 \mathrm{MeV}$. 
Tabela 17: Valores de $\mathrm{R}_{50}$ das curvas de porcentagem de dose profunda para o campo de $5 \times 5 \mathrm{~cm}^{2}$.

\begin{tabular}{l|c|c|c}
\multicolumn{1}{c|}{} & \multicolumn{3}{c}{ Valores de $\mathrm{R}_{50}(\mathrm{~cm})$} \\
\hline Energia (MeV) & 6 & 9 & 12 \\
\hline PENELOPE & 2,50 & 3,71 & 4,45 \\
\hline MAGIC- $f$ & 2,55 & 3,70 & 4,48 \\
\hline TPS- Eclipse & 2,55 & 3,70 & 4,45
\end{tabular}

Tabela 18: Valores de $\mathrm{d}_{\max }$ das curvas de porcentagem de dose profunda para o campo de $5 \times 5 \mathrm{~cm}^{2}$.

\begin{tabular}{l|c|c|c} 
& \multicolumn{3}{c}{ Valores de $\mathrm{d}_{\max }(\mathrm{cm})$} \\
\hline \multicolumn{1}{c|}{ Energia $(\mathrm{MeV})$} & 6 & \multicolumn{1}{c}{9} & 12 \\
\hline PENELOPE & 1,40 & 2,10 & 2,80 \\
\hline MAGIC- $f$ & 1,39 & 2,09 & 2,79 \\
\hline TPS- Eclipse & 1,40 & 2,09 & 2,80
\end{tabular}

Tabela 19: Valores de $R_{P}$ das curvas de porcentagem de dose profunda para o campo de $5 \times 5 \mathrm{~cm}^{2}$.

\begin{tabular}{l|c|c|c}
\multicolumn{1}{c|}{} & \multicolumn{3}{|c}{ Valores de $\mathrm{R}_{\mathrm{P}}(\mathrm{cm})$} \\
\hline \multicolumn{1}{c|}{ Energia $(\mathrm{MeV})$} & 6 & 9 & 12 \\
\hline PENELOPE & 3,28 & 4,70 & 6,03 \\
\hline MAGIC- $f$ & 3,36 & 4,52 & 6,05 \\
\hline TPS Eclipse & 3,28 & 4,53 & 6,01
\end{tabular}

Tabela 20: Valores de dose na superfície para o campo de $5 \times 5 \mathrm{~cm}^{2}$.

\begin{tabular}{l|c|c|c}
\multicolumn{1}{c|}{} & \multicolumn{3}{|c}{ Valores de dose naperfície (\%) } \\
\hline \multicolumn{1}{c|}{ Energia (MeV) } & 6 & 9 & 12 \\
\hline PENELOPE & 76,8 & 87,0 & 87,0 \\
\hline MAGIC- $f$ & 76,4 & 84,9 & 85,0 \\
\hline TPS Eclipse & 77,0 & 85,0 & 86,0
\end{tabular}

As diferenças entres os parâmetros $R_{50}, d_{\max }$ e $R_{p}$ e da dose em profundidade para o campo de $5 \times 5 \mathrm{~cm}^{2}$ se mostraram mais baixas que daquelas obtidas para o campo de 
$1 \mathrm{x} 1 \mathrm{~cm}^{2}$. Assim, as diferenças máximas encontradas entre os dados clínicos PENELOPE e MAGIC- $f$ gel foram de $2,0 \%, 0,7 \%$ e 2,4\%, relativos aos parâmetros $R_{50}, d_{\max }$ e $R_{p}$ para o feixe de $6 \mathrm{MeV}$, respectivamente. Uma diferença máxima de 1,10\% foi obtida quando comparou-se os valores da dose em profundidade entre os valores do MAGIC- $f$ gel e do PENELOPE, para o feixe de $15 \mathrm{MeV}$.

Comparando os resultados obtidos com os campos de $1 \times 1 \mathrm{~cm}^{2}$ e de referência, 10 x $10 \mathrm{~cm}^{2}$, pode-se observar que os parâmetros $\mathrm{R}_{50}, \mathrm{~d}_{\max }$ e $\mathrm{R}_{\mathrm{p}}$ diminuem em aproximadamente em até $50 \%$, para todas as energias avaliadas

\subsubsection{Campos somados}

Na literatura existem vários trabalhos (KLEIN et al, 2008; ELDIB et al, 2013) que vêm estudando a possibilidade da realização de terapia com intensidade modulada para feixes de elétrons, MERT, semelhante à modalidade de terapia tão comumente empregada para feixes de fótons, IMRT. Nesse tipo de terapia, o campo de irradiação é composto por vários campos menores, que somados irão formar o campo de irradiação desejado. Dessa maneira, é importante que o método dosimétrico, como o dosímetro MAGIC- $f$ gel, tenha resolução espacial e em dose para a avaliação dessa técnica como parte do controle da qualidade.

Inicialmente, o código de simulação Monte Carlo PENELOPE foi utilizado para a determinação das distribuições de dose de cinco campos adjacentes de $5 \times 1 \mathrm{~cm}^{2}$ que somados resultam em um campo final $5 \times 5 \mathrm{~cm}^{2}$ para as energias de 6, $9 \mathrm{e} 12 \mathrm{MeV}$. Essas distribuições de dose dos campos somados foram comparadas com aquelas obtidas para o campo único de $5 \times 5 \mathrm{~cm}^{2}$.

A figura 48 apresenta as distribuições de doses depositadas no objeto simulador, no plano central na direção do feixe de irradiação. Qualitativamente, observa-se as diferenças nas distribuições de dose para o campo $5 \times 5 \mathrm{~cm}^{2}$ e para a soma dos cinco campos $5 \times 1 \mathrm{~cm}^{2}$ para a energia de $6 \mathrm{MeV}$. 


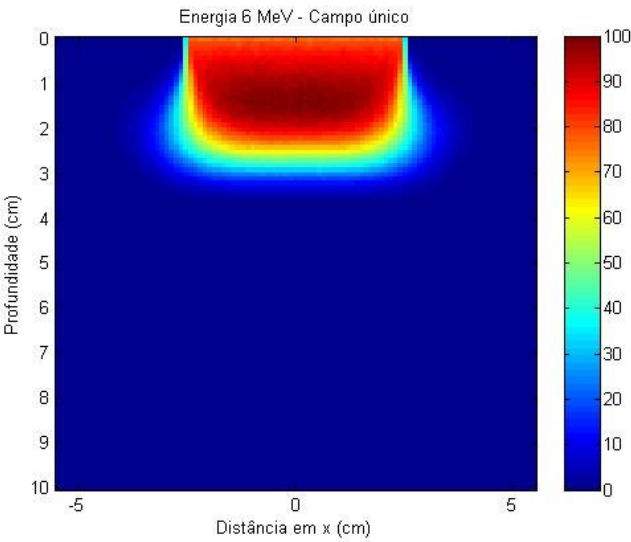

(a)

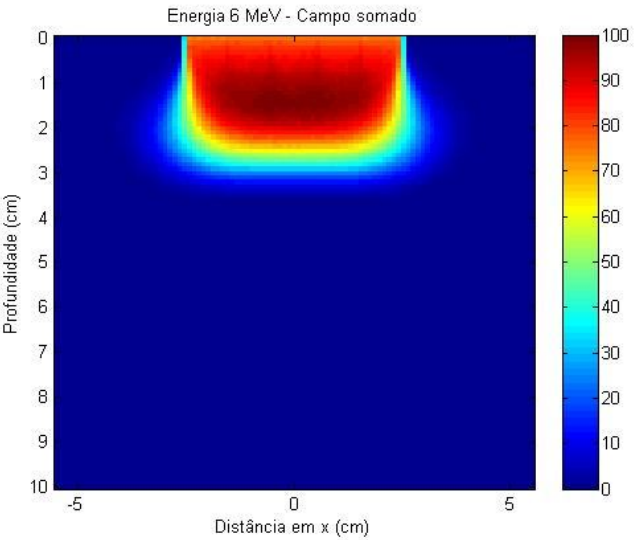

(b)

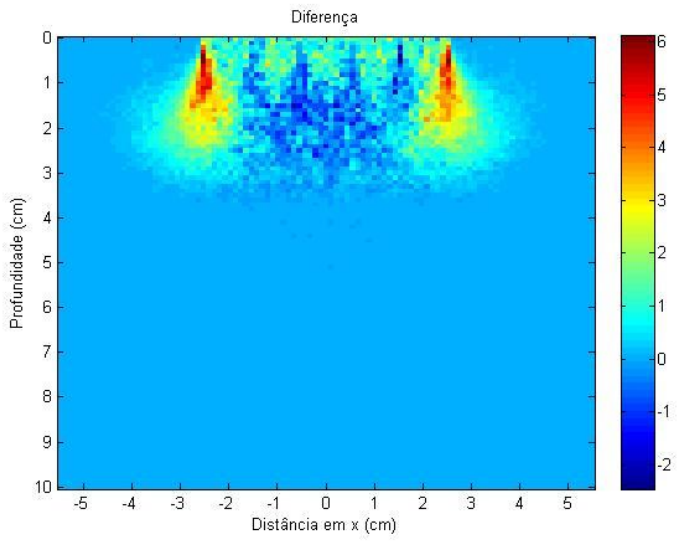

(c)

Figura 48: Distribuições de dose para um feixe clínico de elétrons de $6 \mathrm{MeV}$ obtida utilizando PENELEOPE para um campo $5 \times 5 \mathrm{~cm}^{2}$ irradiados: (a) campo único, (b) soma de campos $5 \times 1 \mathrm{~cm}^{2}$ e (c) subtração das distribuições de dose de (a) e (b).

Para avaliar as diferenças das distribuições de doses em função da geometria de colimação do campo de irradiação foram determinadas curvas de perfil de dose em diferentes profundidades: na entrada do objeto simulador, na profundidade de máxima dose e na profundidade terapêutica. Os resultados são apresentados nas figuras 49, 50 e 51 mostrando os perfis de dose para as energias avaliadas de 6, 9 e $12 \mathrm{MeV}$, respectivamente. 


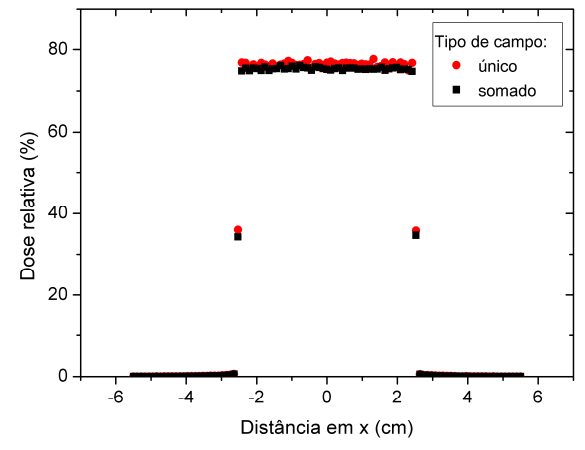

(a)

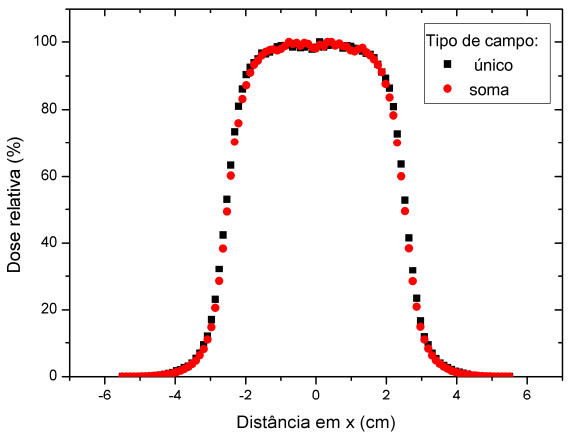

(b)

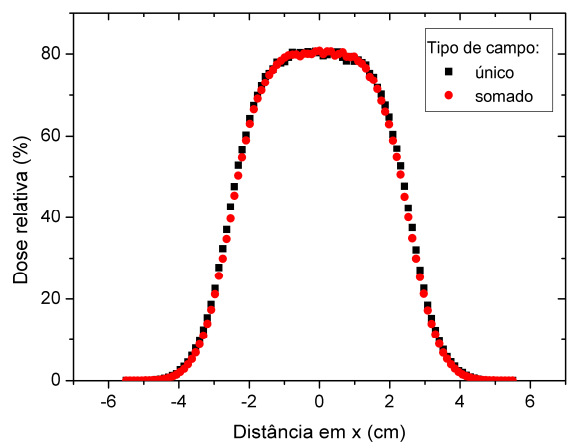

(c)

Figura 49: Perfis de campo obtidos de dados simulados com PENELOPE para um feixe clínico de elétrons de $6 \mathrm{MeV}$ em um campo $5 \times 5 \mathrm{~cm}^{2}$ irradiados com campo único e soma de campos $5 \times 1 \mathrm{~cm}^{2}$ em diferentes profundidades: (a) entrada do objeto simulador, (b) profundidade de máxima dose e (c) profundidade terapêutica.

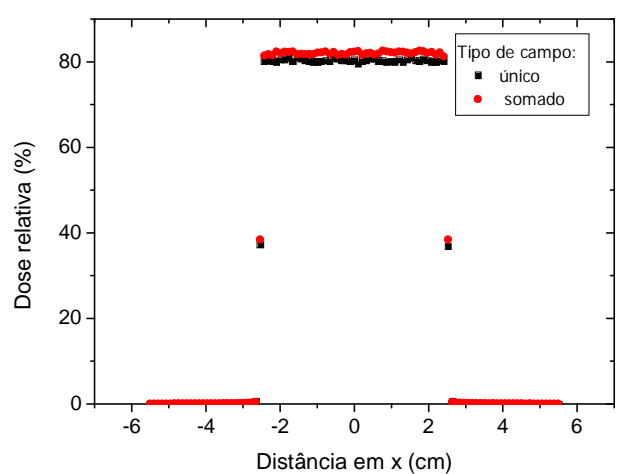

(a)

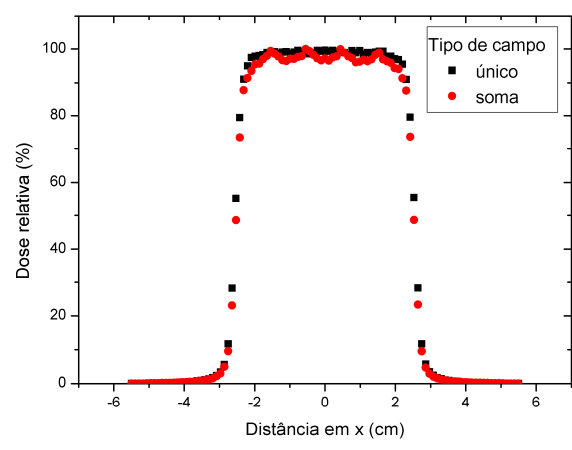

(b)

Figura 50: Perfis de campo obtidos de dados simulados com PENELOPE para um feixe clínico de elétrons de $9 \mathrm{MeV}$ em um campo $5 \times 5 \mathrm{~cm}^{2}$ irradiados com campo único e soma de campos $5 \times 1 \mathrm{~cm}^{2}$ em diferentes profundidades: (a) entrada do objeto simulador, (b) profundidade de máxima dose e (c) profundidade terapêutica, continuação. 


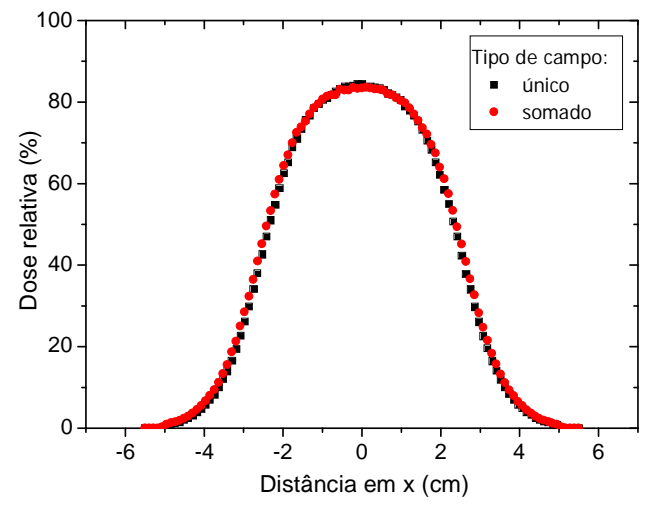

(c)

Figura 50: Perfis de campo obtidos de dados simulados com PENELOPE para um feixe clínico de elétrons de $9 \mathrm{MeV}$ em um campo 5 × $5 \mathrm{~cm}^{2}$ irradiados com campo único e soma de campos $5 \times 1 \mathrm{~cm}^{2}$ em diferentes profundidades: (a) entrada do objeto simulador, (b) profundidade de máxima dose e (c) profundidade terapêutica.

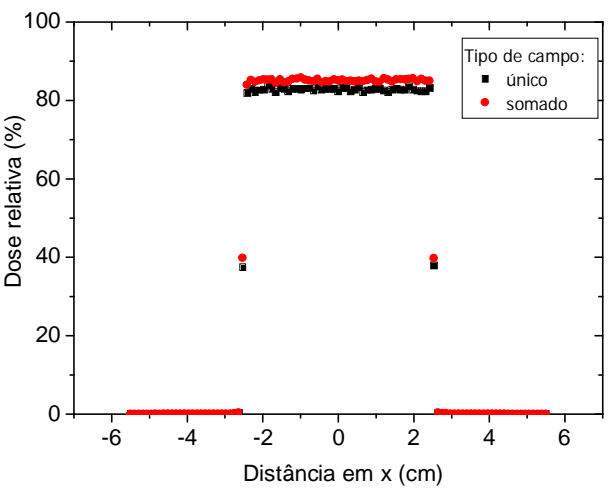

(a)

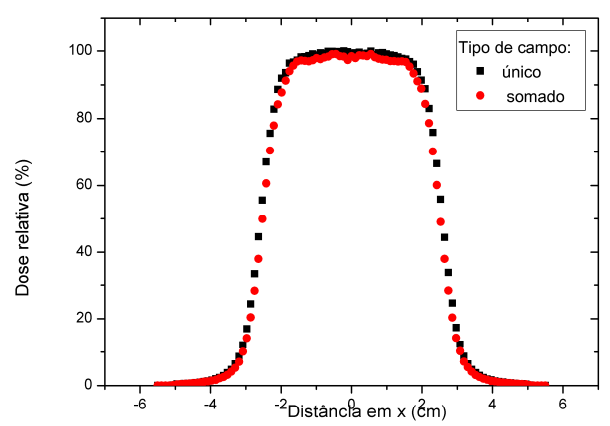

(b)

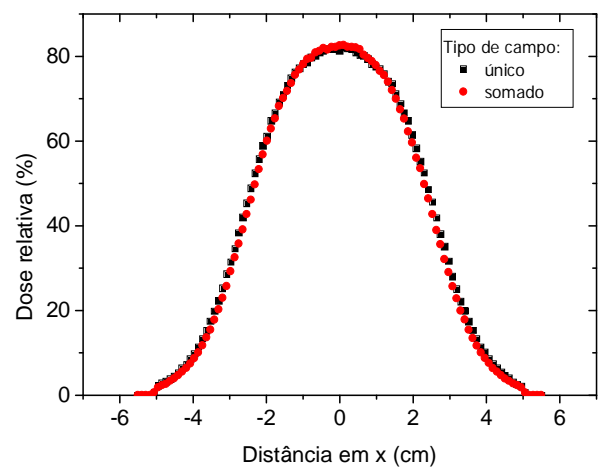

(c)

Figura 51: Perfis de campo obtidos de dados simulados com PENELOPE para um feixe clínico de elétrons de $12 \mathrm{MeV}$ em um campo 5 x $5 \mathrm{~cm}^{2}$ irradiados com campo único e soma de campos $5 \times 1 \mathrm{~cm}^{2}$ em diferentes profundidades: (a) entrada do objeto simulador, (b) profundidade de máxima dose e (c) profundidade terapêutica. 
Comparando todos os perfis de dose, mostradas anteriormente, obteve-se diferenças menores que $3 \%$ nas doses na superfície, quando comparado os valores da irradiação com campo único e campo somado para todas as energias, sendo a maior diferença encontrada para a energia de $12 \mathrm{MeV}$. Para os perfis, na profundidade máxima dose, as diferenças foram menores que $5 \%$ quando comparados os dois tipos de campos, sendo a maior diferença, também, para o feixe de energia mais alta, $12 \mathrm{MeV}$. Entretanto, analisando a não homogeneidade de dose devido ao campo de irradiação somado, para todas as energias, obteve-se uma variação de aproximadamente $8 \%$, sendo a diferença máxima para o feixe de $12 \mathrm{MeV}$.

Analisando, as curvas na profundidade terapêutica, as diferenças entre as formas de irradiação, somado e campo único, apresentam uma diferença de 1,5\% entre as duas formas de determinação do campo total, também para a energia de $12 \mathrm{MeV}$. Observando o comportamento apenas da curva de campos composto, percebe-se que na profundidade terapêutica ela tem o mesmo comportamento da irradiação com campo único, diferente do comportamento encontrado na profundidade de máxima dose.

A partir dos resultados das análises dos perfis obtidos com o código PENELOPE, observa-se que as maiores diferenças são apresentadas nas energias de $12 \mathrm{MeV}$, já que o perfil de dose depende da energia. Consequentemente ao somar campos para compor com um campo somado, as junções dos campos "pequenos" resulta em pontos "quentes" que são mais pronunciados para altas energias.

Dessa forma, para avaliar se o dosímetro MAGIC- $f$ gel tem resolução espacial e em dose para determinar diferenças entre $m$ distribuições de dose para um irradiação de campo somado e único, determinou-se as distribuições semelhantes às simuladas, para o feixe de $6 \mathrm{MeV}$, como mostrada na figura 52. Os perfis de dose nas mesmas profundidades: (a) na entrada do objeto simulador, (b) na profundidade de máxima dose e (c) na profundidade terapêutica, também foram determinados utilizando TPS Eclipse ${ }^{\circledR}$, como apresentado na figura 53. 


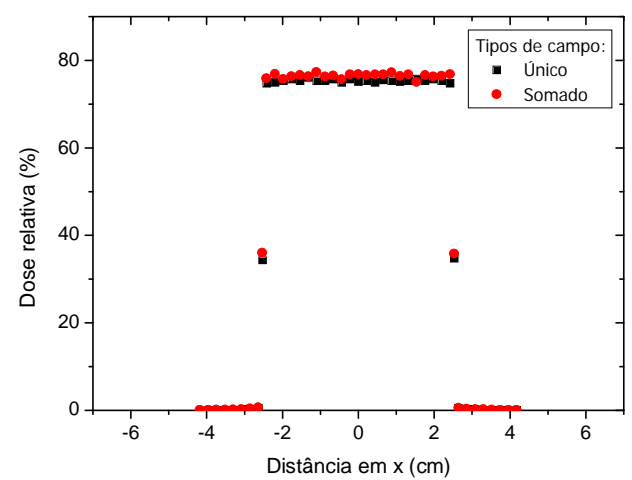

(a)

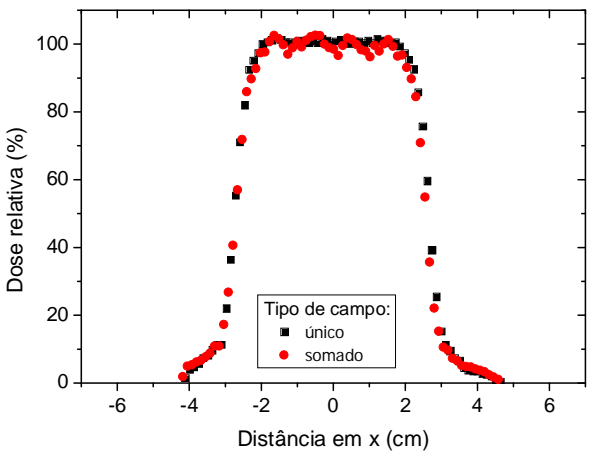

(b)

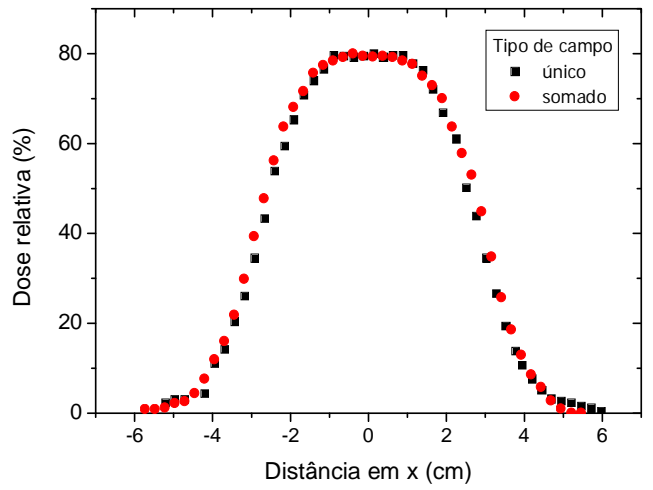

(c)

Figura 52: Perfis de campo obtidos de dados simulados com MAGIC- $f$ para um feixe clínico de elétrons de $6 \mathrm{MeV}$ em um campo 5 x $5 \mathrm{~cm}^{2}$ irradiados com campo único e soma de campos $5 \mathrm{x} 1 \mathrm{~cm}^{2}$ em diferentes profundidades: (a) superfície, (b) profundidade de máxima dose e (c) profundidade terapêutica.

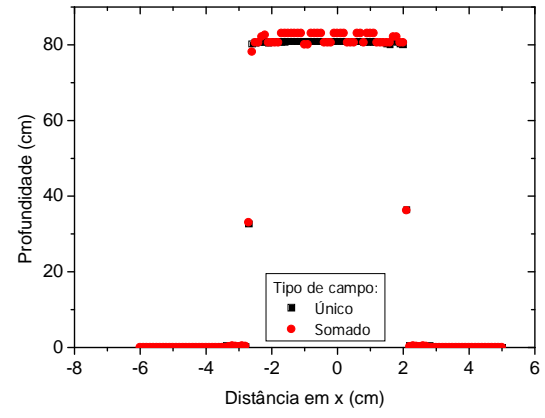

(a)

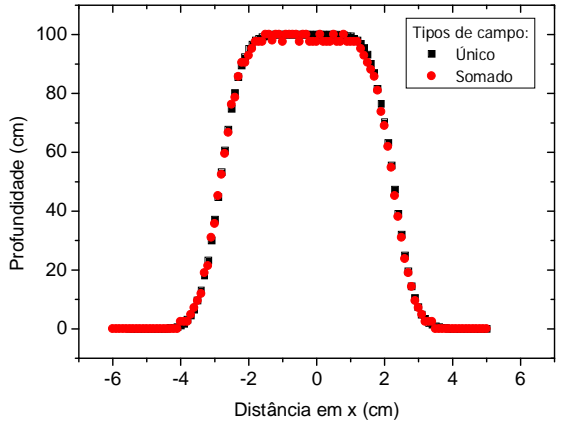

(b)

Figura 53: Perfis de campo obtidos de dados simulados com Eclipse ${ }^{\circledR}$ para um feixe clínico de elétrons de $6 \mathrm{MeV}$ em um campo $5 \times 5 \mathrm{~cm}^{2}$ irradiados com campo único e soma de campos $5 \mathrm{x} 1 \mathrm{~cm}^{2}$ em diferentes profundidades: (a) superfície, (b) profundidade de máxima dose e (c) profundidade terapêutica, continuação. 


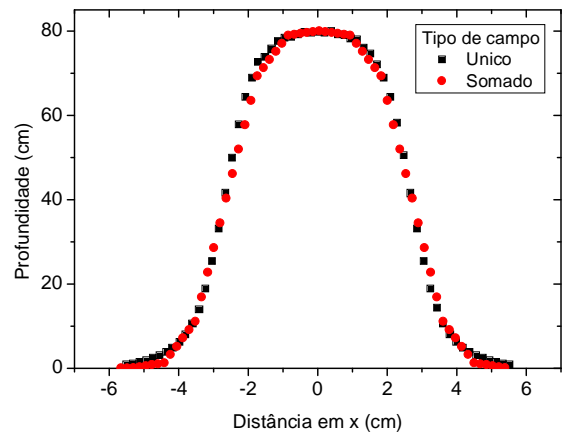

(c)

Figura 53: Perfis de campo obtidos de dados simulados com Eclipse ${ }^{\circledR}$ para um feixe clínico de elétrons de $6 \mathrm{MeV}$ em um campo 5 x $5 \mathrm{~cm}^{2}$ irradiados com campo único e soma de campos $5 \mathrm{x} 1 \mathrm{~cm}^{2}$ em diferentes profundidades: (a) superfície, (b) profundidade de máxima dose e (c) profundidade terapêutica.

Das comparações realizadas entre os perfis de dose, obtidos com o dosímetro MAGIC- $f$ gel, determinaram-se diferenças máximas de 4,5\%, 7,3\% e 1,7\%, relativos aos perfis determinados na superfície, profundidade máxima e profundidade terapêutica, respectivamente.

Para as comparações dos perfis de dose, obtidos com o TPS, obteve-se diferenças máximas de $2,3 \%, 4,9 \%$ e $1,0 \%$, relativos aos perfis determinados na superfície, profundidade máxima e profundidade terapêutica, respectivamente.

De acordo com os resultados obtidos com o código de simulação PENELOPE, MAGIC- $f$ gel e o TPS Eclipse ${ }^{\circledR}$ observa-se que, para a energia de $6 \mathrm{MeV}$, as doses em porcentagem na superfície e na profundidade de máxima dose, as diferenças nas curvas dos perfis de dose para ambas as configurações apresentam diferenças altas. Entretanto, na profundidade em que é realizado o tratamento a diferença é considerada razoável, diferença menor que $1 \%$. Dessa forma, uma composição de campos não alteraria o resultado esperado para distribuição de dose no volume irradiado. Para feixes de elétrons, entretanto, a dose na superfície é relevante, pois é depositado em torno de $90 \%$ da dose máxima nessa região. Assim, considerando a pele como um órgão de risco em tratamento com elétrons, para aplicações com MERT, por exemplo, seria necessário um controle da qualidade dos tratamentos para avaliação dessas diferenças de deposição de dose. 


\subsubsection{Campos adjacentes}

O posicionamento de campos adjacentes de feixes de elétrons para irradiação é complexo devido ao espalhamento apresentado por esse tipo de partícula. Esse espalhamento causa uma característica única na forma funcional da curva de isodose, isto é, o abaulamento nas curvas de isodose apresentado para feixes de elétrons em doses baixas. Dessa forma, devido às restrições apresentadas para as doses altas ou pontos quentes e a necessidade de uma irradiação homogênea dentro do volume alvo, é difícil encontrar a região de junção na qual não irá produzir níveis altos ou baixos de dose sem a utilização de filtros modificadores. Irradiação com junções de campos é muito comum em tratamentos para micose fungóide, pois, na maioria das vezes, devido a extensão do tumor é necessário mais de um campo de irradiação (NAVI et al, 2011; LLOYD et al, 2013; HINDS et al, 2013).

Dessa forma, uma composição com dois campos adjacente foi utilizada para avaliar as possibilidades da utilização dos métodos dosimétricos, PENELOPE e MAGIC- $f$, em determinar a distribuição de dose em casos de tratamentos que necessitem de espaços entre os campos de irradiação. Primeiramente, o planejamento com TPS Eclipse ${ }^{\circledR}$ foi feito para um feixe clínico de elétrons de $6 \mathrm{MeV}$, com dois campos de irradiação adjacentes de $5 \times 5 \mathrm{~cm}^{2}$ e espaçamento de $1,2 \mathrm{~cm}$. Nas mesmas condições e geometria do planejamento foi realizada a simulação com o código PENELOPE e os procedimentos experimentais com o dosímetro MAGIC- $f$ gel, como mostrado na figura 54 .

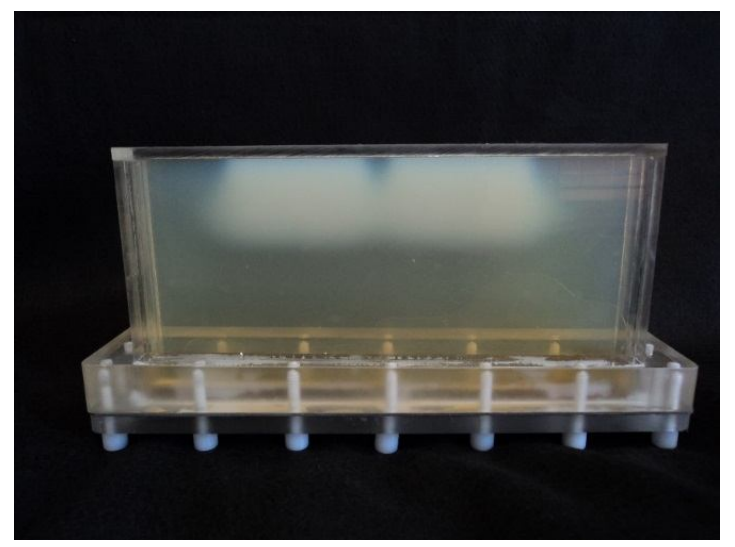

Figura 54: MAGIC- $f$ irradiado com um feixe clínico de elétrons de $6 \mathrm{MeV}$ para avaliação das distribuições de dose para tratamentos que necessitem de espaço entre campos de irradiação. 
As distribuições de dose para dois campos adjacentes obtidas com o código PENELOPE, MAGIC- $f$ e TPS Eclipse ${ }^{\circledR}$ foram analisadas em um programa desenvolvido na plataforma Matlab $^{\circledR}$. As distribuições de doses obtidas no plano central dos volumes irradiados são mostradas na figura 55 .

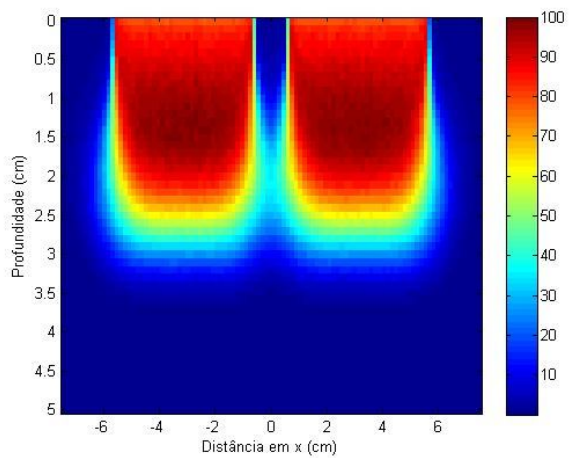

(a)

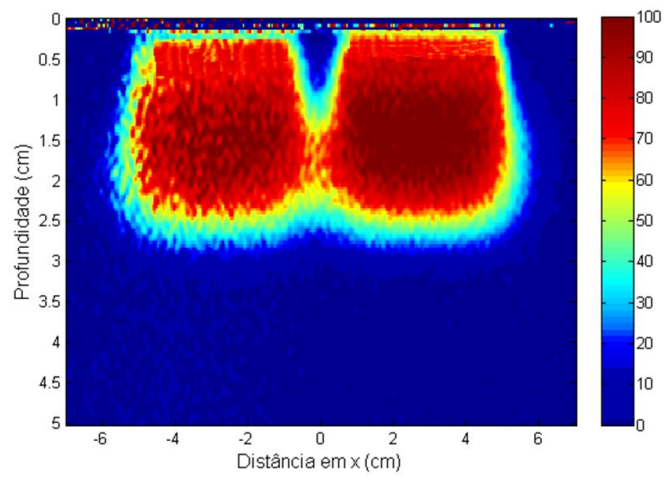

(b)

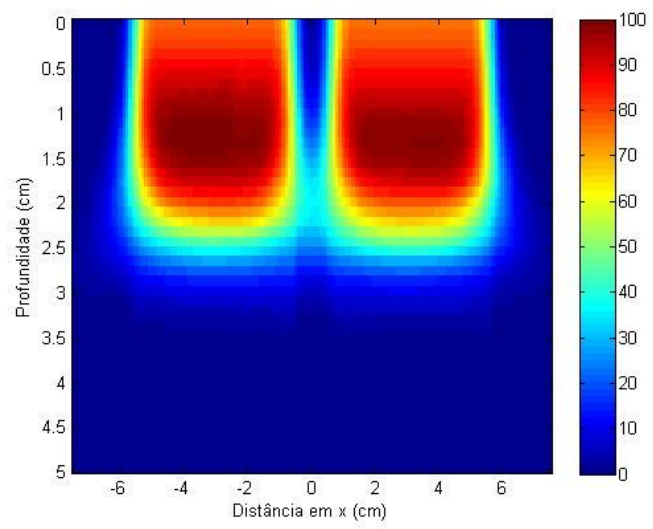

(c)

Figura 55: Distribuições de dose para dois campos adjacentes irradiados em um feixe clínico de elétrons de $6 \mathrm{MeV}$ obtidas com: (a) PENELOPE, (b)MAGIC- $f$ e (c) TPS Eclipse $^{\circledR}$.

Para avaliação das distribuiç̧ões de dose obtidas com os métodos dosimétricos foram comparadas as curvas de perfil de campo na profundidade de máxima dose, como mostrado na figura 56. 


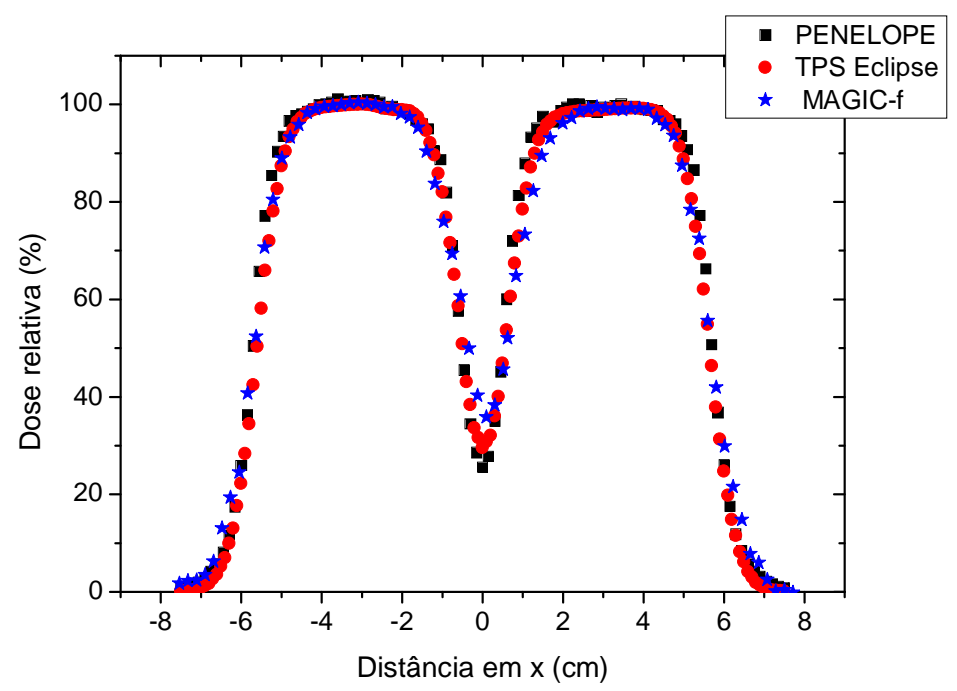

Figura 56:Perfil de campo da irradiação adjacentes de dois campos obtidas utilizando PENELOPE, MAGIC- $f$ e TPS Eclipse ${ }^{\circledR}$, para o feixe clínico de elétrons de $6 \mathrm{MeV}$ na profundidades de máxima dose.

Como mostrado na figura 56, as três curvas do perfil de campo mostram um comportamento semelhante. Comparando-se as curvas, obteve-se uma diferença percentual máxima de 3,58\% quando comparado os valores de dose relativa entre o código PENELOPE e o TPS Eclipse ${ }^{\circledR}$, para valores de dose até $20 \%$. Para valores de dose acima dos $20 \%$, a diferença máxima percentual foi de $5,13 \%$ na junção entre os dois campos, quando comparado os valores do MAGIC- $f$ gel com os valores do PENELOPE.

A diferença entre as junções dos campos, para o feixe de $6 \mathrm{MeV}$, ocorre justamente na região de baixa dose onde o abaulamento, característico de feixe elétrons, se forma aumentando a dose nessa região.

\subsection{Verificação de tratamentos com MAGIC- $f$ gel}

Nesta seção são apresentados os resultados referentes ao objetivo principal desse projeto de pesquisa, a utilização de dosimetria gel polimérica e simulação Monte Carlo para determinação de distribuições de doses de tratamentos clínicos utilizando feixe de elétrons. Assim, foram simulados casos clínicos de um linfoma conjuntival, um caso de doença subclínica de linfonodos e, por último, um caso de cabeça e pescoço tratado com uma combinação de feixe de elétrons e fótons. 


\subsubsection{Linfoma conjuntival}

Linfomas conjuntivais, em estágio inicial, são comumente tratados com radioterapia com feixes de elétrons. Nesse tipo de tratamento necessita-se de campos de irradiação pequenos e colimados considerando que o volume alvo está próximo a regiões muito radiossensíveis como retina e glândulas lacrimais. Devido a necessidade de campos pequenos, os sistemas de planejamento convencionais utilizados nos serviços de radioterapia apresentam dificuldade em calcular a dose depositada com precisão, dessa maneira é importante uma metodologia que seja capaz de avaliar a dose depositada nessas configurações.

Trabalhos da literatura, como o proposto por trabalho de Brualla e colaboradores compararam as doses absorvidas determinadas com o código de simulação Monte Carlo PENELOPE e dados experimentais obtidos para feixes de irradiação em tratamentos típicos de linfoma conjuntival, chegando ao resultado que o código de simulação permite a determinação dos mapas de doses absorvidas para esse tipo de aplicação (BRUALLA et al, 2009).

No intuito de testar o dosímetro MAGIC- $f$ gel um objeto simulador foi irradiado com o colimador construído para esse tratamento como apresentado na seção 3.8.1. A figura 57 mostra o objeto simulador depois de irradiado.

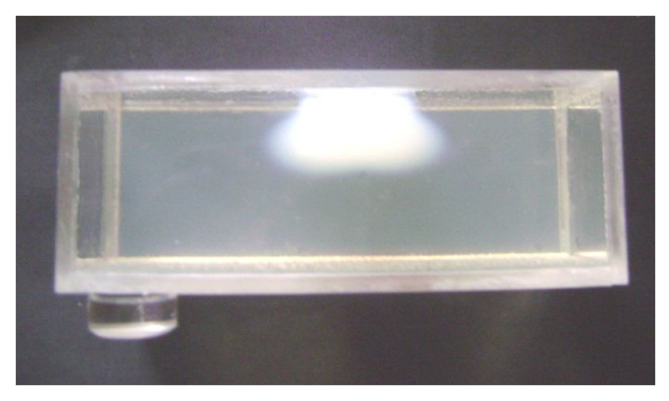

(a)

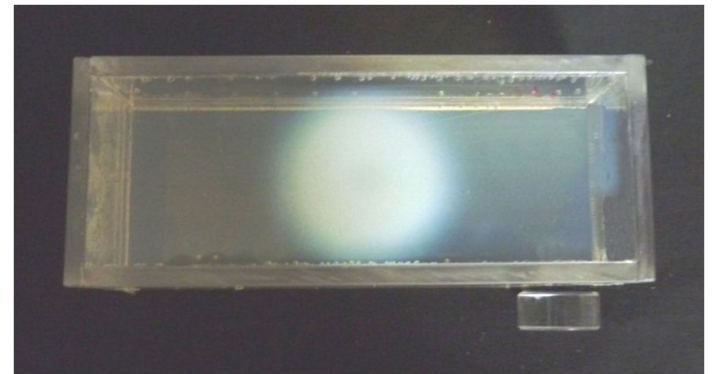

(b)

Figura 57: MAGIC- $f$ irradiado simulando um tratamento de linfoma conjuntival, com visualização: (a) lateral (b) superior.

Os dados de simulação Monte Carlo PENELOPE não são apresentados, pois os dados da literatura forma feitos com o código PENELOPE por Brualla e colaboradores (BRUALLA et al, 2009). Assim, as doses depositadas no objeto simulador foram comparadas com os dados da literatura através da determinação do perfil do campo. A 
figura 58 mostra o perfil de campo obtido para a simulação de tratamento de linfoma conjuntival utilizando os colimadores de cerrobend.

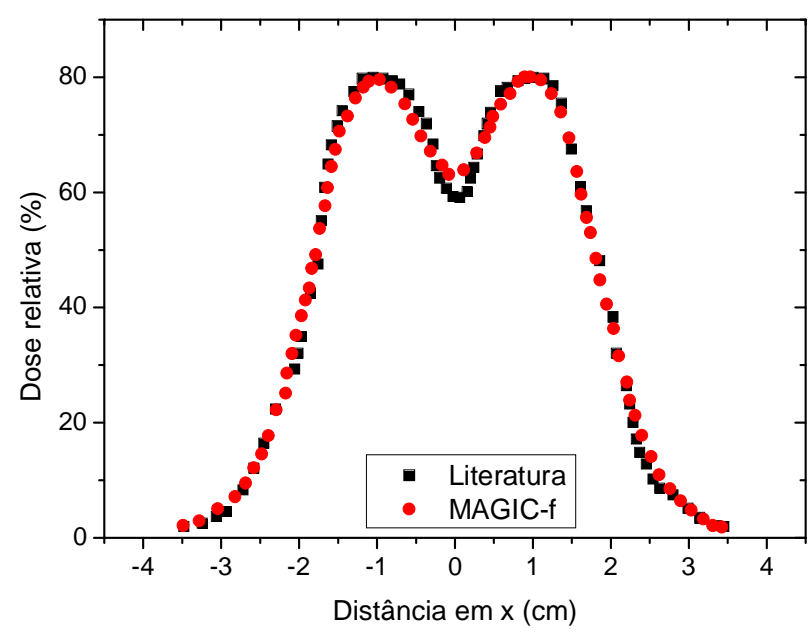

Figura 58: Perfis de campo de um tratamento de linfoma conjuntival irradiado com colimador central de cerrobend.

Como mostrado na figura 58, o perfil de campo obtido com MAGIC- $f$ mostra um comportamento similar aquele mostrado por Brualla e colaboradores. Assim, comparando os dados da literatura com os dados obtidos com MAGIC- $f$, uma diferença máxima de $5,85 \%$ foi encontrada no centro do campo de irradiação, quando utilizado a colimação de cerrobend para um linfoma conjuntival. Com a figura 58, também, pode- se observar que o aplicador posicionado no centro do campo de radiação pode, realmente, proteger a córnea, pois reduz a dose depositada em 40\%. Assim, esse resultado mostra que o dosímetro polimérico gel pode ser usado como uma ferramenta complementar para o controle de qualidade desse tipo de tratamento.

\subsubsection{Doença subclínica de linfonodos}

Feixes de elétrons podem ser usados para tratar doenças subclínicas, possibilitando, por exemplo, que tratamentos cirúrgicos sejam menos agressivos, pois a cirurgia retira o volume tumoral macroscópico e a doença microscopia pode ser tratada com radioterapia com feixes de elétrons. Por exemplo, em câncer de mama, as regiões da axila podem ser tratadas com feixes de elétrons, assim como os linfonodos cervicais por estarem próximos a medula espiral e linfonodos da cavidade oral (SARADA et al, 1997; WI et al, 2008). 
Para avaliar a utilização do dosímetro MAGIC- $f$ na determinação da distribuição de dose para feixes de elétrons, o tratamento para uma doença subclínica de linfoma tratada com feixe de $6 \mathrm{MeV}$, com campo de 6 × $6 \mathrm{~cm}^{2}$ e planejando a uma profundidade de 2,0 $\mathrm{cm}$ foi reproduzido em um objeto simulador.

O planejamento feito com TPS Eclipse ${ }^{\circledR}$ foi reproduzido na simulação com o código PENELOPE e experimentalmente com MAGIC- $f$ e as distribuições de dose, para o plano central paralelo ao feixe de irradiação, obtidas com os métodos dosimétricos são apresentadas na figura 59 .

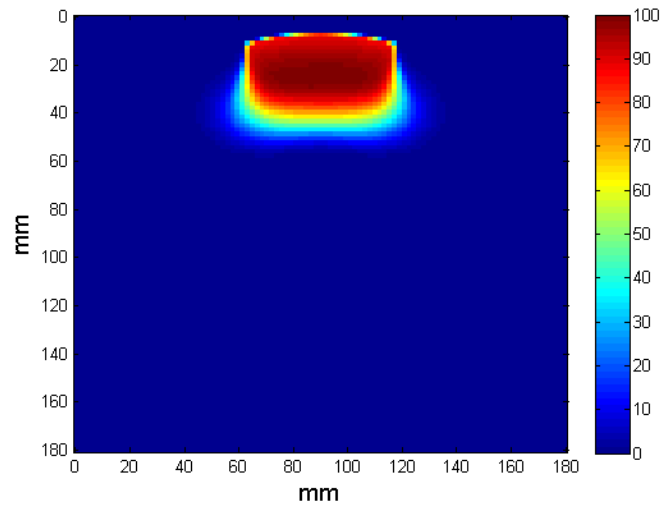

(a)

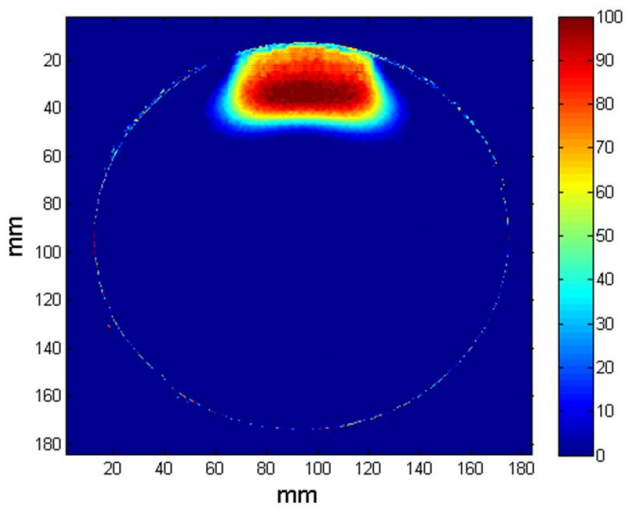

(b)

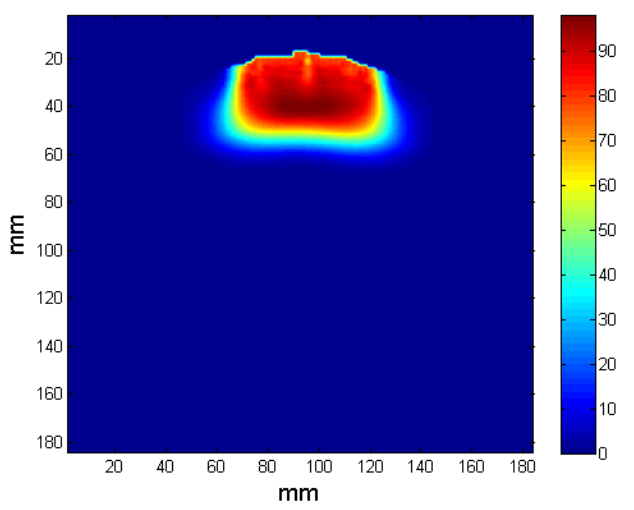

(c)

Figura 59: Distribuição de dose do plano central para campo único para o feixe clínico de elétrons de $6 \mathrm{MeV}$ obtidas com: (a) PENELOPE, (b) MAGIC- $f$ e (c) TPS Eclipse ${ }^{\circledR}$.

Para avaliar as distribuições de dose obtidas com os métodos dosimétricos foram determinados mapas de índice $\gamma$ com os seguintes parâmetros: 3\% de DD e 3 mm DTA, 
valores esse estabelecidos pela literatura (ALI et al, 2011). Os resultados da análise são mostrados na figura 60.

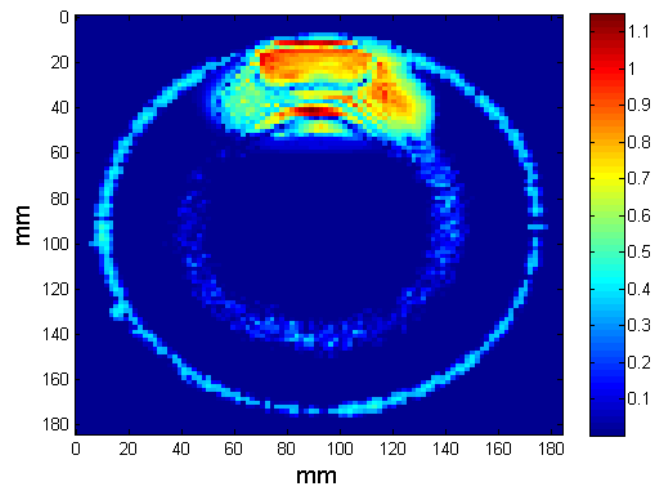

(a)

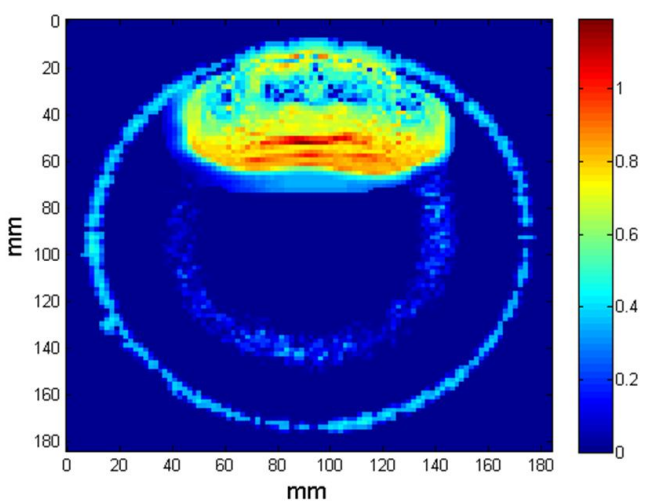

(b)

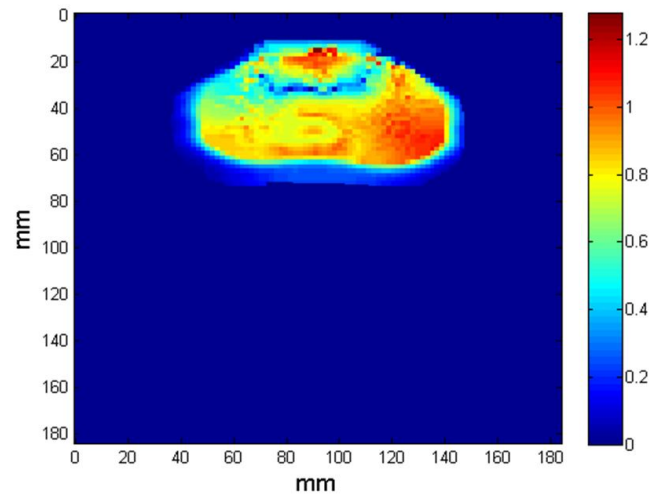

(c)

Figura 60: Mapas de índice $\gamma$ comparando as distribuições de dose obtidas com (a) PENELOPE e MAGIC- $f$, (b) TPS Eclipse ${ }^{\circledR}$ e MAGIC- $f$, (c) TPS Eclipse ${ }^{\circledR}$ e PENELOPE, para os critérios $3 \%$ de DD e $3 \mathrm{~mm}$ de DTA, para um feixe clínico de elétrons de $6 \mathrm{MeV}$.

Na avalição do índice $\gamma$ com os parâmetros de 3\% de DD e 3 mm de DTA, utilizada na comparação das distribuições obtidas com PENELOPE e MAGIC- $f$, mostrou que 97,5\% do pixels apresentaram valores menores que 1, passando pelo teste; em outras palavras, ambos os planos de dose obtidos pelos métodos dosimétricos são similares, relativos aos parâmetros de análise. A comparação entre as distribuições de dose obtidas com TPS Eclipse ${ }^{\circledR}$ e MAGIC- $f$ mostraram que 97,0\% dos pixels apresentaram valores menores que 1, passando pelo teste. Já na comparação entre TPS Eclipse ${ }^{\circledR}$ e PENELOPE $98,2 \%$ dos pixels obtiveram valores menores que 1 . 
Por meio das comparações das distribuições de dose avaliadas pode-se concluir que o dosímetro MAGIC- $f$ gel teve uma resposta adequada quando comparado com os outros métodos para determinação de dose para feixes de elétrons, que representaria um caso real para um tratamento com este tipo de feixe, simulando um dos contornos do corpo humano.

\subsubsection{Cabeça e pescoço}

Alguns tipos de tumores podem ser tratados com combinações de feixes de elétrons e fótons, por exemplo tumores de cabeça e pescoço, tumores de glândulas salivares, entre outros (STEEL et al, 2009; SHIAU et al, 2011).

Para avaliar a utilização do dosímetro MAGIC- $f$ na determinação da distribuição de dose de tratamentos clínicos, a simulação de um tratamento de cabeça e pescoço foi simulado em um objeto simulador de cabeça. Para esse tratamento foram utilizados dois feixes de irradiação: dois feixes de fótons de $6 \mathrm{MV}$ com o campo de $11 \times 7 \mathrm{~cm}^{2}$ e dois feixe de elétrons de $9 \mathrm{MeV}$ para um campo de $6 \times 6 \mathrm{~cm}^{2}$, ambos paralelos e opostos.

O planejamento feito com TPS Eclipse ${ }^{\circledR}$ foi reproduzido na simulação com o código PENELOPE e experimentalmente com MAGIC- $f$. As distribuições de dose obtidas no plano central são apresentadas na figura 61.

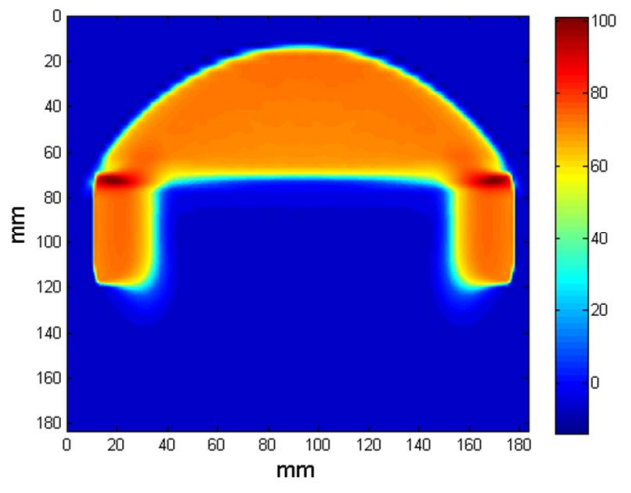

(a)

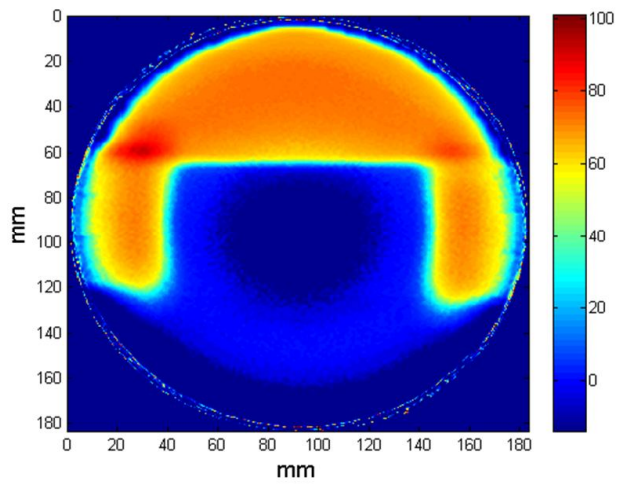

(b)

Figura 61: Distribuição de dose do plano central para um tratamento de cabeça e pescoço irradiado com uma combinação de feixes clínicos, dois feixes de elétrons de $9 \mathrm{MeV}$ e dois feixes de fótons de $6 \mathrm{MV}$ ambos paralelos e opostos, obtidas com: (a) PENELOPE, (b) MAGIC- $f$ e (c) TPS Eclipse ${ }^{\circledR}$, continuação. 


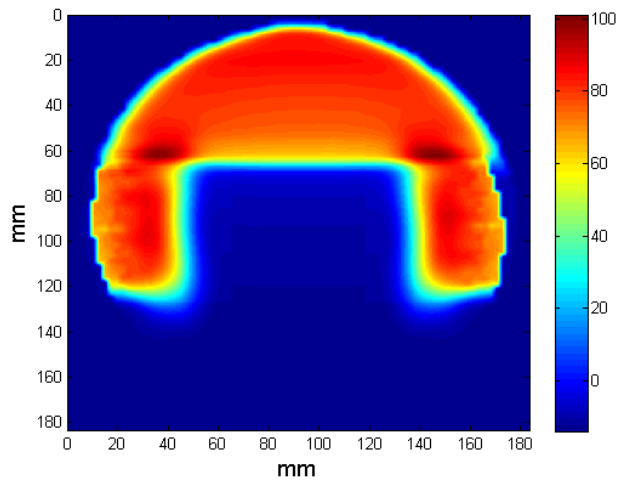

(c)

Figura 61: Distribuição de dose do plano central para um tratamento de cabeça e pescoço irradiado com uma combinação de feixes clínicos, dois feixes de elétrons de $9 \mathrm{MeV}$ e dois feixes de fótons de $6 \mathrm{MV}$ ambos paralelos e opostos, obtidas com: (a) PENELOPE, (b) MAGIC- $f$ e (c) TPS Eclipse ${ }^{\circledR}$.

Para avaliar as distribuições de dose obtidas determinaram-se os mapas de índice $\gamma$ com os parâmetros: $3 \%$ de DD e 3 mm de DTA. Os resultados da análise são mostrados na figura 62.

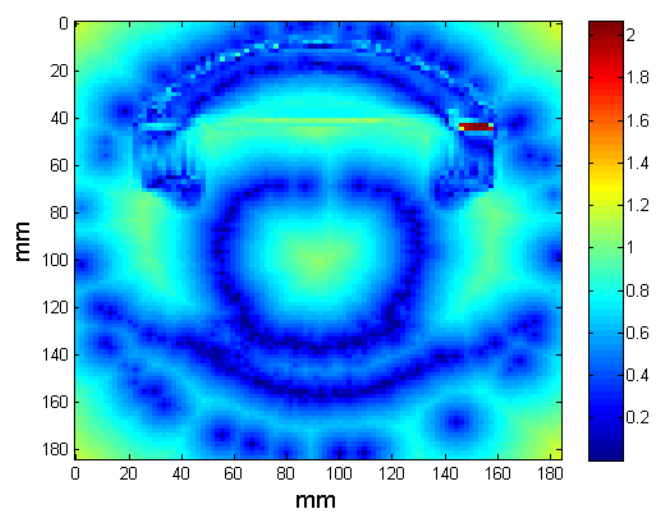

(a)

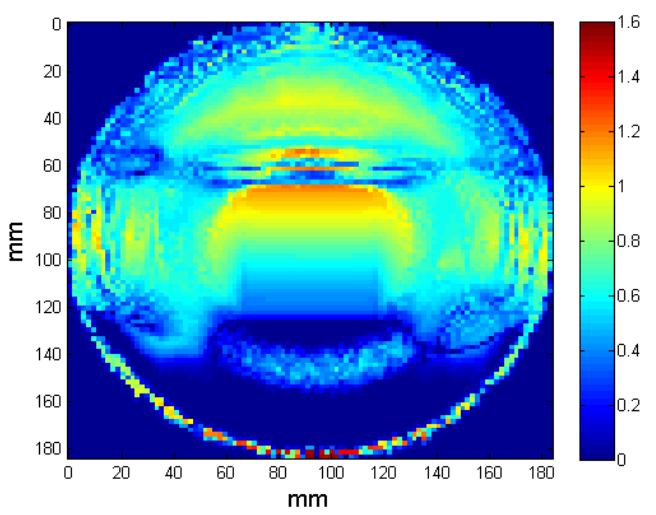

(b)

Figura 62: Mapas de índice $\gamma$ comparando as distribuições de dose obtidas com (a) PENELOPE e MAGIC- $f$, (b)TPS Eclipse ${ }^{\circledR}$ e MAGIC- $f$ (c) TPS Eclipse ${ }^{\circledR}$ e PENELOPE, critérios 3\% de DD e $3 \mathrm{~mm}$ de DTA e, para um tratamento de cabeça e pescoço irradiado com feixes clínicos de elétrons de $9 \mathrm{MeV}$ e de fótons de $6 \mathrm{MV}$, continuação. 


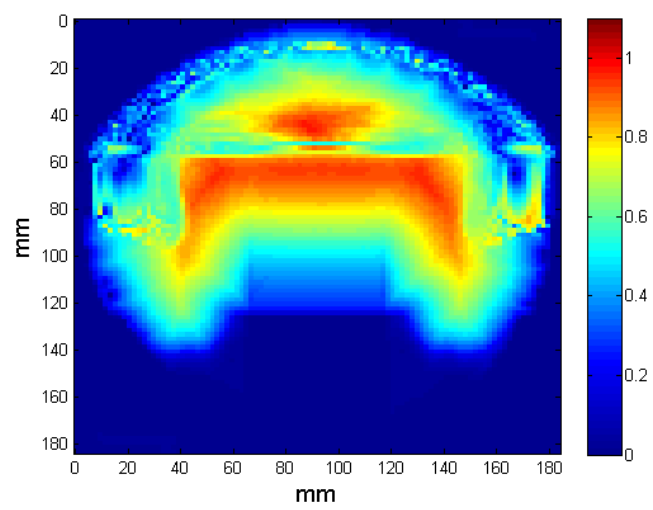

(c)

Figura 62: Mapas de índice $\gamma$ comparando as distribuições de dose obtidas com (a) PENELOPE e MAGIC- $f$, (b)TPS Eclipse ${ }^{\circledR}$ e MAGIC- $f$ (c) TPS Eclipse ${ }^{\circledR}$ e PENELOPE, critérios 3\% de DD e $3 \mathrm{~mm}$ de DTA e, para um tratamento de cabeça e pescoço irradiado com feixes clínicos de elétrons de $9 \mathrm{MeV}$ e de fótons de $6 \mathrm{MV}$.

Como mostrado na 62, a avalição do índice $\gamma$ com os parâmetros de $3 \%$ de DD e $3 \mathrm{~mm}$ de DTA, para a comparação entre distribuições de dose obtidas com o código PENELOPE e o dosímetro MAGIC- $f$ mostrou que $98,3 \%$ do pixels apresentaram valores menores que 1, passando no teste. Na comparação das distribuições de dose obtidas com TPS Eclipse ${ }^{\circledR}$ e MAGIC- $f$, 94,2\% dos pixels apresentaram valores menores que 1, passando pelo teste, e comparando os dados obtidos entre o TPS Eclipse ${ }^{\circledR}$ e o PENELOPE, 96,8\% dos pixels obtiveram valores menores que 1, no plano todo.

Dos dados apresentados utilizando a técnica de comparação do índice $\gamma$, os métodos dosimétricos utilizados mostram respostas adequadas, da mesma forma que foi apresentada para o caso simulado de doença subclínica de linfonodos. Em ambos os casos, pode-se ressaltar a importância de utilização do dosímetro MAGIC- $f$ para as determinações experimentais de distribuições de dose para casos clínicos que utilizam feixes de elétrons, pois esta prática não é realizada nos serviços de radioterapia. Além disso, este dosímetro pode auxiliar e nesta em outras aplicações dosimétricas devido as suas características de resposta em dose e alta resolução espacial, tanto em duas dimensões como em três dimensões. 


\section{CONCLUSÕES}

Nesse trabalho foi avaliada a aplicação do dosímetro gel polimérico MAGIC- $f$ com leitura por ressonância magnética para o controle da qualidade em radioterapia com feixe de elétrons.

Os parâmetros dosimétricos (curva de porcentagem de dose em profundidade e perfil de campo) obtidos em condições de referência com o MAGIC- $f$, dados clínicos e aqueles obtidos por simulação com o código de PENELOPE mostraram-se similares. Dessa forma, validou-se a utilização do MAGIC- $f$ para realização de medidas dosimétricas, como parte de um controle da qualidade para feixes de elétrons.

As distribuições de dose em aplicações de feixes de elétrons, em condições de irradiação com campos pequenos, somados e adjacentes, obtidas com os métodos dosimétricos utilizados, também apresentaram valores aproximados dentro de 5,0\%, mostrando que o dosímetro MAGIC- $f$, pode ser utilizado para avaliação de distribuições de dose em condições de irradiação diferentes daquelas utilizadas atualmente nas rotinas dos serviços de Radioterapia para esse tipo de feixe.

Distribuições de doses em algumas aplicações de tratamentos com feixes de elétrons foram simuladas e planejadas utilizando-se objetos simuladores e analisadas utilizandose o índice gama com critérios de $3 \%$ de DD e $3 \mathrm{~mm}$ de DTA sendo que as concordâncias encontradas foram maiores que $94 \%$. Os resultados da análise das distribuições de dose através dos mapas de índices gama permitiu a verificação do uso do MAGIC- $f$ gel em feixes de elétrons. Apesar do potencial do dosímetro polimérico, ainda é preciso sistematizar o processo de manufatura para a determinação das distribuições de dose tridimensionais com alta resolução espacial em um curto espaço de tempo.

Com base nos resultados encontrados no presente trabalho pode-se afirmar que o dosímetro MAGIC- $f$ gel possui um alto potencial para a realização de medidas dosimétricas e obtenção de distribuições de dose tridimensional, tornando-o uma ferramenta auxiliar para o controle da qualidade de feixes de elétrons. Além disso, permite verificações de distribuições de dose em condições de irradiação que ainda não são utilizadas nas rotinas clínicas, como a utilização de campos pequenos para conformação da dose por meio de uma futura técnica da modulação de feixes de elétrons. 


\section{REFERÊNCIAS}

Agencia Nacional de Vigilância Sanitária. Regulamento Técnico para o Funcionamento de Serviços de Radioterapia, ANVISA RDC no 20, publicada no Suplemento $n^{\circ} 26$ do D.O.U. de 06 de fevereiro de 2006.

ALEXANDER, A.; SOISSON, E.; HIJAL, T.; SARFEHNIA, A. et al. Comparision of modulated electron radiotherapy to conventional electron boost irradiation and volumetric modulated photon arc therapy for treatment of tumour bed boost in breast cancer. Radiother Oncol., v. 100, n. 2, p. 253-258, 2011.

ALEXANDER, A.; SOISSON, E.; RENAUD, M. A. et al. Direct aperture optimization for FLEC-based MERT and its application in mixed beam radiotherapy. Med Phys., v. 39 , n. 8, p. 4820-4831, 2012.

ALI, O.A.; WILLEMSE, C. A.; SHAW, W. et al. Monte Carlo electron source model validation for an Elekta Precise linac. Med Phys., v. 38, n. 5, p. 2366-2373, 2011.

ALJAMAL, M.; ZAKARIA, A.; SHAMSUDDIN, S. Radiological properties of MAGIC normoxic polymer gel dosimetry. Journal of Physics Conference Series, v. 423, 2013,

ALLISON, J.; AMAKO,J.; APOSTOLAKIS, H.; et al: Geant4 developments and applications, IEEE Transactions on nuclear science, v. 53 (1), p. 70 - 78, 2006.

ALVA, M. et al. Monte Carlo Simulation of MAGIC- $f$ gel for Radiotherapy using PENELOPE. Journal of Physics Conference Series. v. 250, 2010.

ALVA, M. S. Verificação 3D da distribuição da dose em radiocirurgia estereotáxica através de simulação Monte Carlo e dosimetria por ressonância magnética nuclear. Tese (Doutorado em Ciências) - Departamento de Física, Faculdade de Filosofia, Ciências e Letras de Ribeirão Preto, Universidade de São Paulo, Ribeirão Preto, 2012.

AL-YAHYA, K.; VERHAEGEN, F.; SEUNTJENS, J. Design and dosimetry of a few leaf electron collimator for energy modulated electron therapy. Med. Phys., v. 34, n. 12, p. 4782-4791, 2007.

ANDREWS, H.L.; MURPHY, R.E.; LEBRUN, E.J. Gel dosimeter for depth dose measurements. Rev. Sci. Instrum. v. 28, p. 329-332, 1957.

ARJOMANDY, B.; TAILOR, R.; ANAND, A. et al. Energy dependence and dose response of Gafchromic EBT2 film over a wide range of photon, electron, and proton beam energies. Med. Phys., v. 37, n. 5, p. 1942 - 1947, 2010.

Association America of Medical Physics. Clinical Electro-Beam. AAPM Report No 32, AAPM, 1991.

BALDOCK, C.; BURFORD, R.P.; BILLINGHAM, N.C. et al. Experimental procedure for the manufacture of polyacrylamide gel (PAG) for magnetic resonance imaging (MRI) radiation dosimetry. Phys. Med. Biol., v. 43, p. 695-702, 1998. 
BALDOCK, C.; HARRIS, P.J.; PIERCY, A.R.; et al. Experimental determination of the diffusion coeficiente in 2D in ferrous sulphate gels using the finite element method Australas. Phys. Eng. Sci. Med., v. 24, p. 19-30, 2001.

BARAS, P.; SEIMENIS,I.; KIPOUROS, P.; et al Polymer gel dosimetry using a threedimensional MRI acquisition technique. Med. Phys., v. 29, p. 11, 2002.

BECK, J. A.; BUDGELL, G. J.; ROBERTS, D.A. et al. Electron beam quality control using an amorphous silicon EPID. Med. Phys., v. 36, n. 5, p. 1859-1866, 2009.

BIELAJEW, A.F.; ROGERS, D.W.O.: A standard timing benchmark for EGS4 Monte Carlo calculation, Medical Physics, v. 19 (2), p. 303 - 304, 1992.

BLAKE, S. J.; McNAMARA, A. L.; DESHPANDE, S. et al. Characterization of a novel EPID designed for simultaneous imaging and dose verification in radiotherapy. Med. Phys. v. 40, n. 9, p. 091902-1 - 091902-11.

BOYD, R. A.; HOGHSTROM, K. R.; WHITE, R. A. et al. Modelling pencil-beam divergence with the electron pencil-beam redifinition algorithm. Phys Med Biol., v. 46, n. 11, p. 2841-2856, 2001.

BRUALLA, L.; PALANCO-ZAMORA, R.; WITTING, A. et al. Comparison between PENELOPE and electron Monte Carlo simulations of electron fields used in the treatment of conjunctival lymphoma. Phys. Med. Biol., v. 54, n. 18, p. 5469-5481, 2009.

CHI, P. C.; HOGSTROM, K. R.; STARKSCHALL, G.; BOYD, R. A. et al. Application of the electron pencil beam redifinition algorthm to electron arc therapy. Med Phys., v. 33, n. 7, p. 2369-2383, 2006.

CRESCENTI, R.A.; SCHEIB, S. G.; SCHENEIDER, U. et al. Introducing gel dosimetry in a clinical environment: Customization of polymer gel composition and magnetic resonance imaging parameters used for $3 \mathrm{D}$ dose verifications in radiosurgery and intensity modulated radiotherapy. Med. Phys. v. 34, n.4, p. 1286-1297, 2007.

DAY, M.J e STEIN, G. "Chemical effects of ionization radiation in some gels". Nature. v. 166, p. 141-147, 1950.

DE DEENE, Y. Essential characteristic of polymer gel dosimeter. Proceedings of the third International Conference on Radiotherapy Gel Dosimetry, p.5-58, 2004a.

DE DEENE, Y.; HURLEY, C.; VENNING, A. et al. A basic study of some normoxic polymer gel dosimeters. Phys. Med. Biol. v.47, p. 3441-3463, 2002.

DE DEENE, Y.; PITTOMVILS, G.; VISALATCHI, S. The influence of cooling rate on the accuracy of normoxic polymer gel dosimeters. Phys. Med. Biol., v. 52, n. 10, p. 2719 2728, 2007.

DE DEENE, Y.; VERGOTE, K,; CLAEYS,C.; et al. The fundamental radiation properties of normoxic polymer gel dosimeters: a comparison between a methacrylic acid based gel and acrylamide based gels. Phys. Med. Biol., v. 51, p. 653-673, 2006 a. 
DE DEENE, Y.; VERGOTE, K,; CLAEYS,C.; et al. Three dimensional radiation dosimetry in lung-equivalent regions by use of an radiation sensitive gel foam: Proof of principle. Med. Phys., v. 33, p. 2586-2597, 2006 b.

DEBENHAM, B. J.; HU, K. S.; HARRISON, L. B. Present status and future directions of intraoperative radiotherapy. Lancet Oncol., v. 14, n. 11, p. 457-464, 2013.

DING, G. X.; CYGLER, J. E.; YU, C. W. et al. A comparison of electron beam dose calculation accuracy between treatment planning systems using a pencil beam or a Monte Carlo algorithm. Int J Radiat Oncol Biol Phys., v. 63, p. 622-633, 2005.

DING, X.; BOURLAND, J.; DOLESH, W. et al. Small Field Output Factor Measuremet Using MAGIC Gel Dosimeter in 3T MRI. Med. Phys., v. 39, n. 6, p. 3725-3725, 2012.

DOGAN, M. H.; ZINCIRCIOGLU, S. B.; AYDINOL, M. Research on different techniques in breast cancer radiotherapy. Wspolczesna Onkol., v. 17, n. 3, p. 291-297, 2013.

ELDIB, A. JIN, L. H.; LI, J. S. et al. Feasibility of replacing patient specific cutouts with a computer-controlled electron multileaf collimator. Phys Med Biol., v. 58, n. 16, p. 5653-5672, 2013.

European Society for Radiotherapy \& Oncology. Recommendation for a Quality assurance program in External Radiotherapy: Physics for clinical radiotherapy. ESTRO Booket No2. Nancy, France, 1995 PÁGINA.

FERNANDES, J.P.; PASTORELLO, B.F.; de ARAUJO, D.B., et al Formaldehyde increases magic gel dosimeter melting point and sensitivity. Phys. Med. Biol., v. 53, p.N1-N6, 2008.

FONG, P.M.; KEIL, D.C.; DOES, M.D., et al.Polymer gels for magnetic resonance imaging of radiation dose distributions at normal room atmosphere. Phys. Med. Biol., v. 46, p. 3105-3113, 2001.

FURNARI, L. Controle da qualidade em radioterapia. Revista Brasileira de Física Médica. v.3, p.77-90, 2009.

GAUER, T.; SOKOLL, J.; CREMERS, F. et al. Characterization of an add-on multileaf collimator for electron beam therapy. Phys. Med. Biol., v. 53, n. 4, p. 1071-1085, 2008.

GERBI B.J.; ANTOLAK, J.A.; DEIBEL, F. C. et al. Recomendations for clinical electron beam dosimetry: Supplement to the recommendation of Task Group 25. Med. Phys, v. 36, p. 3239-3279, 2009.

GORE, J.C.; KANG, Y.S.; SCHULZ, R.J. Measuremente of radiation dose distribuition by nuclear magnetic resonance (NMR) imaging. Phys. Med. Biol. v. 29, p. 1189-1197, 1984.

GORIJIARA, T.; HILL, R.; KUNCIC, Z. et al. Radiological characterization and water equivalency of genipin gel for x-ray and electron beam dosimetry. Phys. Med.Biol., v. 56, p. 4685-4699, 2011. 
GREER, P. B. 3D EPID based dosimetry for pre-treatment verification of VMAT methods and challenges. Journal of Physics Conference Series, v. 444, 2013.

GUSTAVSSON, H.; KARLSSON, A,; BÄCK, S.A., et al. MAGIC-type gel for threedimensional dosimetry: Intensity-modulated radiation therapy verification. Med. Phys., v. 30, p. 1264-1271, 2003.

HARRISON, C.; YOUNG, J.; NAVI D.; RIAZ, N. et al. Revisting low-dose total skin electron beam therapy in mycosis fungoides. Int. J. Radiat. Oncol Biol Phys. v. 81, p. 665-657, 2011.

HENDRIKCS, J.S.; ADAMS, K.J., BOOTH, T.E.: Present and future capabilities of MCNP, Applied Radiation and Isotopes, v. 53, p. 857 - 861, 2000.

HERMIDA-LOPEZ, M. Calculation of dose distributions for $12 \mathrm{Ru}-106 / \mathrm{Rh}-106$ ophthalmic applicator models with the PENELOPE Monte Carlo code. Med Phys., v. 40, n. 10 , p. 101705-1 - 101705-13, 2013.

HILL, B.; VENNING, A.; BALDOCK, C. The dose response of normoxic polymer gel dosimeters measured using X-ray CT. The British J. Radio., v.78, p. 623-630, 2005.

HILTS, M.; AUDET, C.; DUZENLI, C.; et al. Polymer gel dosimetry using x-ray computed tomography: a feasibility study. Phys. Med. Biol. v. 45, p. 2559-2571, 2000.

HINDS, G. A.; ALHARIRI, J.; KLEIN, R. Q. et al. Treatment of mycosis fungoides with total skin electron beam response and relapse by ethnicity and sex. Am J Clin Oncol., v. 36, n. 5, p. 481-485, 2013.

HOGSTROM, K.R.; ALMOND, P.R. Review of electron beam therapy physics. Phys Med Biol., v. 51, n. 13, p. 455-489, 2006

Institute for National Measurements Standards. Energy spectra, angular spread and dose distributions of electron beams from various accelerators used in radiotherapy. INMS, PIRS-0439, Ottawa, Canada, 2003.

Institute of Physic and Engineering in Medicine. Physics Aspects of Quality Control in Radiotherapy. IPEM, York, 1999.

Internacional Commission on Radiation Units and Measurements Prescribing, recording and reporting electron beam therapy. International Commission on Radiation units and measurements. ICRU Report No 71, Washington DC, 2004.

Internacional Commission on Radiation Units and Measurements, Prescribing, Recording and Reporting Photon Beam Therapy. ICRU Report 62, Washington DC, 1999.

Internacional Commission on Radiation Units and Measurements. Stopping Power for electrons and positrons. ICRU Report 37, Washington DC, 1984b.

International Atomic Energy Agency. Absorbed dose determination in external beam radiotherapy: an international code of practice for dosimetry based on satandards of absorbed dose to water. International atomic energy agency. IAEA TRS 398, 2000b. 
International Atomic Energy Agency. Aspectos físicos de la garantía de calidad en radioterapia: Protocolo de control de calidad. IAEA TECDOC 1151, Vienna, 2000a.

International Atomic Energy Agency. Commissioning and quality assurance of computadorized planning system for radiation treatment of cancer. IAEA Technial Report 430, Vienna, IAEA, 2004.

International Atomic Energy Agency: Review of radiation oncology Physics: A handbook for teachers and students. IAEA, Viena, 2003.

International Commission on Radiation Units and Measurements, Eletrons beams with energies between 1 and $50 \mathrm{MeV}$. ICRU report 35, 1984a.

International Commission on Radiation Units and Measurements, Tissue substitutes in radiation dosimetry and measurement. ICRU report 44, Bethesda, EUA, 1989.

JIN, L.; MA, M-C.; FAN, J. Dosimetric verification of modulated electron radiotherapy delivered using a photon multileaf collimator for intact breasts. Phys. Med. Biol., v. 53, n. 21, p. 6009-6025, 2008

KAWRALOW, I.; BIELAJEW, F. On the condensed history technique for electron transport. Nuclear Instruments and Methods in Physics Research B, v. 142, p. 253$280,1998$.

KHAN F The Physics of Radiation Therapy. Fourth Edition, Philadelphia,PA, USA, 2010.

KHAN, F. M.; DOPPKE, K. P.; HOGSTROM, K. R. et al. Clinical electron-beam dosimetry: Report of AAPM Radiation Therapy Committee Task Group No. 25. Med Phys., v. 18, n.1, p. 73-107, 1991.

KLEIN E.E.; HANLEY J.; BAYOUTH J. et al. Task Group 142 report: Quality assurance of medical accelerators. Med. Phys., v. 9, p. 4197-4212, 2009.

KLEIN, E.E.; VICIC, M.; MA, C.M.; et al: Validation of calculations for electrons modulated with convencional photon multileaf collimators. Phys. Med. Biol. 53(5), 1183-1208, 2008.

KOIVUNORO, H.; SIISKONEN, T.; KOTILUOTO, P. et al. Accuracy of the electron transport in MCNP5 and its suitability for ionization chamber response simulations: A comparison with the EGSNRC and PENELOPE codes. Med. Phys., v.39, n. 3, p. 1335$1344,2012$.

KRAMER, G.H.; CROWLEY, P.; BURNS, L. C. Investigating the impossible: Monte Carlo simulations. Radiat. Prot. Dosimetry, v. 89, n.3 - 4, p. 259 - 26, 2000.

KROLL, F.; PAWELKE, J.; KARSCH, L. Preliminary investigations on the determination of three-dimensional dose distributions using scintillator blocks and optical tomography. Med. Phys. v. 40, n. 8, p. 082104-1 - 082104-12, 2013. 
LAWLESS, M. J.; JUNELL, S.; HAMMER, C. et al. Response of TLD-100 in mixed fields of photons and eletrons. Med Phys., v. 40, n. 1, p. 012103-1 - 012103-4, 2013.

LIU, X.; LACK, D.; RAKOWSKI, J.T. et al. Fast Monte Carlo simulation for total body irradiation using a (60)Co teletherapy unit. J Appl Clin Med Phys., v. 14, n. 3, p. 4214, 2013.

LLOYD, S.; FOSS, F. M.; GIRARDI, M. et al. Acute toxicity and risk of infection during total skin electron beam therapy for mycosis fungoides. Journal of the American of Dermatology. v. 69, p. 537-543, 2013.

LONDONO, G. D.; LALLENA, A. M. Specific absorbed fractions in thyroid diagnostics and treatment: Monte Carlo calculation with PENELOPE. Radiat Prot Dosimetry, v. 150, n. 1, p. 41-49, 2012.

Low, D.A. et al A technique for the quantitative evaluation of dose distributions. Med. Phys., v. 25, p. 656-661, 1998.

LUCI, J.J.; WHITNEY, H.M.; GORE, J.C. Optimization of MAGIC gel formulation for three-dimensional radiation therapy dosimetry. Phys. Med. Biol. 52, p.N241-N248, 2007.

MA, C. M.; DING, M.; LI, J. S. et al. A comparative dosimetric study on tangential photon beams, intensity-modulated radiation therapy (IMRT) and modulated electron radiotherapy (MERT) for breast treatment. Phys Med Biol., v. 48, n. 7, p. 909-924, 2003.

MARIANI, M.; VANOSSI, E.; GAMBARINI, G.; et al. Preliminary results from a polymer gel dosimeter for absrorbed dose imaging in radiotherapy. Rad. Phys. Chemis., v. 76, p. 1507-1510, 2007.

MARSOLAT, F.; TROMSON, D.; TRANCHANT, N. et al. Diamond dosimeter for small beam stereotactic radiotherapy. Diamond and Related Materials, v. 33, p. 63-70, 2013

MARYANSKI, M. J.; SCHULTZ, R. J.; IBBOTT, G. S. et. al. Magnetic resonance imaging of radiation dose distributions using a polymer-gel dosimeter. Phys. Med. Biol., v. 39, n. 9 , p. $1437-1455,1994$

MARYANSKI, M.J.; GORE, J.C.; KENNAN, R.P.; et al. NMR relaxation enhancement in gels polymerized and cross-linked by ionizing radiation: a new approach to 3D dosimeter by MRI. Mag. Reson. Imaging., v. 11, p. 253-258, 1993.

MARYANSKI, M.J.; IBOBOTT, G.S.; EASTMAN, P.; et al. Radiation therapy dosimetry using magnetic resonance imaging of polymer gel. Med. Phys. V.23, p. 699705 .

MATHER, M.; WHITTAKER, A.K.; BALDOCK, C. Ultrason evaluation of polymer gel dosimeters. Phys. Med. Biol. v. 47, p. 1449-1458, 2002

McJURY, M.; OLDHAM, M.; COSGROVE V. P. et al. Radiation dosimetry using polymer gels: method and application. The British Journal of Radioiology, v. 73, p. 919-929, 2000. 
NAVI, D.; RIAZ, N.; LEVIN, Y. S. et al. The Standfor University experience with conventional-dose, total skin electron-beam therapy in the treatment of generalized patch or plaque (T2) and tumor (T3) mycosis fungoides. Arch Dermatol. v. 47, n. 5 p. 561$567,2011$.

NELSON, V.; McLEAN, D.; HOLLOWAY, L. Thermoluminescent dosimetry (TLD) for megavoltagem electron beam energy determination. Radiation Measurements, v. 45, p. 698-700, 2010.

NIST, 2013 Stopping Power and Attenuation Coefficients. National Institute of Standards and Technology. http://physics.nist.gov/cgi-bin/Star/e_table.pl, and Attenuation Coefficients, http://physics.nist.gov/PhysRefData/XrayMassCoef/ComTab/water.html. acesso em November 13, 2013

OLIVEIRA, L. N.; CALCINA, C. S. G.; CAVALCANTE, F. et al. 6 MV Wedge Photon Beam Profiles with the Fricke Xylenol Gel Dosimeter. Brasilian Journal of Physics, v. 39. n. 4, p. 615-618, 2009a.

OLIVEIRA, L. N.; ZIMMERMAN, R. L.; MOREIRA, M. V. et al. Determination of diffusion coefficient in Fricke Xylenol gel dosimeter after electron beam bombardment. Surface and Coating Technology, v. 203, p. 2367-2369, 2009 b.

OSTI, M. F.; CARNEVALE, A.; BRACCI, S. et al. Exclusive Electron Intraoperative Radiotherapy in Early-stage Breast Cancer: A Monoinstitutional Experience. Anticancer Res., v. 33, n. 3, p. 1229-1235, 2013.

PAPACONSTADOPOULOS, P.; SEUNTJENS, J. A source model for modulated electron radiation therapy using dynamic jaw movements. Med Phys., v. 40, n.5, p. 051707-1 - 051707-12, 2013.

Pavoni JF. Dosimetria tridimensional por imagens de ressonância magnética com gel MAGIC modificado. 2009. 157f, Tese (Doutorado em Ciências) - Faculdade de Filosofia, Ciências e Letras de Ribeirão Preto - Departamento de Física e Matemática, Universidade de São Paulo, Ribeirão Preto

PAVONI, J. F.; BAFFA, O. An evaluation of dosimetric characteristics of MAGIC gel modified by adding formaldehyde (MAGIC- $f$ ). Radiation Measurements, v. 47, p. 1074-1082, 2012.

PAVONI, J. F.; PIKE, T. L.; SNOW, J. et al. Tomotherapy dose distribution verification using MAGIC-f polymer gel dosimetry. Med. Phys., v. 39, n. 5, p. 2877-2884, 2012.

PODGORSAK, E. B. et al. Radiation Oncology Physics: A Handbook for Teachers and Students, Austria, 2005, ISBN 92-0-107304-6.

PRICE, M. J.; HOGHSTROM, K. R.; ANTOLAK, J. A. et al. Calculation percent depth dose with the electron pencil-beam redefinition algorithm. J Appl Clin Med Phys, v.8, n. 2, p. 61-75, 2007. 
RODRÍGUEZ, E.A.V.; ALCÓN, E.P.Q.; RODRIGUEZ, M.L. et al. Dosimetric parameters estimation using PENELOPE Monte-Carlo simulation code: Model 6711 a 125I brachytherapy seed. Appl Radiat Isot., v.63, p. 41- 48, 2005.

ROGERS, D. W. Revies: Fifty years of Monte Carlo simulations for medical physics. Phys Med Biol., v. 51, n. 13, p. R287-R301, 2006

SALVAJOLI, J. V.; FARIA, S. L.; SOUHAMI, L. Radioterapia em Oncologia, $2^{\text {a }}$ Edição, Medsi, Brasil, 1999, ISBN 978853880381-2.

SALVAT, F.; FERNÁNDEZ-VAREA, J.M.; SEMPAU, J. A Code System for MonteCarlo Simulation of Electron and Photon Transport. Nuclear Energy Agency, Organization FOR Economic Co-Operation and Development. September, 2008. ISBN 978-92-64-99066-1.

SAMPAIO, F. G. A.; DEL LAMA, L.S.; PETCHEVIST, P. C. D. et al. Gap application results for adjacent electron beams treatment. Nuclear Instruments and Methos in Physics Research B, v. 269, n. 24, p. 3141-3144, 2011.

SCHIAPPARELLI, P.; ZEFIRO, A. D.; MASSONE, F. et al . Total skin electron therapy (TSET): a reimplementation using radiochromic films and IAEA TRS-398 code of practice. Med. Phys., v.30,p. 2455- 2464, 2003

SELLAKUMAR, P.; SAMUEL, E. J. J. Study on energy dependence of PAGAT polymer gel dosimeter evaluated using X-Ray CT. Radiation Measurements, v. 45, n.1, p. 92 97, 2010.

SEMNICKA, J.; KLUSON, J. Simulation and experimental verification of dose distributions of electron beams. Radioprotection, v. 47, n.1, p. 79-91, 2012.

SEMPAU, J.; BADAL, A.; BRUALLA, L. A PENELOPE-based system for the automated Monte Carlo simulation of clinacs and voxelized geometries - application to far-from-axis fields. Med. Phys., v.38, n.11, p. 5887-5895, 2011.

SEMPAU, J.; FERNANDEZ-VAREA, J.M.; ACOSTA, E. et al. Experimental benchmarks of the Monte Carlo code PENELOPE. Nuclear Instruments \& Methods in Physics Research Section B-Beam Interactions with Materials and Atoms, v.207, n. 2, p. 107-123, 2003.

SEMPAU, J.; SÁNCHEZ-REYES, A.; SALVAT, F. et al. Monte Carlo simulation of electrons beam from an accelerator head uising PENELOPE. Phys Med. Biol. v. 46, n. 4, p. 1163-1186, 2001.

SHIAU, A. C.; LAI, P. L.; LIANG, J. A. et al. Dosimetric verification of surface and superficial doses for head and neck IMRT with different PTV shrinkage margins. Med Phys., v. 38, n. 3, p. 1435-1443, 2011

SPEIGHT, R. J. et al. Quality assurance of electron and photon beam energy using the BQ-Check phantom. J Appl Clin Med Phys., v. 12, n. 2, 2011. 
STATHAKIS, S.; MYERS, P.; ESQUIVEL, C. et al. Characterization of a novel 2D array dosimeter for patient-specific quality assurance with volumetric arc therapy. Med. Phys. v. 40, n. 7, p. 071731-1-071731-9, 2013.

STEEL, J.; STEWART, A.; SATORY, P. Matching extended-SSD electron beams to multileaf collimated photon beams in the treatment of head and neck cancer. Med Phys., v. 36, n. 9, p. 4244-4249, 2009.

SU, F. C.; LIU, Y.; STATHAKIS, S. et al. Dosimetry characteristics of GAFCHROMIC EBT film responding to therapeutic electron beams. Appl Radiat Isot., v. 65, n.10, p. 1187-1192, 2007.

SUCURU, M.; KLEIN, E.E.; MAMALUI-HUNTER, M. et al. Planning tools for modulated electron radiotherapy. Med Phys., v. 37, n. 5, p. 2215-2224, 2010.

SWEETING, R.S; DEAL, A. M.; LLAGUNA, O. H. et al. Intraoperative electron radiation therapy as an important treatment modality in retroperitoneal sarcoma. Journal of Surgical Research, v. 185, p. 245-249, 2013.

TILLY, N.; FERNÁNDEZ-VAREA, J.M.; GRUSELL, E. et al. Comparison of Monte Carlo calculated electron slowing-down spectra generated by 60Co $\gamma$-rays, electrons, protons and light íons, Phys. Med. Biol., v. 47, n. 8, p.1303-1319, 2002.

VANDECASTEELE, J.; DE DEENE, Y. Evaluation of radiochromic gel dosimetry and polymer gel dosimetry in a clinical dose verification. Phys. Med. Biol., v. 58, n. 18, p. 6241-6262, 2013.

VATANEN, T.; TRANEUS, E.; LAHTINEN, T. Dosimetric verification of a Monte Carlo electron beam model for na add-on eMLC. Phys. Med. Biol., v. 53, n.2, p. 391404, 2008.

VERHAEGEN, F. Evaluation of the EGSnrc Monte Carlo code for interface dosimetry near high-Z media exposed to kilovolt and ${ }^{60}$ Co photons. Phys. Med. Biol., v. 47, p.16911705, 2002.

WEBER, L.; NILSSON, P. Verification of dose calculations with a clinical treatment planning system based on a point kernel dose engine. J Appl Clin Med Phys., v.3, n. 2, p. 73-87, 2002.

WI, J.; WU, H.G.; CI, PARK. et al. Treatment of patients with clinically lymph nodenegative squamous cell carcinoma of the oral cavity. Jpn J Clin Oncol., v. 38, n. 6, p. 395-401, 2008.

WONG, C. J.; ACKERLY, T.; HE, C. et al. High-resolution measurements of small field beams using polymer gels. Appl. Radiat. Isot., v. 65, n. 10, p. 1160-1164, 2007.

World Health Organization. Radiotherapy Risk Profile. WHO Technical Manual, Switzerland, WHO, 2008.

XU, Z.; WALSH S. E.; TELIVALA T. P., MEEK A. G. et al. Evaluation of the eclipse electron Monte Carlo dose calculation for small fields. J Appl Clin Med Phys., v. 10, n. 3, p. 75-85, 2009. 
YAPARPALVI, R.; FONTENLA, D.P.; VIKRAM, B. Clinical experience with routine diode dosimetry for electron beam radiotherapy. Int J Radiat Oncol Biol Phys., v. 48, n. 4 , p. $1259-1265,2000$.

YOSHIMURA, E.M. Física das Radiações: interação da radiação com a matéria. Rev. Bras. Fis. Med.v.3, n.1, p. 57-67, 2009. 